\title{
Dynamic Finite Element (DFE) Formulation of Functionally Graded Beams
}

\author{
by \\ Aaron Gee \\ Bachelor of Engineering, Ryerson University (2015) \\ A thesis \\ presented to Ryerson University \\ in partial fulfillment of the \\ requirements for the degree of \\ Master of Applied Sciences \\ in the program of \\ Aerospace Engineering
}

Toronto, Ontario, Canada, 2017

(C)Aaron Gee, 2017 


\section{AUTHOR'S DECLARATION FOR ELECTRONIC SUBMISSION OF A THESIS}

I hereby declare that I am the sole author of this thesis. This is a true copy of the thesis, including any required final revisions, as accepted by my examiners.

I authorize Ryerson University to lend this thesis to other institutions or individuals for the purpose of scholarly research.

I further authorize Ryerson University to reproduce this thesis by photocopying or by other means, in total or in part, at the request of other institutions or individuals for the purpose of scholarly research.

I understand that my dissertation may be made electronically available to the public. 


\title{
DYNAMIC FINITE ELEMENT (DFE) FORMULATION OF FUNCTIONALLY GRADED BEAMS
}

\author{
Aaron Gee \\ Master of Applied Science, Aerospace Engineering, Ryerson University, Toronto (2017)
}

\begin{abstract}
The Dynamic Finite Element (DFE) theory is applied to calculate the natural frequencies of Functionally Graded Material (FGM) beams. The formulation derived is based on Euler-Bernoulli beam theory and material grading is assumed to follow a power law variation through the thickness of the beam. Results from DFE are numerically validated against methods such as Classical Finite Element Method (FEM) and the Dynamic Stiffness Method (DSM), as well as other data found in literature. Commercial software was used to further validate the proposed DFE formulation. The test cases showed that DFE results displayed excellent agreement to published results. When compared to the FEM method, DFE showed higher accuracy while requiring fewer elements to converge to the solution. Finally some general comments are made on possible future research paths for DFE method on FGM beams.
\end{abstract}




\section{Acknowledgements}

I would first like to extend tremendous gratitude to my advisor, Dr. Seyed M. Hashemi. His guidance and unending patience over the past few years has made writing this thesis a truly enriched learning experience.

I would also like to extend my sincere thanks to my thesis review committee, Dr. Jeff Xi, Dr. Goetz Bramesfeld, Dr. Seyed M. Hashemi, and the program director, Dr. Jeffrey Yokota. Thank you for taking the time to review my thesis. 


\section{Dedication}

Dedicated to my parents Michael and Amy, my brother Tony, and my loving partner Jazz. 


\section{Table of Contents}

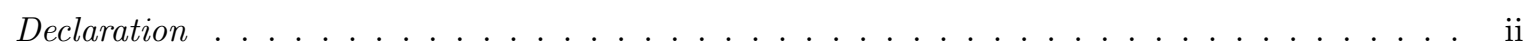

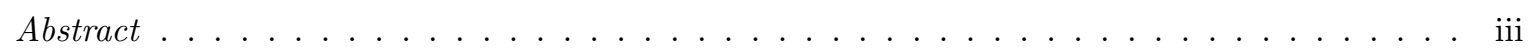

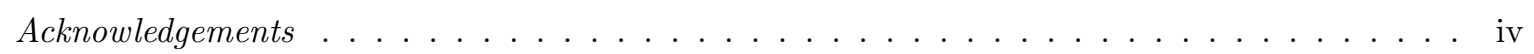

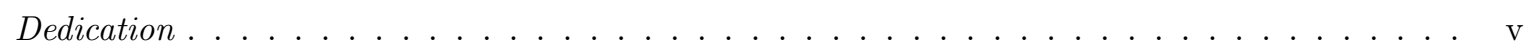

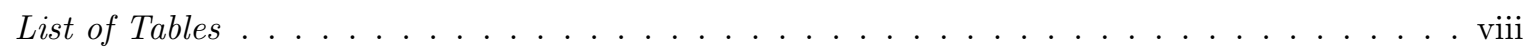

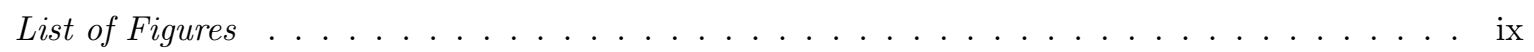

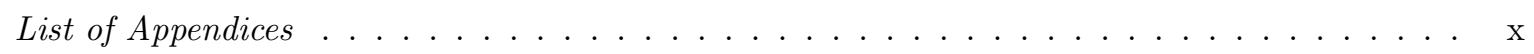

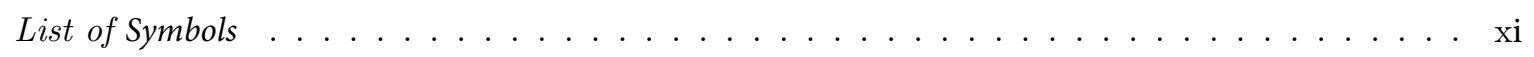

1 Introduction $\quad 1$

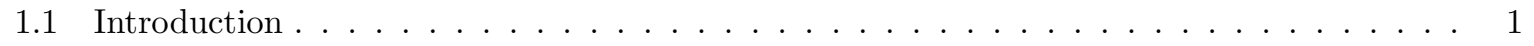

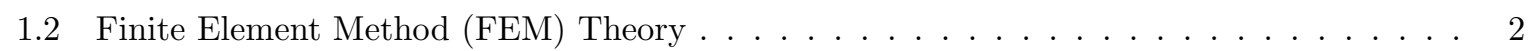

1.3 Dynamic Stiffness Method $(\mathrm{DSM})$ Theory $\ldots \ldots \ldots \ldots \ldots$

1.4 Dynamic Finite Element $(\mathrm{DFE})$ Theory $\ldots \ldots \ldots \ldots \ldots$

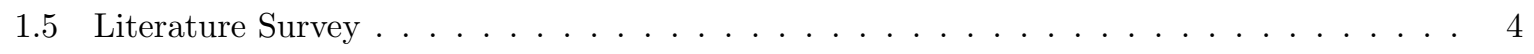

1.6 Research Motivation . . . . . . . . . . . . . . . . . . . 6

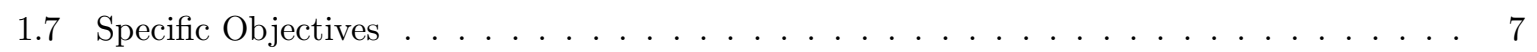

1.8 Thesis Document Organization $\ldots \ldots \ldots \ldots \ldots \ldots$

2 Functionally Graded Euler-Bernoulli Beam $\quad 9$

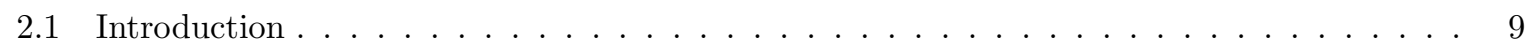

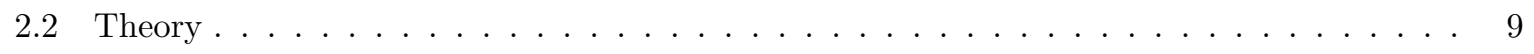

2.3 Finite Element Method $(\mathrm{FEM})$ Derivation $\ldots \ldots \ldots \ldots \ldots \ldots$

2.4 Dynamic Stiffness Method(DSM) Formulation . . . . . . . . . . . . . . . . . . 16 
2.5 Dynamic Finite Element (DFE) Formulation . . . . . . . . . . . . . . . . . 19

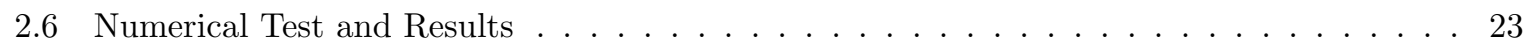

3 Verification Using Commercial FEM Software $\quad 46$

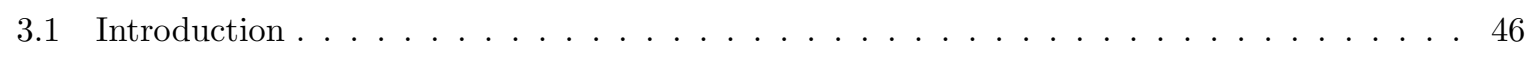

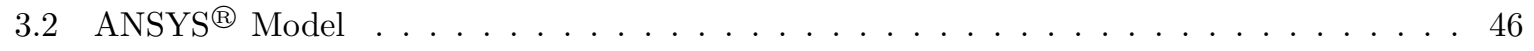

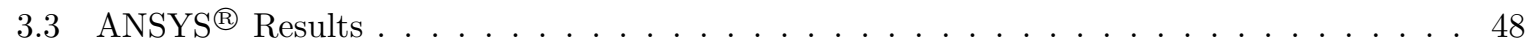

$\begin{array}{llr}4 \text { Conclusion } & 50\end{array}$

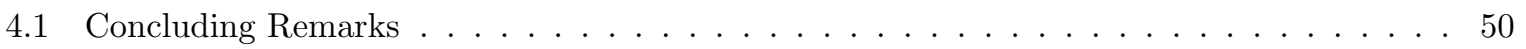

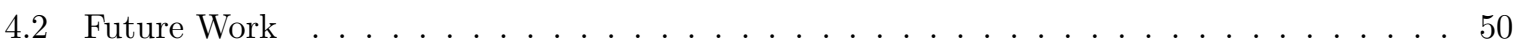

$\begin{array}{ll}\text { List of Contributions } & 75\end{array}$

$\begin{array}{ll}\text { References } & 76\end{array}$ 


\section{List of Tables}

2.1 First 3 natural frequencies of a $\mathrm{Al}$ beam with $L / h=10$ for various boundary conditions. . 25

2.2 First 3 natural frequencies of a $\mathrm{Al}$ beam with $L / h=30$ for various boundary conditions. . 26

2.3 First 3 natural frequencies of a $\mathrm{Al}$ beam with $L / h=100$ for various boundary conditions. 27

2.4 First non-dimensional frequency of a FGM beam with $k=0.3$ under S-S boundary condition. 27

2.5 First non-dimensional frequency of a FGM beam with $k=1$ under S-S boundary condition. 29

2.6 First 4 non-dimensional frequency of a C-F FGM beam for various $k$ values. . . . . . . . 30

2.7 First 4 non-dimensional frequency of a S-S FGM beam for various $k$ values. . . . . . . . 30

2.8 First 4 non-dimensional frequency of a C-C FGM beam for various $k$ values. . . . . . . . 31

2.9 First 4 non-dimensional frequency of a C-P FGM beam for various $k$ values. . . . . . . . . 32

3.1 Course and fine mesh ANSYS ${ }^{\circledR}$ results for various boundary conditions. . . . . . . . . . 48

5.1 Reference values for $k=0.3$ in the original non-dimensional form. . . . . . . . . . . 74

5.2 Reference values for $k=1$ in the original non-dimensional form. . . . . . . . . . . . . 74 


\section{List of Figures}

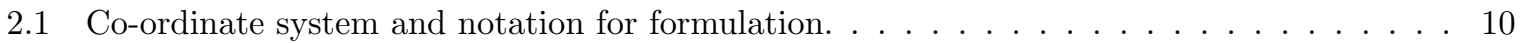

2.2 Variation in volume fraction through thickness in terms of $k \ldots \ldots \ldots \ldots \ldots$

2.3 Convergence study for the $3^{\text {rd }}$ mode of an aluminum beam with C-F boundary conditions. 28

2.4 Convergence study for the $4^{\text {th }}$ mode of a FGM beam $(k=1)$ with C-F boundary conditions. 32

2.5 First mode shapes for a C-F FGM beam $(k=1) \ldots \ldots \ldots \ldots \ldots$

2.6 Second mode shapes for a C-F FGM beam $(k=1) \ldots \ldots \ldots \ldots \ldots \ldots$

2.7 Third mode shapes for a C-F FGM beam $(k=1) \ldots \ldots \ldots \ldots \ldots$

2.8 First 4 mode shapes for a FGM beam $(k=1)$ with C-F boundary conditions. . . . . . . 36

2.9 First 4 mode shapes for a FGM beam $(k=1)$ with S-S boundary conditions. . . . . . . 37

2.10 First 4 mode shapes for a FGM beam $(k=1)$ with C-C boundary conditions. . . . . . . 38

2.11 First 4 mode shapes for a FGM beam $(k=1)$ with C-P boundary conditions. . . . . . . . 39

2.12 First 3 mode shapes for a FGM C-F beam $(k=0.1) \ldots \ldots \ldots \ldots \ldots$

2.13 First 3 mode shapes for a FGM C-F beam $(k=5) \ldots \ldots \ldots \ldots \ldots \ldots$

2.14 The effect of $k$ on the first four natural frequencies for C-F boundary condition. . . . . . 42

2.15 The effect of $k$ on the first four natural frequencies for S-S boundary condition. . . . . . . 43

2.16 The effect of $k$ on the first four natural frequencies for C-C boundary condition. . . . . . 44

2.17 The effect of $k$ on the first four natural frequencies for C-P boundary condition. . . . . . 45

3.1 Cross section and mesh of ANSYS ${ }^{\circledR}$ FGM model. . . . . . . . . . . . . . . . . . 47 


\section{List of Appendices}

$\begin{array}{ll}\text { Appendix } & 52\end{array}$

1 Hermite based Shape Functions $\quad 52$

1.1 Hermite shape function for axial displacement. . . . . . . . . . . . . . . . . 53

1.2 Hermite shape function for bending displacement. . . . . . . . . . . . . . 54

2 Dynamic Trigonometric Shape Functions $\quad 55$

2.1 Axial dynamic trigonometric shape function $\lambda=2500 \ldots \ldots \ldots \ldots \ldots$

2.2 Axial dynamic trigonometric shape function $\lambda=5000 \ldots \ldots \ldots \ldots \ldots$

2.3 Bending dynamic trigonometric shape function $\lambda=50 \ldots \ldots \ldots \ldots \ldots \ldots$

2.4 Bending dynamic trigonometric shape function $\lambda=500 \ldots \ldots \ldots \ldots \ldots$

2.5 Axial dynamic trigonometric shape function $\lambda=0 . \ldots \ldots \ldots \ldots \ldots$

2.6 Bending dynamic trigonometric shape function $\lambda=0 \ldots \ldots \ldots \ldots$

3 Coupled and Uncoupled Submatrices $\quad 63$

4 Classical Solution $\quad 65$

5 Original Data Tables for Validation Study $\quad 74$ 


\section{List of Symbols}

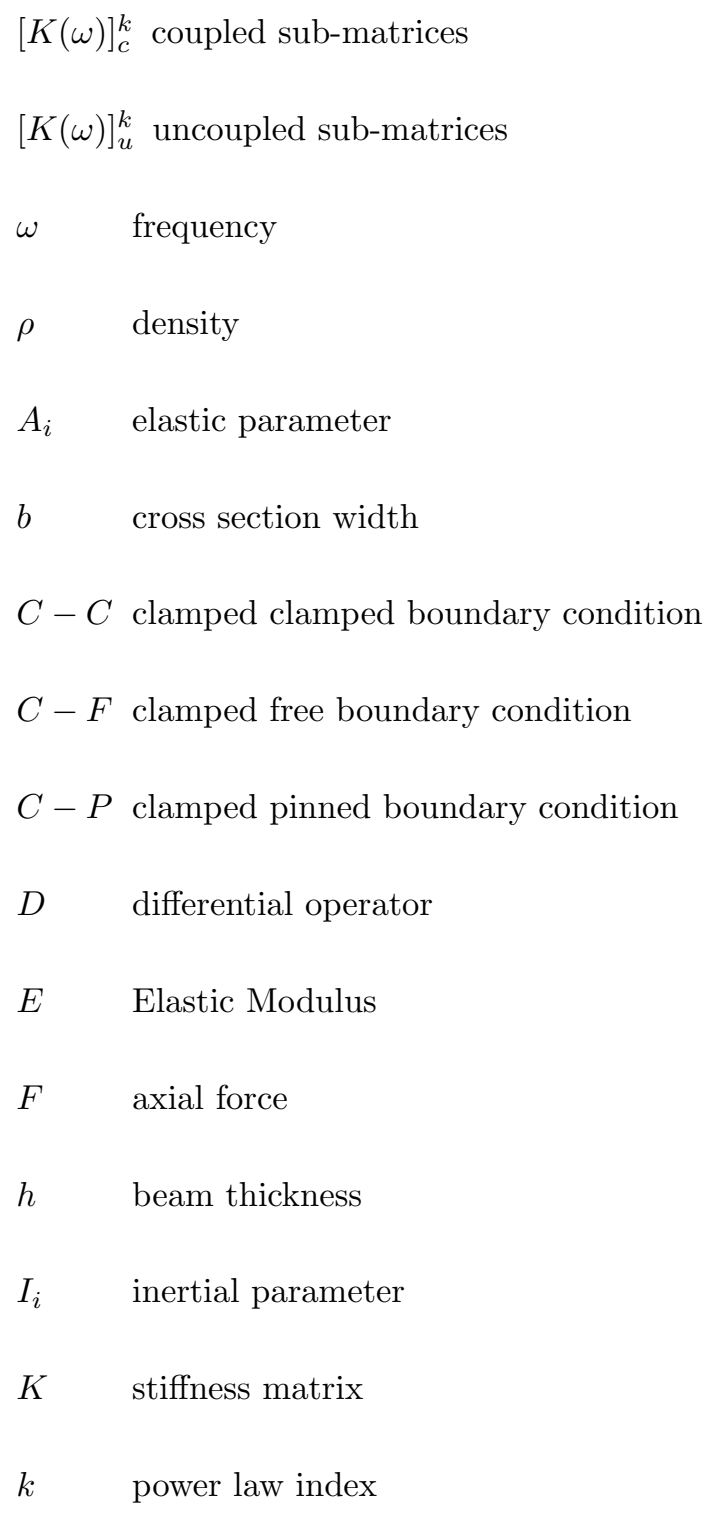




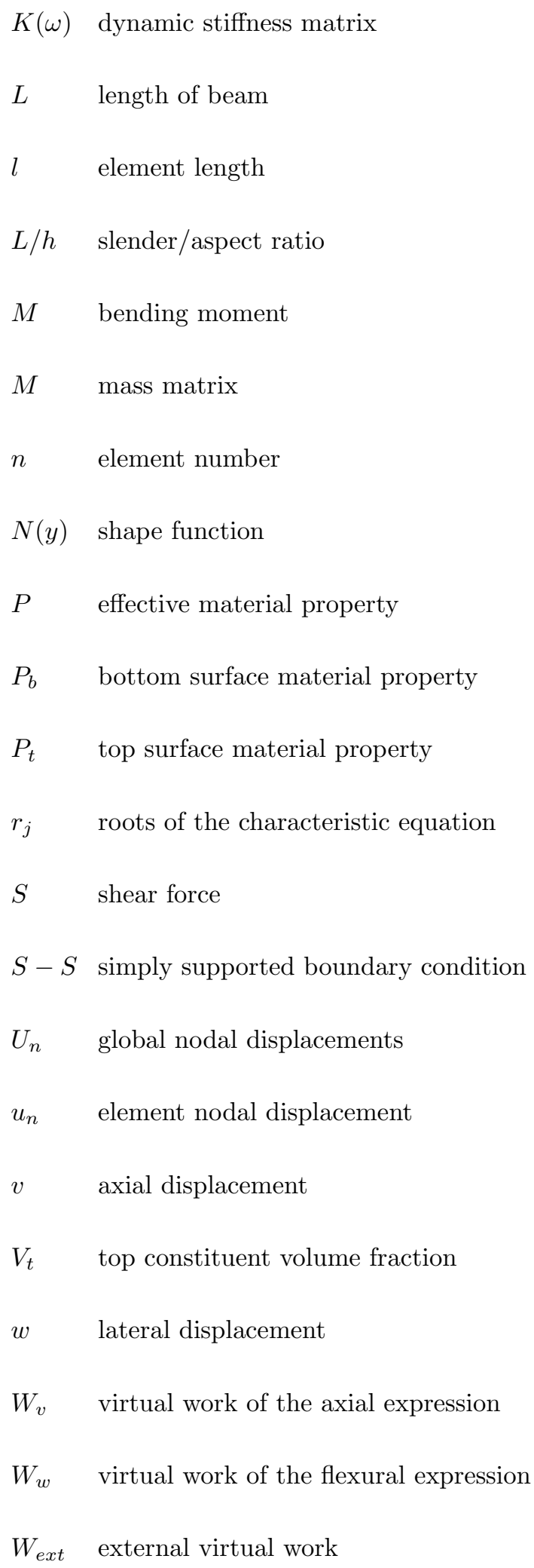




\begin{tabular}{|c|c|}
\hline$W_{\text {int }}$ & internal virtual work \\
\hline$W_{\text {total }}$ & total virtual work \\
\hline$\alpha$ & imaginary root for the $4^{t} h$ order differential equation \\
\hline$\beta$ & real root for the $4^{t} h$ order differential equation \\
\hline$\delta v$ & axial displacement test function \\
\hline$\delta w$ & flexural displacement test function \\
\hline$\gamma$ & root for the $2^{n} d$ order differential equation \\
\hline$\lambda$ & non-dimensional frequency \\
\hline$\theta$ & amplitude of the bending rotation \\
\hline
\end{tabular}




\section{Chapter 1}

\section{Introduction}

\subsection{Introduction}

Functionally Graded Material (FGM) are a class of composites characterised by a change in composition through its volume, resulting in properties that vary spatially throughout the material [1]. Originally these materials were designed for use as heat shields to protect spacecrafts during re-entry. Presently, the applications of this material have been limited due to challenges in manufacturing. Powder pressing and sintering is a common method to produce FGMs, however the sintering temperature for each constitutive material can vary. The challenge is finding an optimal sintering environment that satisfies the requirements of all of the constitutive materials. For example, to illustrate the challenges in manufacturing, consider a medical implant, which may use titanium (Ti) and Hydroxyapatite (HAP). The optimal temperature for sintering $\mathrm{HAP}$ is $1150 \mathrm{C}$ and $1300 \mathrm{C}$ for $\mathrm{Ti}$, a difference of $150 \mathrm{C}$ [2]. Titanium adds an additional level of difficulty as it must be sintered in a vacuum to reduce oxidation; however HAP is unstable in a vacuum and decomposes [2]. Engineers must determine an optimal solution that minimizes the negatives and maximizes the benefits of the material combination. The advent of novel manufacturing techniques such as electron beam freeform fabrication and additive manufacturing seem promising in solving/avoiding the challenges in manufacturing FGM and could lead to the wider use of the material $[1,3-5]$. FGMs have seen use in industries such as aerospace, automotive, electrical/electronic and have many more potential applications in various industries such as biomedical implants $[2,6]$.

FGMs offer designers with high tailoring ability; they can use a variety of material types such as 
metals, ceramics or polymers and can choose the amount to vary throughout the component. For example, similar to a bi-material composite (e.g. metallic component coated with ceramic), a metallicceramic FGM would offer a combination of the strength of the metal and the heat resistance property of a ceramic. However, the real advantage of FGM lies in the gradual change in the content of one material into the other. A traditional metallic-ceramic composite would have a sharp interface between the two materials, resulting in high interlaminar stresses. This is particularly detrimental for ceramic coatings as interlaminar stress caused by thermal loading leads to delamination and chipping of the protective coating. The gradual change of FGMs theoretically eliminates the sharp boundary between the two materials, reducing interlaminar stress, delamination, and thermal stress concentrations [5]. Due to the many advantages of FGMs over traditional composites and the possible proliferation of FGMs resulting from novel manufacturing techniques, closed-form analytical and numerical methods for static, dynamic, stability and vibration analysis of FGM beams have been a growing area of research.

\section{$1.2 \quad$ Finite Element Method (FEM) Theory}

The Finite Element Method (FEM) is a well-established numerical method that can be used for a variety of engineering applications, such as modal analysis. It is a robust method that uses a systematic approach to solve complex systems by breaking the problem down into simpler forms. Polynomial shape functions are typically used and an element mass and stiffness matrices are produced. For modal analysis, the problem reduces into a linear eigenvalue problem, which when solved yields the natural frequencies and mode shapes of the system. The strength of FEM lies in its versatility, complex/irregular geometries and bodies of different materials can be analyzed with relative ease. Various loading types and boundary conditions can be introduced into a model. Furthermore, many companies have commercialized FEM software packages that simplify model creation and analysis for the user. The use of FEM has expanded beyond its original intended use as a structural analysis tool, to other disciplines such as mathematical physics, heat transfer, and acoustics. The wide range of applications that can be solved using this method is a testament to its versatility [7]. However, since FEM is an approximate method, the accuracy is dependent on the number of elements used. This is especially true when performing modal analysis

at high frequencies, where larger numbers of elements are required to accurately capture the system's natural frequencies and mode shapes. 


\subsection{Dynamic Stiffness Method (DSM) Theory}

Advancement in computing power has led to the development of the frequency dependent Dynamic Stiffness Method (DSM). The DSM is an exact frequency method; it provides an analytical solution to the free vibration problem. Where applicable, this method combines the coupled governing equations of motions into a single ordinary differential equation, where a closed-form solution can be found $[8,9]$. The general closed-form solution is used to obtain the frequency dependent stiffness matrix. In conventional FEM, there is a stiffness and mass matrix, but in DSM the resultant frequency dependent stiffness matrix combines the elastic and inertial properties into a single matrix. The DSM stiffness matrix is non-linear and the solution is exact within the limits of the theory. The DSM element can express an infinite number of natural frequencies and therefore, only one element is required to find any frequency. Consequently, the DSM method exhibits superior convergence performance than FEM, particularly at higher frequencies, where a greater number of FEM elements are required to obtain suitable accuracy. The major drawback of DSM is that a closed form solution to the governing equations of motion is fundamental to the formulation. This is only available for certain special cases and can be difficult to obtain for complex models.

\subsection{Dynamic Finite Element (DFE) Theory}

Hashemi [10] introduced a hybrid method, the Dynamic Finite Element (DFE) formulation, which combines the versatility of FEM with the accuracy of DSM. The DFE method is a semi-analytical solution; similar to FEM it uses the general procedure of the weighted residual method. In the DFE formulation an additional set of integration by parts on the weak form equation is performed and frequency dependent trigonometric shape functions are used, in contrast to polynomial shape functions, which are commonly used in FEM formulations. Since the DFE is a hybrid method it retains some characteristics from the FEM and DSM formulation. The formulation results in a single frequency dependent stiffness matrix that combines the inertial and elastic properties similar to DSM. Since DFE uses a weighted residual approach it retains the robustness of the FEM and can be applied to complex cases where DSM cannot. When compared to conventional FEM, the DFE generally exhibits much higher convergence rates, particularly at higher vibration frequencies. It is also interesting to note that Hashemi [10], has developed basis function expression that revert to the shape functions produced 
by Hermite cubic polynomials at zero frequency. This means the DFE element would reduce to a conventionally FEM element when performing static analysis.

\subsection{Literature Survey}

The modeling of the effective properties caused by material grading was a prominent research topic in the 1990s. There were two approaches towards modeling of the effective properties, a detailed micromechanical approach or a simplified model based on the assumption of a smooth property distribution. The micromechanical model was a material science approach. Research focused on how the microstructure formed and the resulting effect on the distribution of material properties through the volume of the component. Micromechanical approaches included representative volume elements, percolation theory, fractal analysis, lattice-based microstructure models, renormalization group, neural networks, and Voronoi cell finite element method, a few selected papers are quoted, which provide an introduction and reference to the subject [11-15]. Researchers also attempted to use laminate theory to model the properties of FGM [16]. This method was not a popular approach because the laminate theory would use step changes in material properties. Steps changes would result in a sandwich beam architecture, which defeats the purpose of FGM because the model would not have a continuous transition of properties.

The simplified model assumed a smooth property distribution and ignored the details of the materials microstructure. The justification of this model was that research focused on micromechanical modeling and manufacturing would produce the desired continuous property distribution. Instead, the simplified model would be used to demonstrate the benefits of actually applying FGMs to various applications. The rule of mixtures was used to model the properties of the FGM. Various functions to model the volume variation of the material was proposed, similar functions were used depending on the research area. Typically, research on fracture mechanics often used exponential variations [17] and linear variations were used for thermo-elastic/plastic effects [18]. Researches on modal analysis have commonly modeled material property variation according to a power law distribution [19].

As mentioned previously, the majority of early research on FGMs focused on manufacturing, micromechanical modeling and thermal stress. Prior to the 2000s papers on the topic of vibration were rare, a paper was found which dealt with the vibration of FGM shells [20]. However, in the last 17 years research on the free vibration of FGMs has risen drastically. A number of research papers have been 
written for approximate and analytical solution of FGM beams.

Supposedly, Elishakoff and Candan formed the first closed-form solution for general inhomogeneous beams [21]. This concept was further developed to include axial varying properties [22-24]. Li formulated an analytical solution to analyze the static and dynamic behaviours of FGM Timoshenko and EulerBernoulli beams [25]. Higher order theories were investigated to introduce more complex characteristics such as shear deformation and warping, a sample of research papers [26-38] are quoted here which provide a good introduction on the subject.

Studies typically varied properties along the thickness for numerical simplicity. To maximize use of FGMs, designers should be able to tailor components by axially grading the material. A sample of research quoted here investigated varying properties axially [39-49]. Building on axially varying FGM beams, research has expanded into the variation of material properties along multiple directions (axially and through thickness) [50,51]. Research has also expanded to stepped and tapered functionally graded beams $[52,53]$. Turbine blades are a prime candidate for FGM use and as a result there have been a number of research papers on rotating thin walled beams. The objective of the research is to model FGM structures for turbines and rotating discs. Various authors quoted here, analyzed the vibration of rotating thin-walled beams [54-61]. The Timoshenko beam was a common beam theory used to model thin-walled rotating laminated beams [62-64].

In terms of approximate solutions, finite element approaches were found to be the most common. Various authors have applied the FEM to FGM beams based on Euler-Bernoulli and Timoshenko beam theory [19,65-73]. Pradhan and Chakraverty [69] used the Rayleigh-Ritz method to formulate an element model to solve for the free vibration of Euler and Timoshenko beams. The Chebyshev collocation method has been investigated by various authors $[70,73]$ for Timoshenko and axially graded beams. Kahya and Turan [72] used a Lagrange equation approach to develop a model for analysing the vibration and buckling of first-order shear deformation theory beams. Shakeri et al. used Galerkin and Newmark methods to solve layered graded thick hollow shells [65,66]. Simsek [67] investigated the vibration of functionally graded beams for Euler-Bernoulli, Timoshenko and the third order deformation theory.

Several studies used the Dynamic Stiffness Method to find an analytical solution for FGM beams. Su and Banerjee have applied the DSM to the vibrational analysis of both Euler-Bernoulli and Timoshenko beams $[74,75]$. Rajasekaran applied Banerjee's DSM method to axially functionally graded beams [76]. Lee and Lee used the exact transfer matrix expression, which is similar to the DSM solution, to find 
the natural frequency of an Euler-Bernoulli FGM beam [77]. Similarly, Hao and Wei [78] derived the dynamic stiffness matrix using state space differential equations.

The DFE method has been extended to the vibration analysis of various beam-like structure problems [79-82]. Hashemi and Richard (1999) [79] presented dynamic shape functions and a DFE for the vibration analysis of thin spinning beams. Kashani et al. [80] extended the analysis of coupled bending-torsion beams to combined loadings. Hashemi and Adique [81] presented a DFE approach to various threelayered sandwich beam models. Erdelyi and Hashemi [82] applied the DFE method to delaminated Euler-Bernoulli beams. In all studies, when DFE is compared to the conventional FEM, the DFE generally exhibits much higher convergence rates, especially for higher modes of vibration.

\subsection{Research Motivation}

A main design motivator in the commercial aerospace industry is increasing the fuel efficiency of the aircraft and FGMs could be part of the solution. Two design levers that increase the fuel efficiency of an aircraft is a reduction of the aircrafts overall weight and increasing the thermal efficiency of its turbofan engines through higher core temperatures. A FGM using a combination of metallic materials could be optimized to provide similar structural characteristics to conventional materials with the goal of optimizing the weight. Metallic-ceramic FGMs can replace turbo-machinery components such as ceramic coated turbine blades or combustion liners. Theoretically a metallic-ceramic FGM should be more durable than traditional ceramic coatings due to the benefits of not having a sharp interface between layers. With more heat durable components a rise in core temperature could be possible, leading to higher thermal efficiencies. It is important to develop reliable methods of predicating the vibration behavior of FGMs as they can be a solution to the material constraints in today's aerospace industry.

Free vibration analysis of functionally graded beams can be performed using various numerical and analytical techniques. From literature it is observed that conventionally FEM is commonly used and the frequency dependent DSM approach has been explored. These two approaches have their advantages and disadvantages. The conventional FEM is a robust tool that can perform analysis on complex geometry and loadings. In terms of accuracy, the DSM method is a better alternative particularly at high frequencies, providing 'exact' solutions to an infinite number of frequencies. However, the DSM 
procedure requires the solution to the governing equations which can be difficult to obtain for complex problems and therefore the application of the method is often limited to special cases.

The DFE method is a hybrid approach that combines the FEM and DSM method to retain the advantages of each method. The DFE method has been applied to various beam and plate structures and composites such as sandwich beams. To the best of the author's knowledge a DFE formulation has not yet been applied to the vibration modeling of structural members made of continuous nonhomogeneous materials such as FGMs. In the present study, a DFE method for the free vibration analysis of FGM Euler-Bernoulli beams under various boundary conditions and material variation is developed. The gradient properties vary along the thickness with a power-law distribution. Based on previously developed applicable governing differential equations of motion [74], the weighted residual method is used to develop the weak integral form of the governing equations. The closed-form solutions of the differential equations governing the uncoupled lateral and axial vibrations of the system are used as the basis functions of approximation space to derive the relevant Dynamic Trigonometric Shape Functions (DTSFs). Introducing the field variables, in terms of the DTSFs and nodal displacements, into the weak integral form of the governing equations and through additional mathematical manipulation leads to an element matrix resembling the frequency dependent element from the Dynamic Stiffness Method. The element matrices are then assembled and the boundary conditions applied to form the system's non-linear eigenvalue problem. The natural frequencies and modes of the system are extracted by solving the non-linear eigenproblem. A parametric study is performed to investigate the effects of various material grading and boundary conditions on the natural frequency and mode shapes. To validate the DFE formulation, results will be compared against FEM, DSM, sources from literature and results from a commercial FEM package.

\subsection{Specific Objectives}

The purpose of the research was to develop a Dynamic Finite Element formulation for functionally graded beams. The specific objectives of the research were:

- Apply a conventional FEM formulation for Euler-Bernoulli functionally graded beams.

- Develop a MATLAB code based on the FEM formulation for benchmarking. 
- Develop a MATLAB code based on the DSM formulation found in literature for benchmarking.

- Apply the DFE formulation for Euler-Bernoulli functionally graded beams.

- Develop a MATLAB code based on the DFE formulation.

- Numerically validate the Dynamic Finite Element formulation with classical FEM, DSM, and results found from literature.

- Create a finite element model using the commercial software ANSYS ${ }^{\circledR}$ to further validate results.

\subsection{Thesis Document Organization}

The document is organized into four chapters and five appendices. A brief introduction to FEM, DSM, DFE methods as well as a literature survey are presented in the present chapter.

Chapter 2 begins with introducing the methodology of modeling the material variation of FGM. The FEM, from governing equations to the matrices of the system, is presented. The DSM formulation used for the MATLAB code is also briefly presented. The DFE formulation is then introduced starting from the FEM weak form equation. The DFE is created through an additional set of integration by parts and the application of trigonometric shape functions. Some methods to solve the non-linear eigenvalue problem of DFE and DSM are briefly discussed. The natural frequencies are studied for various FGM beam configurations and parameters. Using the data, convergence test and numerical validations are presented. Finally, a parametric study is performed by varying the material grading parameter to investigate higher mode frequency and shapes.

In Chapter 3 a FGM beam model created in ANSYS ${ }^{\circledR}$ is introduced. The model is created using a number of discrete layers with homogenous material properties in each layer. The properties of each layer were dependent on its location on the height of the beam cross section; i.e., through the beam thickness. The methodology used to model FGM using commercial software is discussed. Two models are presented with different mesh refinements and are used to compare with the results presented in Chapter 2 .

Finally, in Chapter 4 some conclusions are drawn based on the results of Chapters 2 and 3, and prospective topics to further the research of functionally graded beams is discussed. 


\section{Chapter 2}

\section{Functionally Graded Euler-Bernoulli}

\section{Beam}

\subsection{Introduction}

In this chapter FEM and DFE formulations for functionally graded Euler-Bernoulli beams are presented. Using the Galerkin method of weighted residual the weak form equation of the governing equations is derived. For the FEM formulation polynomial shape functions are used to find the stiffness and mass matrices of the system. Additional mathematical manipulation is performed on the weak form equations to develop the DFE formulation. The trigonometric shape functions for the uncoupled bending and axial vibrations are then used to find the frequency dependent stiffness matrix. The DSM method derived by $\mathrm{Su}$ and Banerjee [74] is also presented and briefly discussed as it was used to create a MATLAB code for benchmarking and numerical validation purposes.

\subsection{Theory}

The co-ordinate system and notation used in this investigation is shown in Figure 2.1, where the beam has a length $L$ along $y$, thickness $h$ along $z$, and width $b$ along the $x$ axes. Relevant material properties are Young's Modulus, $E$, and density, $\rho$. 


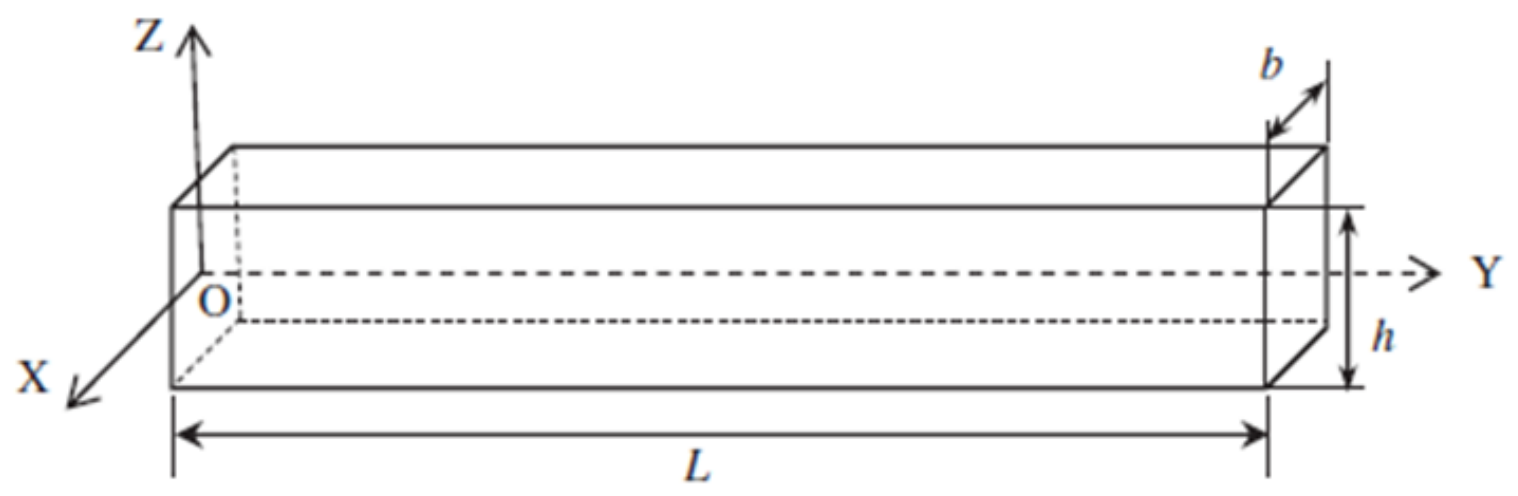

Figure 2.1: Co-ordinate system and notation for formulation [74].

The Euler-Bernoulli beam is the simplest beam model and is based on the following assumptions [83]:

- The cross section can be assumed to be rigid under the application of transverse and axial loads.

- The cross section is assumed to remain planar and normal to the deformed axis during deformation

To model the effective material property, $P$, of a FGM beam, the rule of mixtures is used and can be expressed as $[67,74,75]$ :

$$
P(z)=\left(P_{t}-P_{b}\right) V_{t}+P_{b}
$$

where $P_{t}$ and $P_{b}$ are the material properties at the top and bottom surfaces of the beam, respectively. $V_{t}$ is the volume fraction of the top constituent of the beam which is defined as $[67,74,75]$ :

$$
V_{t}=\left(\frac{z}{h}+\frac{1}{2}\right)^{k}
$$

As mentioned previously in the literature survey, the effective material properties for research on modal analysis commonly vary according to a power law distribution. Variation of the volume fraction against thickness for different values of $k$ is represented in Figure 2.2, where $k=1$ indicates a linear variation of material composition from the top to the bottom, $k=0$ represents a beam composed entirely of the top material, and $k=\infty$ represents a beam made entirely of the bottom material.

In this investigation, the same governing equations of motions as those used by Su's and Banerjee's research [74], are utilized. To derive the governing differential equations, Su and Banerjee calculated the 


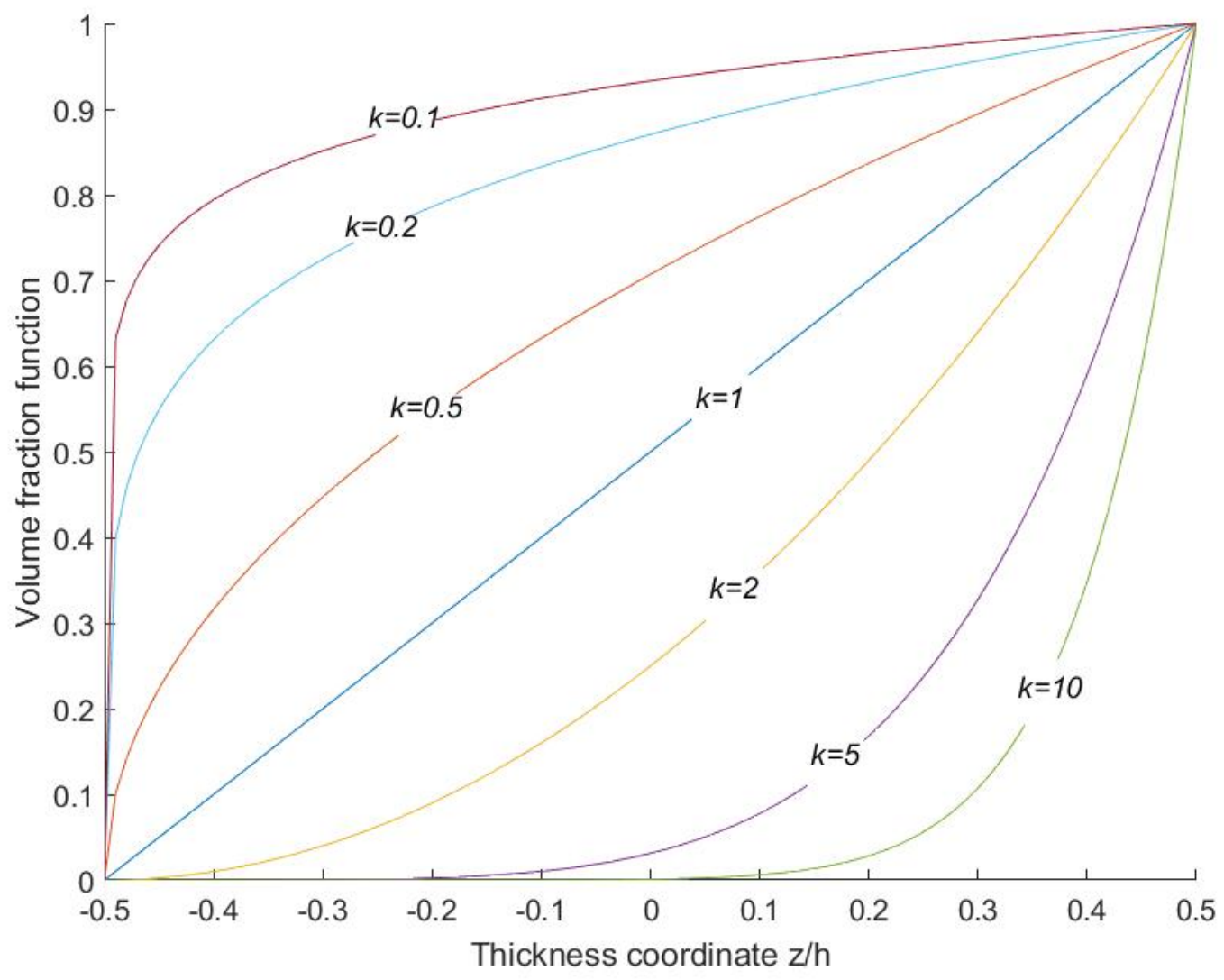

Figure 2.2: Variation in volume fraction through thickness in terms of $k$.

strain and kinetic energy and applied Hamilton's principle. The boundary conditions were also produced as a by-product of the Hamilton formulation. The result was the two coupled differential equations of motion [74]:

$$
\begin{gathered}
-I_{0} \ddot{v}+I_{1} \ddot{w}^{\prime}+A_{0} v^{\prime \prime}-A_{1} w^{\prime \prime \prime}=0 \\
-I_{0} \ddot{w}-I_{1} \ddot{v}^{\prime}+I_{2} \ddot{w}^{\prime \prime}+A_{1} v^{\prime \prime \prime}-A_{2} w^{\prime \prime \prime \prime}=0
\end{gathered}
$$

where ( $)^{\prime}$ stands for the derivative with respect to $y$ for $(0 \leq y \leq L)$ and $\left({ }^{\circ}\right)$ denotes the derivative with 
respect to $t$ (time). The parameters $I_{i}$ and $A_{i}$ are defined as:

$$
\begin{aligned}
I_{i} & =\int z^{i} \rho(z) d A \\
A_{i} & =\int z^{i} E(z) d A
\end{aligned}
$$

Assuming simple harmonic motion, axial displacements, $v$ and lateral displacement, $w$ can be written as:

$$
\begin{aligned}
v(y, t) & =V(y) e^{i \omega t} \\
w(y, t) & =W(y) e^{i \omega t}
\end{aligned}
$$

where $\omega$ denotes the frequency, $V(y)$ and $W(y)$ are the amplitudes of axial and flexural displacements, respectively. By substituting (6) into (3) and (4), the governing equations can be rewritten as:

$$
\begin{gathered}
I_{0} V \omega^{2}-I_{1} W^{\prime} \omega^{2}+A_{0} V^{\prime \prime}-A_{1} W^{\prime \prime \prime}=0 \\
I_{0} W \omega^{2}+I_{1} V^{\prime} \omega^{2}-I_{2} W^{\prime \prime} \omega^{2}+A_{1} V^{\prime \prime \prime}-A_{2} W^{\prime \prime \prime \prime}=0
\end{gathered}
$$

The loads or natural boundary conditions are the resultant axial force $(F)$, shear force $(S)$, and bending moment $(M)$, which are defined as [74]:

$$
\begin{gathered}
F=-A_{0} V^{\prime}+A_{1} W^{\prime \prime} \\
S=-I_{1} V \omega^{2}-A_{1} V^{\prime \prime}+I_{2} W^{\prime} \omega^{2}+A_{2} W^{\prime \prime \prime} \\
M=A_{1} V^{\prime}-A_{2} W^{\prime \prime}
\end{gathered}
$$

\subsection{Finite Element Method (FEM) Derivation}

In what follows, a finite element formulation for the free vibration analysis of a FGM beam is presented based on a Galerkin weighted residual method. From the Euler-Bernoulli beam theory and assuming simple harmonic motion, the equations of motions take the following form:

$$
I_{0} V \omega^{2}-I_{1} W^{\prime} \omega^{2}+A_{0} V^{\prime \prime}-A_{1} W^{\prime \prime \prime}=0
$$




$$
I_{0} W \omega^{2}+I_{1} V^{\prime} \omega^{2}-I_{2} W^{\prime \prime} \omega^{2}+A_{1} V^{\prime \prime \prime}-A_{2} W^{\prime \prime \prime \prime}=0
$$

Following the Galerkin method of weighted residuals, the above equation is expressed as a residual equation weighted by axial and lateral virtual displacements, $\delta v$ and $\delta w$, respectively. The integral of the residual is set to zero, resulting in the following forms:

$$
\begin{gathered}
W_{v}=\int_{0}^{L} \delta v\left(I_{0} V \omega^{2}-I_{1} W^{\prime} \omega^{2}+A_{0} V^{\prime \prime}-A_{1} W^{\prime \prime \prime}\right) d y=0 \\
W_{w}=\int_{0}^{L} \delta w\left(I_{0} W \omega^{2}+I_{1} V^{\prime} \omega^{2}-I_{2} W^{\prime \prime} \omega^{2}+A_{1} V^{\prime \prime \prime}-A_{2} W^{\prime \prime \prime \prime}\right) d y=0
\end{gathered}
$$

A set of integration by parts are performed, resulting in the following weak form of the above integral equations:

$$
\begin{gathered}
W_{v}=\frac{\left.\delta v\left(-A_{0} V^{\prime}+A_{1} W^{\prime \prime}\right)\right|_{0} ^{L}+\int_{0}^{L}\left(\left(-\omega^{2}\right) \delta v\left(I_{0} V-I_{1} W^{\prime}\right)+\delta v^{\prime}\left(A_{0} V^{\prime}-A_{1} W^{\prime \prime}\right)\right) d y=0}{W_{w}=\underline{\left.\left(\delta w\left(-I_{1} \omega^{2} V-A_{1} V^{\prime \prime}+I_{2} \omega^{2} W^{\prime}+A_{2} W^{\prime \prime \prime}\right)+\delta w^{\prime}\left(A_{1} V^{\prime}-A_{2} W^{\prime \prime}\right)\right)\right|_{0} ^{L}}} \\
+\int_{0}^{L}\left(\left(-\omega^{2}\right) \delta w\left(I_{0} W\right)+\left(-\omega^{2}\right) \delta w^{\prime}\left(I_{2} W^{\prime}-I_{1} V\right)+\delta w^{\prime \prime}\left(A_{2} W^{\prime \prime}-A_{1} V^{\prime}\right)\right) d y=0
\end{gathered}
$$

The above expressions (14) and (15) also satisfy the principle of virtual work (PVW),

$$
W_{\text {total }}=W_{\text {int }}-W_{\text {ext }}=0
$$

where $W_{\text {total }}$ is the total virtual work, $W_{i n t}$ is the internal virtual work, and $W_{\text {ext }}$ is the external virtual work. The underlined terms in expressions (14) and (15) represent the virtual work generated by the load boundary conditions of the system, presented earlier as expression (9). For the free vibration of a 
system, the total external virtual work is $W_{e x t}=0$ and therefore:

$$
\begin{gathered}
\left.\delta v\left(-A_{0} V^{\prime}+A_{1} W^{\prime \prime}\right)\right|_{x=0}=\left.\delta W_{\text {ext }}\right|_{x=0} \\
\left.\delta v\left(-A_{0} V^{\prime}+A_{1} W^{\prime \prime}\right)\right|_{x=L}=\left.\delta W_{\text {ext }}\right|_{x=L} \\
\left.\left(\delta w\left(-I_{1} \omega^{2} V-A_{1} V^{\prime \prime}+I_{2} \omega^{2} W^{\prime}+A_{2} W^{\prime \prime \prime}\right)+\delta w^{\prime}\left(A_{1} V^{\prime}-A_{2} W^{\prime \prime}\right)\right)\right|_{x=0}=\left.\delta W_{e x t}\right|_{x=0} \\
\left.\left(\delta w\left(-I_{1} \omega^{2} V-A_{1} V^{\prime \prime}+I_{2} \omega^{2} W^{\prime}+A_{2} W^{\prime \prime \prime}\right)+\delta w^{\prime}\left(A_{1} V^{\prime}-A_{2} W^{\prime \prime}\right)\right)\right|_{x=L}=\left.\delta W_{e x t}\right|_{x=L}
\end{gathered}
$$

Consequently, the net resultant virtual work caused by the external force and moment terms in (14) and (15) goes to zero. With the boundary conditions satisfied, the remaining parts of the expressions can now be discretized, leading to the following elemental form:

$$
\begin{gathered}
w_{v}^{n}=\int_{0}^{l_{n}}\left(\left(-\omega^{2}\right) \delta v\left(I_{0} V-I_{1} W^{\prime}\right)+\delta v^{\prime}\left(A_{0} V^{\prime}-A_{1} W^{\prime \prime}\right)\right) \delta y \\
w_{w}^{n}=\int_{0}^{l_{n}}\left(\left(-\omega^{2}\right) \delta w\left(I_{0} W\right)+\left(-\omega^{2}\right)\left(\delta w^{\prime}\right)\left(I_{2} W^{\prime}-I_{1} V\right)+\delta w^{\prime \prime}\left(A_{2} W^{\prime \prime}-A_{1} V^{\prime}\right)\right) \delta y
\end{gathered}
$$

Linear and cubic Hermite polynomials approximations are used for axial and bending displacements, respectively.

$$
\begin{gathered}
V(y)=\left[\begin{array}{ll}
1 & y
\end{array}\right]\{A\} \\
W(y)=\left[\begin{array}{llll}
1 & y & y^{2} & y^{3}
\end{array}\right]\{C\}
\end{gathered}
$$

The following vectors represent nodal displacements:

$$
\left\{V_{n}\right\}=\left(\begin{array}{l}
V_{1} \\
V_{2}
\end{array}\right)=\left[\begin{array}{ll}
1 & 0 \\
1 & L
\end{array}\right]\{A\}
$$




$$
\left\{W_{n}\right\}=\left(\begin{array}{c}
W_{1} \\
W_{1}^{\prime} \\
W_{2} \\
W_{2}^{\prime}
\end{array}\right)=\left[\begin{array}{cccc}
1 & 0 & 0 & 0 \\
0 & 1 & 0 & 0 \\
1 & L & L^{2} & L^{3} \\
0 & 1 & 2 L & 3 L^{2}
\end{array}\right]\{C\}=\left[P_{n}\right]\{C\}
$$

Applying the Hermite polynomial approximations presented in Appendix 1:

$$
\begin{gathered}
V(y)=\left[\begin{array}{ll}
1 & y
\end{array}\right]\left[P_{n}\right]^{-1}\left\{V_{n}\right\}=[N(y)]\left\{V_{n}\right\} \\
W(y)=\left[\begin{array}{llll}
1 & y & y^{2} & y^{3}
\end{array}\right]\left[P_{n}\right]^{-1}\left\{W_{n}\right\}=[N(y)]\left\{W_{n}\right\}
\end{gathered}
$$

The row vector $[N(y)]$ represents the shape functions that describe the displacement along the domain of the element. Now that the shape functions have been defined, they are substituted into equations (18) and (19) resulting in:

$$
\begin{gathered}
w_{v}^{n}=\int_{0}^{l_{n}}\left(\left(-\omega^{2}\right)<\delta V_{n}>\left\{N_{v}\right\}\left(I_{0}<N_{v}>\left\{V_{n}\right\}-<N_{w}^{\prime}>\left\{W_{n}^{\prime}\right\} I_{1}\right)\right. \\
+<\delta V_{n}^{\prime}>\left\{N_{v}^{\prime}\right\}\left(A_{0}<N_{v}^{\prime}>\left\{V_{n}^{\prime}\right\}-A_{1}<N_{w}^{\prime \prime}>\left\{W_{n}^{\prime \prime}\right\}\right) \delta y \\
w_{w}^{n}=\int_{0}^{l_{n}}\left(\left(-\omega^{2}\right)<\delta W_{n}>\left\{N_{w}\right\}\left(I_{0}<N_{w}>\left\{W_{n}\right\}\right)\right. \\
+\left(-\omega^{2}\right)<\delta W_{n}^{\prime}>\left\{N_{w}^{\prime}\right\}\left(I_{2}<N_{w}^{\prime}>\left\{W_{n}^{\prime}\right\}-I_{1}<N_{v}>\left\{V_{n}\right\}\right) \\
+<\delta W^{\prime \prime}>\left\{N_{w}^{\prime \prime}\right\}\left(A_{2}<N_{w}^{\prime \prime}>\left\{W_{n}^{\prime \prime}\right\}-A_{1}<N_{v}^{\prime}>\left\{V_{n}\right\}\right) \delta y
\end{gathered}
$$

The above terms can be combined to form the following eigenvalue problem:

$$
\begin{gathered}
<\delta V_{n}>\left(\left(K+K_{\text {coupling }}\right)-\omega^{2}\left(M+M_{\text {coupling }}\right)\right)\left\{V_{n}\right\}=0 \\
<\delta W_{n}>\left(\left(K+K_{\text {coupling }}\right)-\omega^{2}\left(M+M_{\text {coupling }}\right)\right)\left\{W_{n}\right\}=0
\end{gathered}
$$

The two equations above can be combined to create a $6 \times 6$ matrix for each element, where $\mathrm{K}$ is the element stiffness matrix, and $\mathrm{M}$ is the element mass matrix. The coupling terms have been separated to show the coupling relations between the two equations. The assembly of the element matrices and the application of boundary conditions then leads to the system's linear eigenvalue method, which is then 
solved to find the natural frequencies.

\subsection{Dynamic Stiffness Method(DSM) Formulation}

Su and Banerjee [74] have developed a Dynamic Stiffness method for FGM Euler-Bernoulli beams. This method exploits the analytical solution, forgoing any approximation within the limits of the theory. As a result, the DSM method is independent of the number of elements and is capable of providing exact results for all natural frequencies without discretization. The DSM formulation developed by Su and Banerjee [74] is briefly presented here for the sake of completeness. An in-house MATLAB code was created based on the formulation.

First, the governing equations (7) and (8) are combined into a single sixth order ordinary differential equation. Introducing the non-dimensional term $\xi=y / l(0 \leq \xi \leq 1)$ and the differential operator $D=$ $d / d \xi:$

$$
\left(D^{6}+a D^{4}+b D^{2}+c\right) H=0
$$

where,

$$
\begin{gathered}
a=\frac{2 A_{1} I_{1}-A_{0} I_{2}-A_{2} I_{0}}{A_{1}^{2}-A_{0} A_{2}} L^{2} \omega^{2} \\
b=\frac{A_{0} I_{0}+I_{1}^{2} \omega^{2}-I_{0} I_{2} \omega^{2}}{A_{1}^{2}-A_{0} A_{2}} L^{4} \omega^{2} \\
c=\frac{I_{0}^{2}}{A_{1}^{2}-A_{0} A_{2}} L^{6} \omega^{4} \\
H=V(\xi) \quad \text { or } \quad W(\xi)
\end{gathered}
$$

The solution to the differential equation (29) can be expressed as:

$$
V(\xi)=\sum_{j=1}^{6} R_{j} e^{r_{j} \xi}, \quad \text { or } \quad W(\xi)=\sum_{j=1}^{6} Q_{j} e^{r_{j} \xi}
$$


where $r_{j}$ is the roots of the characteristic equation and $R_{j}$ and $Q_{j}$ are constant vectors:

$$
\begin{aligned}
& \{Q\}^{T}=<Q_{1} \quad Q_{2} \quad Q_{3} \quad Q_{4} \quad Q_{5} \quad Q_{6}> \\
& \{R\}^{T}=<R_{1} \quad R_{2} \quad R_{3} \quad R_{4} \quad R_{5} \quad R_{6}>
\end{aligned}
$$

The constant vectors are related to each other through the following relationship:

$$
Q_{j}=\alpha_{j} R_{j}
$$

where,

$$
\alpha_{j}=\frac{I_{0} \omega^{2} L^{3}+L A_{0} r_{j}^{2}}{I_{1} \omega^{2} L^{2} r_{j}+A_{1} r_{j}^{3}}
$$

The expressions for rotation $\theta(\xi)$, axial force $F(\xi)$, shear force $S(\xi)$ and the bending moment $M(\xi)$ are obtained from equations (38) - (41) as:

$$
\begin{gathered}
\theta(\xi)=\frac{d W}{d y}=\frac{1}{L} \frac{d W}{d \xi}=\frac{1}{L} \sum_{j=1}^{6} r_{j} \alpha_{j} R_{j} e^{r_{j} \xi} \\
F(\xi)=-\frac{A_{0}}{L} V^{\prime}+\frac{A_{1}}{L^{2}} W^{\prime \prime}=\frac{1}{L^{2}} \sum_{j=1}^{6}\left(-A_{0} L+A_{1} \alpha_{j} r_{j}\right) r_{j} e^{r_{j} \xi} R_{j} \\
S(\xi)=-I_{1} \omega^{2} V-\frac{A_{1}}{L^{2}} V^{\prime \prime}+\frac{I_{2} \omega^{2}}{L} W^{\prime}+\frac{A_{2}}{L^{3}} W^{\prime \prime \prime} \\
=\sum_{j=1}^{6}\left[-\left(I_{1} \omega^{2}+\frac{A_{1}}{L^{2}} r_{j}\right)+\left(\frac{I_{2} \omega^{2}}{L}+\frac{A_{2}}{L^{3}} r_{j}^{2}\right) \alpha_{j} r_{j}\right] e^{r_{j} \xi} R_{j} \\
M(\xi)=\frac{A_{1}}{L} V^{\prime \prime}-\frac{A_{2}}{L^{2}} W^{\prime \prime}=\frac{1}{L^{2}} \sum_{j=1}^{6}\left(A_{1} L-A_{2} \alpha_{j} r_{j}\right) r_{j} e^{r_{j} \xi} R_{j}
\end{gathered}
$$

The end conditions for the displacements and forces of the beam element are given as follows:

$$
\begin{aligned}
& \text { At } \quad \xi=0: \quad V=V_{1}, \quad W=W_{1}, \quad \theta=\theta_{1}, \quad F=F_{1}, \quad S=S_{1}, \quad M=M_{1} \\
& \text { At } \xi=1: \quad V=V_{2}, \quad W=W_{2}, \quad \theta=\theta_{2}, \quad F=F_{2}, \quad S=S_{2}, \quad M=M_{2}
\end{aligned}
$$


Using equations (34), (38), (42) and (43), the relationship between displacement and the constant vector $R$ is written as:

$$
u_{n}=B R
$$

where,

$$
B=\left[\begin{array}{cccccc}
1 & 1 & 1 & 1 & 1 & 1 \\
\alpha_{1} & \alpha_{2} & \alpha_{3} & \alpha_{4} & \alpha_{5} & \alpha_{6} \\
r_{1} \alpha_{1} / L & r_{2} \alpha_{2} / L & r_{3} \alpha_{3} / L & r_{4} \alpha_{4} / L & r_{5} \alpha_{5} / L & r_{6} \alpha_{6} / L \\
e^{r_{1}} & e^{r_{2}} & e^{r_{3}} & e^{r_{4}} & e^{r_{5}} & e^{r_{6}} \\
\alpha_{1} e^{r_{1}} & \alpha_{2} e^{r_{2}} & \alpha_{3} e^{r_{3}} & \alpha_{4} e^{r_{4}} & \alpha_{5} e^{r_{5}} & \alpha_{6} e^{r_{6}} \\
r_{1} \alpha_{1} e^{r_{1}} / L & r_{2} \alpha_{2} e^{r_{2}} / L & r_{3} \alpha_{3} e^{r_{3}} / L & r_{4} \alpha_{4} e^{r_{4}} / L & r_{5} \alpha_{5} e^{r_{5}} / L & r_{6} \alpha_{6} e^{r_{6}} / L
\end{array}\right]
$$

The relationship between force $F$, and the constant vector $R$, can be expressed using equation (39) - (43) as:

$$
F=A R
$$

where $A$, is a $6 \times 6$ matrix with each row given by:

$$
\begin{gathered}
A_{1 j}=\frac{1}{L^{2}}\left(-A_{0} L+A_{1} \alpha_{j} r_{j}\right) r_{j} \\
A_{2 j}=-\left(I_{1} \omega^{2}+\frac{A_{1}}{L^{2}} r_{j}^{2}\right)+\left(\frac{I_{2} \omega^{2}}{L}+\frac{A_{2}}{L^{3}} r_{j}^{2}\right) \alpha_{j} r_{j} \\
A_{3 j}=\frac{1}{L^{2}}\left(A_{1} L-A_{2} r_{j} \alpha_{j}\right) r_{j} \\
A_{4 j}=\frac{1}{L^{2}}\left(-A_{0} L+A_{1} \alpha_{j} r_{j}\right) r_{j} e^{r_{j}} \\
A_{5 j}=\left[-\left(I_{1} \omega^{2}+\frac{A_{1}}{L^{2}} r_{j}^{2}\right)+\left(\frac{I_{2} \omega^{2}}{L}+\frac{A_{2}}{L^{3}} r_{j}^{2}\right) \alpha_{j} r_{j}\right] e^{r_{j}} \\
A_{6 j}=\frac{1}{L^{2}}\left(A_{1} L-A_{2} r_{j} \alpha_{j}\right) r_{j} e^{r_{j}}
\end{gathered}
$$

Vector $R$ can be eliminated by substituting equation (44) into (46), resulting in:

$$
F=K u_{n}
$$


where $K$, the required dynamic stiffness matrix is:

$$
K=A B^{-1}
$$

At this point the dynamic stiffness matrix $K$ can be used to calculate the natural frequency and mode shapes. Frequency can be found through various methods, a simple method would be to sweep through a range of frequencies to find the frequencies where the $|K|=0$. Other more complex methods such as the Wittrick-Williams algorithm can be used to solve for the natural frequencies in a more efficient process [74].

\subsection{Dynamic Finite Element (DFE) Formulation}

The DFE formulation follows the conventional FEM formulation using a Galerkin weighted residual approach. The formulation begins to diverge from a conventional FEM formulation after the discretized weak form equation is found. In an FEM formulation, the polynomial shape functions would be introduced at this point. However, for a DFE formulation, additional integration by parts is performed before the shape functions are introduced. Beginning by restating the already discretized weak form equation from the FEM formulation:

$$
\begin{gathered}
w_{v}^{n}=\int_{0}^{l_{n}}\left(\left(-\omega^{2}\right) \delta v\left(I_{0} V-I_{1} W^{\prime}\right)+\delta v^{\prime}\left(A_{0} V^{\prime}-A_{1} W^{\prime \prime}\right)\right) \delta y \\
w_{w}^{n}=\int_{0}^{l_{n}}\left(\left(-\omega^{2}\right) \delta w\left(I_{0} W\right)+\left(-\omega^{2}\right)\left(\delta w^{\prime}\right)\left(I_{2} W^{\prime}-I_{1} V\right)+\delta w^{\prime \prime}\left(A_{2} W^{\prime \prime}-A_{1} V^{\prime}\right)\right) \delta y
\end{gathered}
$$

the following term $\xi=y / l(0 \leq \xi \leq 1)$ is introduced into the above equations, resulting in the following non-dimensional form:

$$
\begin{gathered}
W_{v}^{n}=\int_{0}^{1} \delta v\left(I_{0} l V \omega^{2}-I_{1} W^{\prime} \omega^{2}+\frac{A_{0}}{l} V^{\prime \prime}-\frac{A_{1}}{l^{2}} W^{\prime \prime \prime}\right) \delta \xi \\
W_{w}^{n}=\int_{0}^{1} \delta w\left(I_{0} l W \omega^{2}+I_{1} V^{\prime} \omega^{2}-\frac{I_{2}}{l} W^{\prime \prime} \omega^{2}+\frac{A_{1}}{l^{2}} V^{\prime \prime \prime}-\frac{A_{2}}{l^{3}} W^{\prime \prime \prime \prime}\right) \delta \xi
\end{gathered}
$$

A set of additional integration by parts are performed on the discretized weak form equations above, 
leading to the following form of the equations:

$$
\begin{aligned}
W_{v}^{n}= & {\left.\left[\delta v^{\prime}\left(\frac{A_{0}}{l} V\right)\right]\right|_{0} ^{1}+\underbrace{\int_{0}^{1} V\left(-\omega^{2} I_{0} l \delta v-\frac{A_{0}}{l} \delta v^{\prime \prime}\right) \delta \xi}_{\text {Coupling }} } \\
& +\underbrace{\omega^{2} \int_{0}^{1} \delta v\left(I_{1} W^{\prime}\right) d \xi-\int_{0}^{1} \delta v^{\prime}\left(\frac{A_{1}}{l^{2}} W^{\prime \prime}\right) d \xi}_{\text {* }} \\
W_{w}^{n}= & {\left[\delta w^{\prime}\left(-\frac{\omega^{2} I_{2}}{l} W\right)+\delta w^{\prime \prime}\left(\frac{A_{2}}{l^{3}} W^{\prime}\right)-\delta w^{\prime \prime \prime}\left(\frac{A_{2}}{l^{3}} W\right)\right]_{0}^{1} } \\
& +\underbrace{\int_{0}^{1} W\left(\frac{A_{2}}{l^{3}} \delta w^{\prime \prime \prime \prime}+\frac{\omega^{2} I_{2}}{l} \delta w^{\prime \prime}-\omega^{2} I_{0} l \delta w\right) d \xi}_{\text {Coupling }} \\
& +\underbrace{\omega^{2} \int_{0}^{1} \delta w^{\prime}\left(I_{1} V\right) d \xi-\int_{0}^{1} \delta w^{\prime \prime}\left(\frac{A_{1}}{l^{2}} V^{\prime}\right) d \xi}
\end{aligned}
$$

The coupling terms are separated and labeled here for clarity. The characteristic equation of $(*)$ found in (54) is a second order differential equation having the form $-c_{1} D^{2}-c_{2} \omega^{2}=0$, where the $c$ terms are constants and $D^{2}$ is the second partial derivative operator with respect to the non-dimensional length $\xi$. The characteristic equation of $(* *)$ found in (55) is a fourth order differential equation having the from $c_{3} D^{4}+c_{4} \omega^{2} D^{2}-c_{5} \omega^{2}=0$, where $c$ terms are constants and $D^{4}$ and $D^{2}$ are the fourth partial derivative and second partial derivative operators with respect to the non-dimensional length $\xi$, respectively. The closed-form solutions of the uncoupled integral terms $\left(^{*}\right)$ and $(* *)$, respectively, can be expressed in the following forms:

$$
\begin{gathered}
V(\xi)=D_{1} \cos (\gamma \xi)+D_{2} \sin (\gamma \xi) \\
W(\xi)=C_{1} \cos (\alpha \xi)+C_{2} \sin (\alpha \xi)+C_{3} \cosh (\beta \xi)+C_{4} \sinh (\beta \xi)
\end{gathered}
$$

where $D_{1,2}$ and $C_{1,2,3,4}$ are constants. The term $\gamma$ is based on the characteristic equation of $\left(^{*}\right)$ in expression (54).

$$
\gamma=\sqrt{\frac{-\omega^{2} I_{0} l^{2}}{A_{0}}}
$$


and the terms $\alpha$ and $\beta$ are based on the characteristic equation of (**) in expression (55).

$$
\alpha, \beta=\frac{1}{\sqrt{2 A}} \sqrt{\left(-B \pm \sqrt{\left.B^{2}-4 A C\right)}\right.}
$$

where,

$$
\begin{gathered}
A=\frac{A_{2}}{l^{3}} \\
B=\frac{\omega^{2} I_{2}}{l} \\
C=-\omega^{2} I_{0} l
\end{gathered}
$$

The interpolation functions are then obtained as follows. First, the generalized parameters $\langle a\rangle$, $\langle b\rangle,\langle\delta a\rangle$, and $\langle\delta b>$ are used, respectively, to express the solution functions $V$ and $W$, and test functions $\delta V$ and $\delta W$, written as:

$$
\begin{gathered}
V=<P(\xi)>_{v}\{a\} \\
\delta V=<P(\xi)>_{v}\{\delta a\} \\
W=<P(\xi)>_{w}\{b\} \\
\delta W=<P(\xi)>_{w}\{\delta b\}
\end{gathered}
$$

The axial and flexural dynamic basis functions of approximation space, respectively, are defined as $[10,81]$ :

$$
\begin{aligned}
& V_{n}(\xi)=\left\langle\cos (\gamma \xi) \quad \frac{\sin (\gamma \xi)}{\gamma}\right\rangle \\
& W_{n}(\xi)=\left\langle\cos (\alpha \xi) \quad \frac{\sin (\alpha \xi)}{\alpha} \quad \frac{\cosh (\beta \xi)-\cos (\alpha \xi)}{\alpha^{2}+\beta^{2}} \quad \frac{\sinh (\beta \xi)-\sin (\alpha \xi)}{\alpha^{3}+\beta^{3}}\right\rangle
\end{aligned}
$$

Replacing the generalized parameters $\langle a\rangle,\langle\delta a\rangle,\langle b\rangle$, and $\langle\delta b\rangle$ with the nodal variables, $<V_{1} \quad V_{2}>,<V_{1}^{\prime} \quad V_{2}^{\prime}>,<W_{1} \quad W_{1}^{\prime} \quad W_{2} \quad W_{2}^{\prime}>$, and $<\delta W_{1} \quad \delta W_{1}^{\prime} \quad \delta W_{2} \quad \delta W_{2}^{\prime}>$, respectively, 
expression (61) can be rewritten as:

$$
\begin{gathered}
\left\{V_{n}\right\}=[P(\xi)]_{v}\{a\} \\
\left\{\delta V_{n}\right\}=[P(\xi)]_{v}\{\delta a\} \\
\{W\}=[P(\xi)]_{w}\{b\} \\
\{\delta W\}=[P(\xi)]_{w}\{\delta b\}
\end{gathered}
$$

where the matrices $\left[P_{n}\right]_{v}$ and $\left[P_{n}\right]_{w}$ are define as:

$$
\begin{gathered}
P_{n v}=\left(\begin{array}{c}
P_{1}(\xi=0) \\
P_{2}(\xi=1)
\end{array}\right)_{v}=\left[\begin{array}{cc}
1 & 0 \\
\cos (\gamma) & \frac{\sin (\gamma)}{\gamma}
\end{array}\right] \\
P_{n w}=\left(\begin{array}{c}
P_{1}(\xi=0) \\
P_{1}^{\prime}(\xi=0) \\
\left.P_{2}(\xi)=1\right) \\
\left.P_{2}^{\prime}(\xi)=1\right)
\end{array}\right)=\left[\begin{array}{cccc}
1 & 0 & 0 & 0 \\
0 & 1 & 0 & \frac{\beta-\alpha}{\alpha^{3}+\beta^{3}} \\
\cos (\alpha) & \frac{\sin (\alpha)}{\alpha} & \frac{\cosh (\beta)-\cos (\alpha)}{\alpha^{2}+\beta^{2}} & \frac{\sinh (\beta)-\sin (\alpha)}{\alpha^{2}+\beta^{2}} \\
-\alpha \sin (\alpha) & \cos (\alpha) & \frac{\beta \sinh (\beta)+\alpha \sin (\alpha)}{\alpha^{2}+\beta^{2}} & \frac{\beta \cosh (\beta)-\alpha \cos (\alpha)}{\alpha^{3}+\beta^{3}}
\end{array}\right]
\end{gathered}
$$

By combining (64), (65), and (66) the approximation in nodal variables can be written as:

$$
\begin{gathered}
V(\xi)=<P(\xi)>_{v}\left[P_{n}\right]_{v}^{-1}\left\{V_{n}\right\}=<N\{\xi\}>_{v}\left\{V_{n}\right\} \\
W(\xi)=<P(\xi)>_{w}\left[P_{n}\right]_{w}^{-1}\left\{W_{n}\right\}=<N\{\xi\}>_{w}\left\{W_{n}\right\}
\end{gathered}
$$

where $\left\langle N(\xi)>_{v}\right.$ and $\left\langle N(\xi)>_{w}\right.$ are the frequency-dependent trigonometric shape functions for the axial and flexure, respectively. Equation (67) can be combined and rewritten as:

$$
\left(\begin{array}{c}
V(\xi) \\
W(\xi)
\end{array}\right)=[N]\left\{u_{n}\right\}
$$

where,

$$
\begin{aligned}
& {[N]=\left[\begin{array}{cccccc}
N_{1 v}(\omega) & 0 & 0 & N_{2 v}(\omega) & 0 & 0 \\
0 & N_{1 w}(\omega) & N_{2 w}(\omega) & 0 & N_{3 w}(\omega) & N_{4 w}(\omega)
\end{array}\right]} \\
& u_{n}=<V_{1} \quad W_{1} \quad W_{1}^{\prime} \quad V_{2} \quad W_{2} \quad W_{2}^{\prime}>^{T}
\end{aligned}
$$


Using expressions (54), (55) and the shape functions (1) through (8), presented in Appendix 2, the element dynamic stiffness matrix, $[K(\omega)]^{k}$, is derived which consists of uncoupled and coupled dynamic stiffness matrices, $[K(\omega)]_{u}^{k}$ and $[K(\omega)]_{c}^{k}$, respectively. The resulting expressions for the uncoupled and coupled dynamic stiffness matrices can be found within Appendix 3. The element dynamic stiffness matrix, $[K(\omega)]^{k}$, is formulated by adding the eight coupled and uncoupled sub-matrices. The global dynamic stiffness matrix $[K(\omega)]$, is obtained by assembling all the element matrices and applying the boundary conditions. The non-linear eigenvalue problem resulting from this method is:

$$
[K(\omega)] U_{n}=0
$$

where $U_{n}$ is the global nodal displacements of the system. The natural frequencies of the system would be the values of $\omega$, which yield a zero determinant, $|K(\omega)|=0$, for the global dynamic stiffness matrix [10]. A simple procedure of finding the system's natural frequency is varying $\omega$ in small steps to find the values that make the determinant zero. However, there are more efficient algorithms to solve for the natural frequencies such as the Wittrick-Williams algorithm. Hashemi [10] goes into detail of using various algorithms to solve for natural frequency. For the sake of simplicity, the simple procedure of sweeping through $\omega$ was used for the results presented herein.

It is worth noting that the basis functions are specifically chosen so that when the frequency approaches zero, the roots, $\alpha, \beta$, and $\gamma$ of the characteristic equations also approach zero. Subsequently, the dynamic trigonometric shape functions and basis functions become identical to those generated from the Hermite approximations, which are commonly used for FEM. The form of the DFE basis functions were formulated to exhibit this property to ensure a complete solution at all frequencies. In other words, if this was not considered, a static deformation solution would not be possible.

\subsection{Numerical Test and Results}

In this section, three illustrative examples are presented to numerically validate the DFE formulation through vibration analysis. For the first validation study, the DFE formulation is compared to and numerically validated against the well-defined solution of solid beams. In this example, the beam is assumed to be made of aluminium and the frequency results are compared against classical methods and the DSM method. Various material grading, boundary conditions and slender ratios were investigated. 
The second validation case involves a FGM beam composed of aluminum and alumina. Similar to the first case, the beam is assumed to be subjected to various material grading and slender ratios. However, only the simply supported boundary condition is used due to availability of data in literature. The final validation study is similar to the second study, but uses a linear variation in material properties. Once the numerical validation is completed, further analysis is performed to investigate the natural frequency and mode shapes for FGM beams with different boundary conditions and material variation. Furthermore, comparisons are made between the convergence performance of DFE and FEM.

The following non-dimensional parameter was used to normalize and compare results of various sources:

$$
\lambda_{i}=\omega_{i} L^{2} \sqrt{\frac{\rho_{b} A}{E_{b} I}}
$$

A pure aluminum beam can be considered a special case of a FGM beam. Using the current model, a solid aluminum beam would require an unattainable value of $k=\infty$ (refer to Figure 2.2). To avoid the use of infinity Su and Banerjee [74,75] have proposed two methods; setting the top and bottom properties within $\pm .0001 \%$, or use a value of $k=10^{6}$. It was observed that both methods would produce the same result, and therefore, for the purposes of this investigation the former method was used.

The material properties for the solid aluminum beam are: $\rho_{t}=2700.0027 \mathrm{~kg} / \mathrm{m}^{3}, \rho_{b}=2700 \mathrm{~kg} / \mathrm{m}^{3}$, $E_{t}=70.00007 G P a$, and $E_{b}=70 G P a$. An in-house DSM code was also created using the method presented in reference [74] to numerically validate the DFE formulation. The first three natural frequencies for an aluminum beam using classical Euler-Bernoulli beam solution, DSM, FEM, and DFE for various boundary conditions are presented in Table 2.1 through Table 2.3.

Excellent agreement is achieved for DFE in all conditions. The classical results used generic closedform solutions to the $4^{\text {th }}$ order Euler-Bernoulli governing equation solution that is often found in standard texts [84]. There is a slight deviation between some of the classical results with the element based methods. The discrepancy is caused by the differences between the the equation of motion for a EulerBernoulli FGM beam and the conventional Euler-Bernoulli beam equation. The equation of motion for FGM has three uncoupled terms for lateral displacement, where as the conventional beam equation has two terms. This extra term results in the small difference between the results. However, the effect of this term is diminished as the slender ratio is increased. 
Table 2.1: First 3 natural frequencies of a $\mathrm{Al}$ beam with $L / h=10$ for various boundary conditions.

\begin{tabular}{|c|c|c|c|c|c|c|c|}
\hline \multirow{2}{*}{$\begin{array}{l}\text { Boundary } \\
\text { Condition }\end{array}$} & \multirow{2}{*}{$\begin{array}{l}\text { Frequency } \\
\text { No. i }\end{array}$} & \multicolumn{6}{|c|}{ Non-dimensional fundamental natural frequency $\left(\lambda_{i}\right)$} \\
\hline & & $\begin{array}{l}\text { Classical } \\
\text { Results }\end{array}$ & $\begin{array}{c}\text { DSM } \\
\text { Ref [74]. }\end{array}$ & $\begin{array}{c}\text { DSM } \\
\text { Code }^{b}\end{array}$ & $\begin{array}{c}\text { DFE } \\
(1 \mathrm{ELE})^{a}\end{array}$ & $\begin{array}{c}\text { DFE } \\
(3 \mathrm{ELE})^{a}\end{array}$ & $\begin{array}{c}\text { FEM } \\
(10 \mathrm{ELE})^{a}\end{array}$ \\
\hline \multirow{3}{*}{ S-S } & 1 & 9.8696 & 9.8293 & 9.8293 & 9.8293 & 9.8293 & 9.8293 \\
\hline & 2 & 39.478 & 38.845 & 38.845 & 38.845 & 38.845 & 38.849 \\
\hline & 3 & 88.826 & 85.711 & 85.711 & 85.711 & 85.711 & 85.757 \\
\hline \multirow{3}{*}{$\mathrm{C}-\mathrm{C}$} & 1 & 22.373 & 22.259 & 22.259 & 22.259 & 22.259 & 22.260 \\
\hline & 2 & 61.673 & 60.522 & 60.522 & 60.522 & 60.522 & 60.538 \\
\hline & 3 & 120.90 & 116.21 & 116.21 & 116.21 & 116.21 & 116.32 \\
\hline \multirow{3}{*}{$\mathrm{C}-\mathrm{F}$} & 1 & 3.5160 & 3.5092 & 3.5092 & 3.5092 & 3.5092 & 3.5092 \\
\hline & 2 & 22.035 & 21.743 & 21.743 & 21.743 & 21.743 & 21.743 \\
\hline & 3 & 61.698 & 59.801 & 59.801 & 59.801 & 59.801 & 59.801 \\
\hline \multirow{3}{*}{ C-P } & 1 & 15.418 & 15.345 & 15.345 & 15.345 & 15.345 & 15.345 \\
\hline & 2 & 49.965 & 49.095 & 49.095 & 49.095 & 49.095 & 49.095 \\
\hline & 3 & 104.25 & 100.39 & 100.39 & 100.39 & 100.39 & 100.46 \\
\hline
\end{tabular}

${ }^{a}$ Solution to the classical results can be found in Appendix 4

${ }^{b}$ Results from in-house MATLAB code

Due to the frequency-dependent and highly convergent nature of DFE, both the DFE and DSM results also exhibit excellent convergence for higher frequencies, while FEM results start to deviate. In addition, for the conventional FEM, additional elements would be required to match the results of DFE and DSM.

Figure 2.3 shows the FEM convergence test results for the $3^{\text {rd }}$ mode of the homogeneous beam made from pure aluminum (Al). As can be observed from the figure, the conventional FEM nearly converges at around 10 to 12 elements. In contrast, DFE results show that a single element is capable of producing exact solutions. This is due to the fact the DFE method uses the solution of the uncoupled governing equation to create the DTSFs. Since this validation case uses no material grading, therefore, the coupling terms approach zero and the DFE solution is exact within the limits of the theory.

To further validate the proposed DFE formulation, with coupling terms in effect, a second study is carried out with a FGM beam $k=0.3$ composed of aluminum and alumina $\left(\mathrm{Al}_{2} \mathrm{O}_{3}\right)$, as also presented in [67]. The properties of the aluminum are: $E_{b}=70 G P a, \rho_{b}=2700 \mathrm{~kg} / \mathrm{m}^{3}$ and the properties of the alumina are: $E_{t}=380 \mathrm{GPa}, \rho_{t}=3800 \mathrm{~kg} / \mathrm{m}^{3}$ [67]. The reference results by Simsek [67] used a governing equation based on the third-order shear deformation theory, where solutions for Timoshenko and EulerBernoulli beams were presented. The author also included the effects of a moving mass in the formulation, however for the purpose of this paper only the solutions for a non-moving mass were presented. The 
Table 2.2: First 3 natural frequencies of a $\mathrm{Al}$ beam with $L / h=30$ for various boundary conditions.

\begin{tabular}{|c|c|c|c|c|c|c|c|}
\hline \multirow{2}{*}{$\begin{array}{l}\text { Boundary } \\
\text { Condition }\end{array}$} & \multirow{2}{*}{$\begin{array}{l}\text { Frequency } \\
\text { No. i }\end{array}$} & \multicolumn{6}{|c|}{ Non-dimensional fundamental natural frequency $\left(\lambda_{i}\right)$} \\
\hline & & $\begin{array}{l}\text { Classical } \\
\text { Results }\end{array}$ & $\begin{array}{c}\text { DSM } \\
\text { Ref [74]. }\end{array}$ & $\begin{array}{c}\text { DSM } \\
\text { Code }^{b}\end{array}$ & $\begin{array}{c}\text { DFE } \\
(1 \mathrm{ELE})^{a}\end{array}$ & $\begin{array}{c}\text { DFE } \\
(3 \mathrm{ELE})^{a}\end{array}$ & $\begin{array}{c}\text { FEM } \\
(10 \mathrm{ELE})^{a}\end{array}$ \\
\hline \multirow{3}{*}{ S-S } & 1 & 9.8696 & 9.8651 & 9.8651 & 9.8651 & 9.8651 & 9.8652 \\
\hline & 2 & 39.478 & 38.406 & 38.406 & 38.406 & 38.406 & 38.411 \\
\hline & 3 & 88.826 & 85.463 & 85.463 & 85.463 & 85.462 & 85.511 \\
\hline \multirow{3}{*}{$\mathrm{C}-\mathrm{C}$} & 1 & 22.373 & 22.361 & 22.361 & 22.361 & 22.361 & 22.361 \\
\hline & 2 & 61.673 & 60.542 & 60.542 & 60.542 & 60.542 & 60.558 \\
\hline & 3 & 120.90 & 120.35 & 120.35 & 120.35 & 120.35 & 120.47 \\
\hline \multirow{3}{*}{$\mathrm{C}-\mathrm{F}$} & 1 & 3.5160 & 3.5153 & 3.5153 & 3.5153 & 3.5153 & 3.5153 \\
\hline & 2 & 22.035 & 21.002 & 21.002 & 21.001 & 21.001 & 21.002 \\
\hline & 3 & 61.698 & 61.478 & 61.478 & 61.478 & 61.478 & 61.493 \\
\hline \multirow{3}{*}{ C-P } & 1 & 15.418 & 15.410 & 15.410 & 15.410 & 15.410 & 15.410 \\
\hline & 2 & 49.965 & 49.866 & 49.866 & 49.866 & 49.866 & 49.875 \\
\hline & 3 & 104.25 & 103.80 & 103.80 & 103.80 & 103.80 & 103.87 \\
\hline
\end{tabular}

${ }^{a}$ Solution to the classical results can be found in Appendix 4

${ }^{b}$ Results from in-house MATLAB code

frequency results in the article were non-dimensionalized using the following parameter [67]:

$$
\lambda_{i}=\frac{\omega_{i} L^{2}}{h} \sqrt{\frac{I_{0}}{A_{0}}}
$$

with $I_{0}$ and $A_{0}$ defined previously in (5). The natural frequencies, $\omega$, was calculated by manipulating equation (72) and then using equation (71) to convert to a consistent non-dimensional form. The first natural frequency values obtained using DFE, DSM, FEM and reference results for Euler-Bernoulli and Timoshenko beam theories are presented in Table 2.4.

Since in this case the material grading effects are present, a single DFE element does not produce the exact results of the DSM method due to coupling effects. Additional DFE elements are required to converge to the solution. Note that the in-house DSM code and the reference DSM results deviate by about $1.6 \%$. The author was unfortunately unable to resolve the difference between the two results; however there is an excellent agreement between the results of the in-house DSM code and reference [67]. Furthermore, the results of the in-house DSM, DFE and FEM converge to the same solution at higher element numbers. Therefore for validation and comparison purposes, the in-house DSM results were used as the benchmarks. Excellent agreement was found for reference Euler-Bernoulli results and the threeelement DFE solution, deviation was found to be extremely small; i.e., $0.121 \%, 0.160 \%$, and $0.145 \%$ 
Table 2.3: First 3 natural frequencies of a $\mathrm{Al}$ beam with $L / h=100$ for various boundary conditions.

\begin{tabular}{|c|c|c|c|c|c|c|c|}
\hline \multirow{2}{*}{$\begin{array}{l}\text { Boundary } \\
\text { Condition }\end{array}$} & \multirow{2}{*}{$\begin{array}{l}\text { Frequency } \\
\text { No. i }\end{array}$} & \multicolumn{6}{|c|}{ Non-dimensional fundamental natural frequency $\left(\lambda_{i}\right)$} \\
\hline & & $\begin{array}{l}\text { Classical } \\
\text { Results }^{a}\end{array}$ & $\begin{array}{c}\text { DSM } \\
\operatorname{Ref}[74] .\end{array}$ & $\begin{array}{c}\text { DSM } \\
\text { Code }^{b}\end{array}$ & $\begin{array}{c}\text { DFE } \\
\end{array}$ & $\begin{array}{c}\mathrm{DFE} \\
(3 \mathrm{ELF})^{a}\end{array}$ & $\begin{array}{c}\text { FEM } \\
\end{array}$ \\
\hline \multirow{3}{*}{ S-S } & 1 & 9.8696 & 9.8692 & 9.8692 & 9.8692 & 9.8692 & 9.8693 \\
\hline & 2 & 39.478 & 39.472 & 39.472 & 39.472 & 39.472 & 39.476 \\
\hline & 3 & 88.826 & 88.794 & 88.794 & 88.794 & 88.794 & 88.841 \\
\hline \multirow{3}{*}{$\mathrm{C}-\mathrm{C}$} & 1 & 22.373 & 22.372 & 22.372 & 22.373 & 22.372 & 22.373 \\
\hline & 2 & 61.673 & 61.661 & 61.661 & 61.660 & 61.661 & 61.677 \\
\hline & 3 & 120.90 & 120.85 & 120.85 & 120.86 & 120.85 & 120.97 \\
\hline \multirow{3}{*}{$\mathrm{C}-\mathrm{F}$} & 1 & 3.5160 & 3.5160 & 3.5159 & 3.5159 & 3.5159 & 3.5159 \\
\hline & 2 & 22.035 & 21.032 & 21.032 & 21.032 & 21.032 & 21.032 \\
\hline & 3 & 61.698 & 61.677 & 61.677 & 61.677 & 61.677 & 61.693 \\
\hline \multirow{3}{*}{ C-P } & 1 & 15.418 & 15.418 & 15.417 & 15.417 & 15.417 & 15.418 \\
\hline & 2 & 49.965 & 49.956 & 49.956 & 49.956 & 49.956 & 49.965 \\
\hline & 3 & 104.25 & 104.21 & 104.21 & 104.21 & 104.21 & 104.28 \\
\hline
\end{tabular}

${ }^{a}$ Solution to the classical results can be found in Appendix 4

${ }^{b}$ Results from in-house MATLAB code

Table 2.4: First non-dimensional frequency of a FGM beam with $k=0.3$ under S-S boundary condition.

\begin{tabular}{|c|c|c|c|c|c|c|c|}
\hline \multirow{3}{*}{$L / h$} & \multicolumn{6}{|c|}{ Non-dimensional fundamental natural frequency $\left(\lambda_{i}\right)$} \\
\cline { 2 - 8 } & \multicolumn{2}{|c|}{ Ref $[67]}$. & $\begin{array}{c}\text { DSM } \\
\text { Ref }[74] .\end{array}$ & $\begin{array}{c}\text { DSM } \\
\text { Code }^{a}\end{array}$ & $\begin{array}{c}\text { DFE } \\
(1 \text { ELE })^{a}\end{array}$ & $\begin{array}{c}\text { DFE } \\
(3 \text { ELE })^{a}\end{array}$ & $\begin{array}{c}\text { FEM } \\
(3 \text { ELE })^{a}\end{array}$ \\
\cline { 2 - 8 } & EB & TB & 17.328 & 17.378 & 17.350 & 17.365 \\
\hline 10 & 17.329 & 17.138 & 17.614 & 17.328 & 17.447 & 17.420 & 17.433 \\
\hline 30 & 17.392 & 17.373 & 17.676 & 17.395 & 17.47 & 17.430 & 17.441 \\
\hline 100 & 17.405 & 17.398 & 17.684 & 17.402 & 17.455 & 17.45 \\
\hline
\end{tabular}

${ }^{a}$ Results from in-house MATLAB code

for $L / h$ ratios of 10,30 , and 100 , respectively. As expected, DSM results performed better with a difference of $0.004 \%, 0.0164 \%$ and $0.0163 \%$. Deviation between the DFE results and the Timoshenko beam values are $1.24 \%, 0.269 \%$, and $0.181 \%$. Again, DSM outperforms with a difference of $1.107 \%$, $0.126 \%$, and $0.0202 \%$. The FEM showed the greatest discrepancy between results and reference values. When using the same numbers of elements, an error of $0.210 \%, 0.235 \%$ and $0.208 \%$ for Euler-Bernoulli and $1.323 \%, 0.345 \%$, and $0.208 \%$ for Timoshenko was found. Since the formulations in this thesis are based on Euler-Bernoulli assumptions, a greater discrepancy is expected when comparing to reference Timoshenko beam results.

Finally, a third vibration analysis was carried out for a FGM beam composed of steel and alumina with a linear variation in properties $k=1$. The properties of the steel are: $E_{b}=210 G P a, \rho_{b}=7800 \mathrm{~kg} / \mathrm{m}^{3}$ and the properties of the alumina are: $E_{t}=390 \mathrm{GPa}, \rho_{t}=3960 \mathrm{~kg} / \mathrm{m}^{3}$, also reported in Reference [35]. 


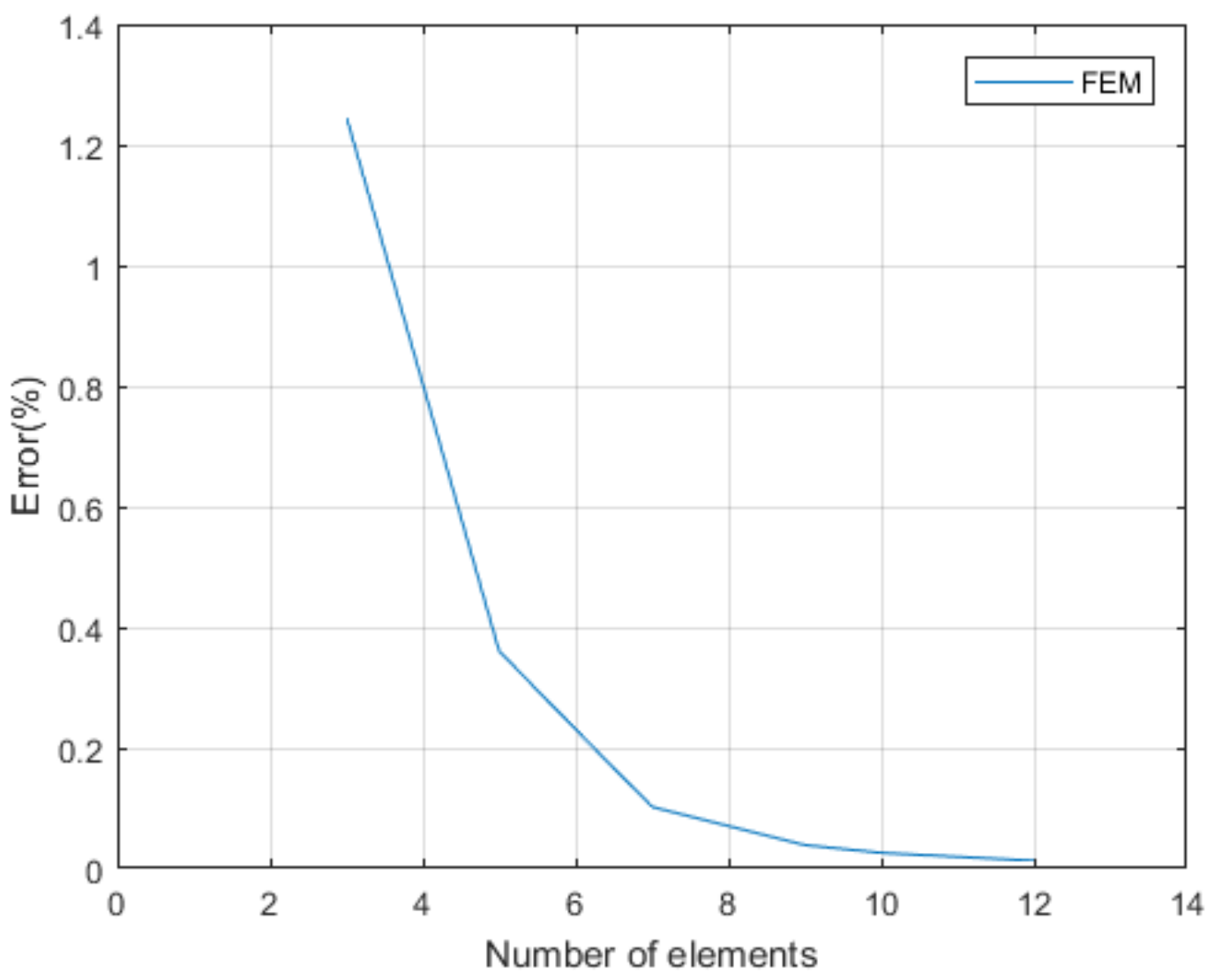

Figure 2.3: Convergence study for the $3^{\text {rd }}$ mode of an aluminum beam with C-F boundary conditions.

The author of the study reported in [35] derived their frequency results using hierarchical beam theories. The first natural frequency using this method is presented in Table 5.2 in Appendix 5. The article used the following non-dimensional parameter [35]:

$$
\lambda_{i}=100 \omega_{i} h \sqrt{\rho_{b} / E_{b}}
$$

The natural frequencies, $\omega$, was calculated by manipulating equation (73) and then using equation (71) to convert to a consistent non-dimensional form. The first natural frequency values for the three aspect ratio of, 5, 10, and 100, obtained using DFE, DSM, and FEM, together with the reference results for Euler-Bernoulli and Timoshenko beam theories are presented in Table 2.5.

The three-element DFE solution error was, $0.233 \%, 0.156 \%$, and $0.131 \%$ for $L / h$ ratios of 5,10 , and 
Table 2.5: First non-dimensional frequency of a FGM beam with $k=1$ under S-S boundary condition.

\begin{tabular}{|c|c|c|c|c|c|c|c|}
\hline \multirow{3}{*}{$L / h$} & \multicolumn{6}{|c|}{ Non-dimensional fundamental natural frequency $\left(\lambda_{i}\right)$} \\
\cline { 2 - 8 } & \multicolumn{2}{|c|}{ Ref [35]. } & $\begin{array}{c}\text { DSM } \\
\text { Ref }[74] .\end{array}$ & $\begin{array}{c}\text { DSM } \\
\text { Code }^{a}\end{array}$ & $\begin{array}{c}\text { DFE } \\
(1 \text { ELE })^{a}\end{array}$ & $\begin{array}{c}\text { DFE } \\
(3 \text { ELE })^{a}\end{array}$ & $\begin{array}{c}\text { FEM } \\
(3 \text { ELE })^{a}\end{array}$ \\
\cline { 2 - 8 } & EB & TB & 13.130 & 13.195 & 13.176 & 13.174 \\
\hline 5 & 13.145 & 12.673 & 13.368 & 13.362 & 13.342 & 13.350 \\
\hline 10 & 13.321 & 13.190 & 13.530 & 13.318 & 13.362 & 13.398 & 13.409 \\
\hline 100 & 13.380 & 13.379 & 13.586 & 13.381 & 13.419 & 13.39 & \\
\hline
\end{tabular}

${ }^{a}$ Results from in-house MATLAB code

100, respectively. DSM results performed better with a difference of $0.117 \%, 0.0240 \%$ and $0.00419 \%$. Deviation between the DFE results and the Timoshenko beam values are 3.97\%, 1.15\%, and $0.142 \%$. Again, DSM outperforms with a difference of $3.61 \%, 0.971 \%$, and $0.0146 \%$. Using three elements FEM had an error of $0.218 \%, 0.216 \%$ and $0.213 \%$ for Euler-Bernoulli and $3.96 \%, 1.21 \%$, and $0.224 \%$ for Timoshenko. At an aspect ratio of $L / h=5$ the frequency obtained from the DFE has a greater error than FEM, although this value is very small, $0.015 \%$ when compared to the reference Euler-Bernoulli value. From Table 2.4 and Table 2.5 it can be seen that there is a higher deviation in results at lower $L / h$ ratios. Note that the present example is the first mode, where quite often the DFE and FEM results are very close. Deviation between DFE and FEM results occur more drastically at higher frequency, which will become apparent in the parametric study.

To further investigate the effect of boundary conditions and material grading, vibrational analysis was performed to find the first four natural frequencies and mode shapes using the FGM beam presented in the third numerical validation study. The beam is composed of steel and alumina, a $L / h$ ratio of 100 is used and the material grading variable $k$ is varied from 0.1 to 5 . The properties of the steel are: $E_{b}=210 \mathrm{GPa}, \rho_{b}=7800 \mathrm{~kg} / \mathrm{m}^{3}$ and the properties of the alumina are: $E_{t}=390 \mathrm{GPa}, \rho_{t}=3960 \mathrm{~kg} / \mathrm{m}^{3}$, as also reported in [35].

The results of Table 2.6 through Table 2.9 show that when using the same number of elements, the DFE model outperforms the FEM. This becomes more apparent at a higher frequency. For example, in the case of $k=1$ and cantilevered boundary conditions, the $4^{t h}$ frequency obtained using the FEM and DFE exhibit an error of $0.274 \%$ and $0.183 \%$, respectively, when compared to the DSM data. Now referring to the first frequency results, the error is found to be $0.00629 \%$ for both FEM and DFE. To model the $4^{\text {th }}$ mode using FEM one would need at least 4 elements just to roughly detect and extract the mode shape. Since DFE uses frequency dependent interpolation functions, a single element can produce 
CHAPTER 2. FUNCTIONALLY GRADED EULER-BERNOULLI BEAM

Table 2.6: First 4 non-dimensional frequency of a C-F FGM beam for various $k$ values.

\begin{tabular}{|c|c|c|c|c|c|c|c|c|c|c|c|c|c|c|c|}
\hline \multirow{3}{*}{$\begin{array}{l}\text { Freq } \\
\text { No. } \\
\text { i }\end{array}$} & \multicolumn{15}{|c|}{ Non-dimensional fundamental natural frequency $\left(\lambda_{i}\right)$} \\
\hline & \multicolumn{3}{|c|}{$k=0.1$} & \multicolumn{3}{|c|}{$k=0.5$} & \multicolumn{3}{|c|}{$k=1$} & \multicolumn{3}{|c|}{$k=2$} & \multicolumn{3}{|c|}{$k=5$} \\
\hline & $\underset{\text { Code }^{a}}{\operatorname{DSM}}$ & $\begin{array}{c}\text { DFE } \\
10 \\
\text { ELE }^{a}\end{array}$ & $\begin{array}{l}\text { FEM } \\
10 \\
\text { ELE }^{a}\end{array}$ & $\underset{\text { Code }^{a}}{\text { DSM }}$ & $\begin{array}{c}\text { DFE } \\
10 \\
\text { ELE }^{a}\end{array}$ & $\begin{array}{l}\text { FEM } \\
10 \\
\text { ELE }^{a}\end{array}$ & $\begin{array}{c}\text { DSM }^{a} \\
\text { Dode }^{a}\end{array}$ & $\begin{array}{c}\text { DFE } \\
10 \\
\text { ELE }^{a}\end{array}$ & $\begin{array}{l}\text { FEM } \\
10 \\
\text { ELE }^{a}\end{array}$ & $\begin{array}{c}\text { DSM } \\
\text { Code }^{a}\end{array}$ & $\begin{array}{c}\mathrm{DFE} \\
10 \\
\mathrm{ELE}^{a}\end{array}$ & $\begin{array}{l}\text { FEM } \\
10 \\
\text { ELE }^{a}\end{array}$ & $\begin{array}{c}\text { DSM } \\
\text { Code }^{a}\end{array}$ & $\begin{array}{l}\mathrm{DFE} \\
10 \\
\mathrm{ELE}^{a}\end{array}$ & $\begin{array}{c}\text { FEM } \\
10 \\
\text { ELE }^{a}\end{array}$ \\
\hline 1 & 6.2673 & 6.2673 & 6.2673 & 5.2779 & 5.2781 & 5.2781 & 4.7669 & 4.7672 & 4.7672 & 4.3766 & 4.3769 & 4.3769 & 4.0493 & 4.0495 & 4.0495 \\
\hline 2 & 39.272 & 39.272 & 39.274 & 33.072 & 33.080 & 33.081 & 29.870 & 29.883 & 29.883 & 27.425 & 27.438 & 27.439 & 25.374 & 25.381 & 25.382 \\
\hline 3 & 109.92 & 109.95 & 109.97 & 92.561 & 92.634 & 92.656 & 83.599 & 83.703 & 83.722 & 76.755 & 76.864 & 76.881 & 71.014 & 71.085 & 71.102 \\
\hline 4 & 215.38 & 215.40 & 215.60 & 181.37 & 181.55 & 181.72 & 163.81 & 164.11 & 164.26 & 150.39 & 150.72 & 150.86 & 139.16 & 139.34 & 139.47 \\
\hline
\end{tabular}

${ }^{a}$ Results from in-house MATLAB code

Table 2.7: First 4 non-dimensional frequency of a S-S FGM beam for various $k$ values.

\begin{tabular}{|c|c|c|c|c|c|c|c|c|c|c|c|c|c|c|c|}
\hline \multirow{3}{*}{$\begin{array}{l}\text { Freq } \\
\text { No. } \\
\text { i }\end{array}$} & \multicolumn{15}{|c|}{ Non-dimensional fundamental natural frequency $\left(\lambda_{i}\right)$} \\
\hline & \multicolumn{3}{|c|}{$k=0.1$} & \multicolumn{3}{|c|}{$k=0.5$} & \multicolumn{3}{|c|}{$k=1$} & \multicolumn{3}{|c|}{$k=2$} & \multicolumn{3}{|c|}{$k=5$} \\
\hline & $\begin{array}{c}\text { DSM } \\
\text { Code }^{a}\end{array}$ & $\begin{array}{c}\text { DFE } \\
10 \\
\text { ELE }^{a}\end{array}$ & $\begin{array}{l}\text { FEM } \\
10 \\
\text { ELE }^{a}\end{array}$ & $\begin{array}{l}\text { DSM } \\
\text { Code }^{a}\end{array}$ & $\begin{array}{c}\text { DFE } \\
10 \\
\text { ELE }^{a}\end{array}$ & $\begin{array}{l}\text { FEM } \\
10 \\
\text { ELE }^{a}\end{array}$ & $\begin{array}{c}\text { DSM } \\
\text { Code }^{a}\end{array}$ & $\begin{array}{l}\text { DFE } \\
10 \\
\text { ELE }^{a}\end{array}$ & $\begin{array}{l}\text { FEM } \\
10 \\
\text { ELE }^{a}\end{array}$ & $\begin{array}{l}\text { DSM } \\
\text { Code }^{a}\end{array}$ & $\begin{array}{c}\text { DFE } \\
10 \\
\mathrm{ELE}^{a}\end{array}$ & $\begin{array}{c}\text { FEM } \\
10 \\
\text { ELE }^{a}\end{array}$ & $\begin{array}{c}\text { DSM } \\
\text { Code }^{a}\end{array}$ & $\begin{array}{c}\text { DFE } \\
10 \\
\operatorname{ELE}^{a}\end{array}$ & $\begin{array}{c}\text { FEM } \\
10 \\
\text { ELE }^{a}\end{array}$ \\
\hline 1 & 17.592 & 17.592 & 17.592 & 14.815 & 14.816 & 14.816 & 13.381 & 13.382 & 13.382 & 12.290 & 12.287 & 12.287 & 11.366 & 11.367 & 11.367 \\
\hline 2 & 70.360 & 70.361 & 70.367 & 59.252 & 59.268 & 59.274 & 53.515 & 53.542 & 53.547 & 49.133 & 49.163 & 49.167 & 45.459 & 45.476 & 45.481 \\
\hline 3 & 158.28 & 158.28 & 158.37 & 133.29 & 133.37 & 133.44 & 120.38 & 120.51 & 120.58 & 110.52 & 110.67 & 110.73 & 102.26 & 102.34 & 102.40 \\
\hline 4 & 281.30 & 281.32 & 281.78 & 236.88 & 237.13 & 237.51 & 213.94 & 214.36 & 214.69 & 196.42 & 196.87 & 197.18 & 181.74 & 182.00 & 182.29 \\
\hline
\end{tabular}

${ }^{a}$ Results from in-house MATLAB code

an infinite number of frequencies. Figure 2.4 shows that even with a single element DFE produces less errors then 5 FEM elements. At higher frequencies fewer DFE elements can be used to develop results that are better or comparable to FEM.

Figure 2.5 through Figure 2.7 show the lateral and axial mode shapes at the first three natural frequency, respectively. These figures show that lateral bending is the dominant mode shape and as a result only the lateral bending mode shapes will be presented moving forward. The bending mode shapes for C-F, S-S, C-C, and C-P boundary conditions for $k=1$ are shown in Figure 2.8 through Figure 2.11, respectively. Figure 2.12 and Figure 2.13 show that C-F mode shape for values of $k=0.1$ and $k=5$, respectively. The mode shape remains unchanged, therefore for the current theory the through thickness variance of material properties does not affect the mode shape. This is expected due the fact that the Euler-Bernoulli theory assumes that the cross section remains plane and deforms only on the neutral axis. 
The effect of $k$ on the natural frequency for various boundary conditions are shown in Figure 2.14 through Figure 2.17. $L / h$ is fixed at 100 and $k$ ranges from 0.1 to 5 , where at 0.1 the beam is made mostly of $\mathrm{Al}_{2} \mathrm{O}_{3}$ and trends towards steel as $k$ increases. As $k$ is increased the natural frequency decreases and at low values of $k$ such as $k<2$ the rate of which the natural frequencies decrease is greater.

Table 2.8: First 4 non-dimensional frequency of a C-C FGM beam for various $k$ values.

\begin{tabular}{|c|c|c|c|c|c|c|c|c|c|c|c|c|c|c|c|}
\hline \multirow{3}{*}{$\begin{array}{l}\text { Freq } \\
\text { No. } \\
\text { i }\end{array}$} & \multicolumn{15}{|c|}{ Non-dimensional fundamental natural frequency $\left(\lambda_{i}\right)$} \\
\hline & \multicolumn{3}{|c|}{$k=0.1$} & \multicolumn{3}{|c|}{$k=0.5$} & \multicolumn{3}{|c|}{$k=1$} & \multicolumn{3}{|c|}{$k=2$} & \multicolumn{3}{|c|}{$k=5$} \\
\hline & $\begin{array}{c}\text { DSM } \\
\text { Code }^{a}\end{array}$ & $\begin{array}{c}\text { DFE } \\
10 \\
\text { ELE }^{a} \\
\end{array}$ & $\begin{array}{c}\text { FEM } \\
10 \\
\text { ELE }^{a}\end{array}$ & $\begin{array}{l}\text { DSM } \\
\text { Code }^{a}\end{array}$ & $\begin{array}{c}\text { DFE } \\
10 \\
\text { ELE }^{a} \\
\end{array}$ & $\begin{array}{c}\text { FEM } \\
10 \\
\text { ELE }^{a} \\
\end{array}$ & 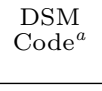 & $\begin{array}{c}\text { DFE } \\
10 \\
\text { ELE }^{a} \\
\end{array}$ & $\begin{array}{c}\text { FEM } \\
10 \\
\text { ELE }^{a} \\
\end{array}$ & $\begin{array}{c}\text { DSM } \\
\text { Code }^{a}\end{array}$ & $\begin{array}{c}\text { DFE } \\
10 \\
\text { ELE }^{a} \\
\end{array}$ & $\begin{array}{c}\text { FEM } \\
10 \\
\text { ELE }^{a} \\
\end{array}$ & $\underset{\text { Code }^{a}}{\text { DSM }}$ & $\begin{array}{c}\text { DFE } \\
10 \\
\text { ELE }^{a} \\
\end{array}$ & $\begin{array}{l}\text { FEM } \\
10 \\
\text { ELE }^{a}\end{array}$ \\
\hline 1 & 39.872 & 39.872 & 39.881 & 33.577 & 33.582 & 33.596 & 30.326 & 30.333 & 30.352 & 27.845 & 27.849 & 27.870 & 25.761 & 25.766 & 25.778 \\
\hline 2 & 109.89 & 109.88 & 109.95 & 92.534 & 92.565 & 92.652 & 83.576 & 83.627 & 83.734 & 76.733 & 76.788 & 76.897 & 70.997 & 71.027 & 71.103 \\
\hline 3 & 215.35 & 215.36 & 215.66 & 181.33 & 181.46 & 181.82 & 163.79 & 164.00 & 164.38 & 150.37 & 150.61 & 150.99 & 139.13 & 139.27 & 139.56 \\
\hline 4 & 355.83 & 355.85 & 356.99 & 299.64 & 299.98 & 301.13 & 270.63 & 270.21 & 272.40 & 248.48 & 249.09 & 250.26 & 229.90 & 230.27 & 231.19 \\
\hline
\end{tabular}

${ }^{a}$ Results from in-house MATLAB code 
Table 2.9: First 4 non-dimensional frequency of a C-P FGM beam for various $k$ values.

\begin{tabular}{|c|c|c|c|c|c|c|c|c|c|c|c|c|c|c|c|}
\hline \multirow{3}{*}{$\begin{array}{c}\text { Freq } \\
\text { No. } \\
\text { i }\end{array}$} & \multicolumn{15}{|c|}{ Non-dimensional fundamental natural frequency $\left(\lambda_{i}\right)$} \\
\hline & \multicolumn{3}{|c|}{$k=0.1$} & \multicolumn{3}{|c|}{$k=0.5$} & \multicolumn{3}{|c|}{$k=1$} & \multicolumn{3}{|c|}{$k=2$} & \multicolumn{3}{|c|}{$k=5$} \\
\hline & $\underset{\text { Code }^{a}}{\mathrm{DSM}}$ & $\begin{array}{c}\mathrm{DFE} \\
10 \\
\mathrm{ELE}^{a}\end{array}$ & $\begin{array}{c}\text { FEM } \\
10 \\
\operatorname{ELE}^{a}\end{array}$ & $\underset{\text { Code }^{a}}{\text { DSM }}$ & $\begin{array}{c}\mathrm{DFE} \\
10 \\
\mathrm{ELE}^{a}\end{array}$ & $\begin{array}{c}\text { FEM } \\
10 \\
\text { ELE }^{a}\end{array}$ & $\underset{\text { Code }^{a}}{\mathrm{DSM}}$ & $\begin{array}{c}\mathrm{DFE} \\
10 \\
\mathrm{ELE}^{a}\end{array}$ & $\begin{array}{c}\text { FEM } \\
10 \\
\operatorname{ELE}^{a}\end{array}$ & $\underset{\text { Code }^{a}}{\text { DSM }}$ & $\begin{array}{c}\mathrm{DFE} \\
10 \\
\mathrm{ELE}^{a}\end{array}$ & $\begin{array}{c}\text { FEM } \\
10 \\
\text { ELE }^{a}\end{array}$ & $\underset{\text { Code }^{a}}{\mathrm{DSM}}$ & $\begin{array}{c}\mathrm{DFE} \\
10 \\
\mathrm{ELE}^{a}\end{array}$ & $\begin{array}{c}\text { FEM } \\
10 \\
\operatorname{ELE}^{a}\end{array}$ \\
\hline 1 & 27.485 & 27.485 & 27.485 & 23.170 & 23.174 & 23.175 & 20.947 & 20.954 & 20.955 & 19.240 & 19.247 & 19.248 & 17.783 & 17.788 & 17.788 \\
\hline 2 & 89.050 & 89.053 & 89.069 & 75.014 & 75.051 & 75.063 & 67.770 & 67.832 & 67.842 & 62.229 & 62.296 & 62.305 & 57.560 & 57.597 & 57.607 \\
\hline 3 & 185.75 & 185.77 & 185.90 & 156.45 & 156.59 & 156.70 & 141.32 & 141.56 & 141.66 & 129.76 & 130.02 & 130.11 & 120.04 & 120.19 & 120.27 \\
\hline 4 & 317.55 & 317.59 & 318.25 & 267.43 & 267.82 & 268.37 & 241.55 & 242.21 & 242.70 & 221.79 & 222.49 & 222.94 & 205.20 & 205.60 & 206.02 \\
\hline
\end{tabular}

${ }^{a}$ Results from in-house MATLAB code

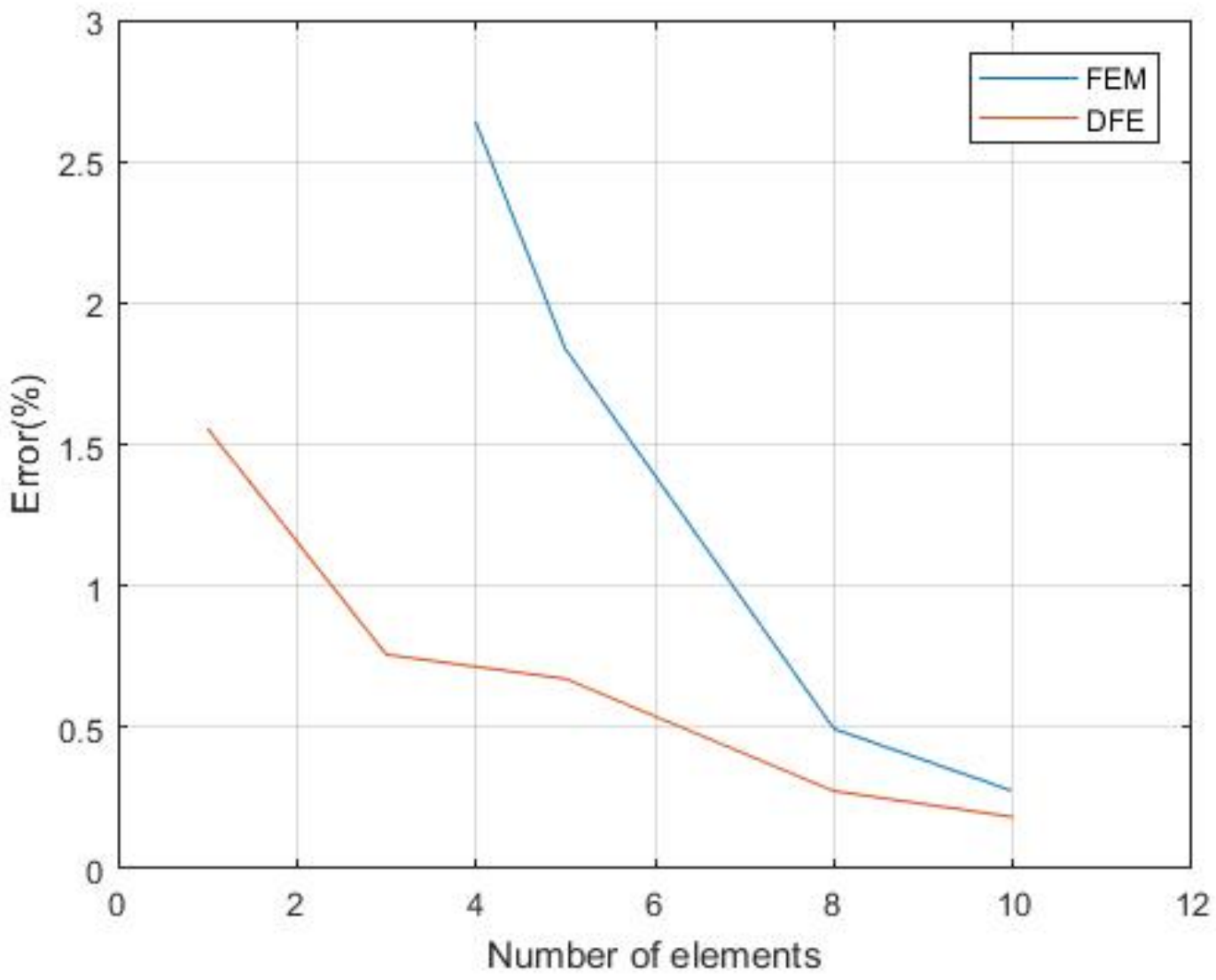

Figure 2.4: Convergence study for the $4^{\text {th }}$ mode of a FGM beam $(k=1)$ with C-F boundary conditions. 


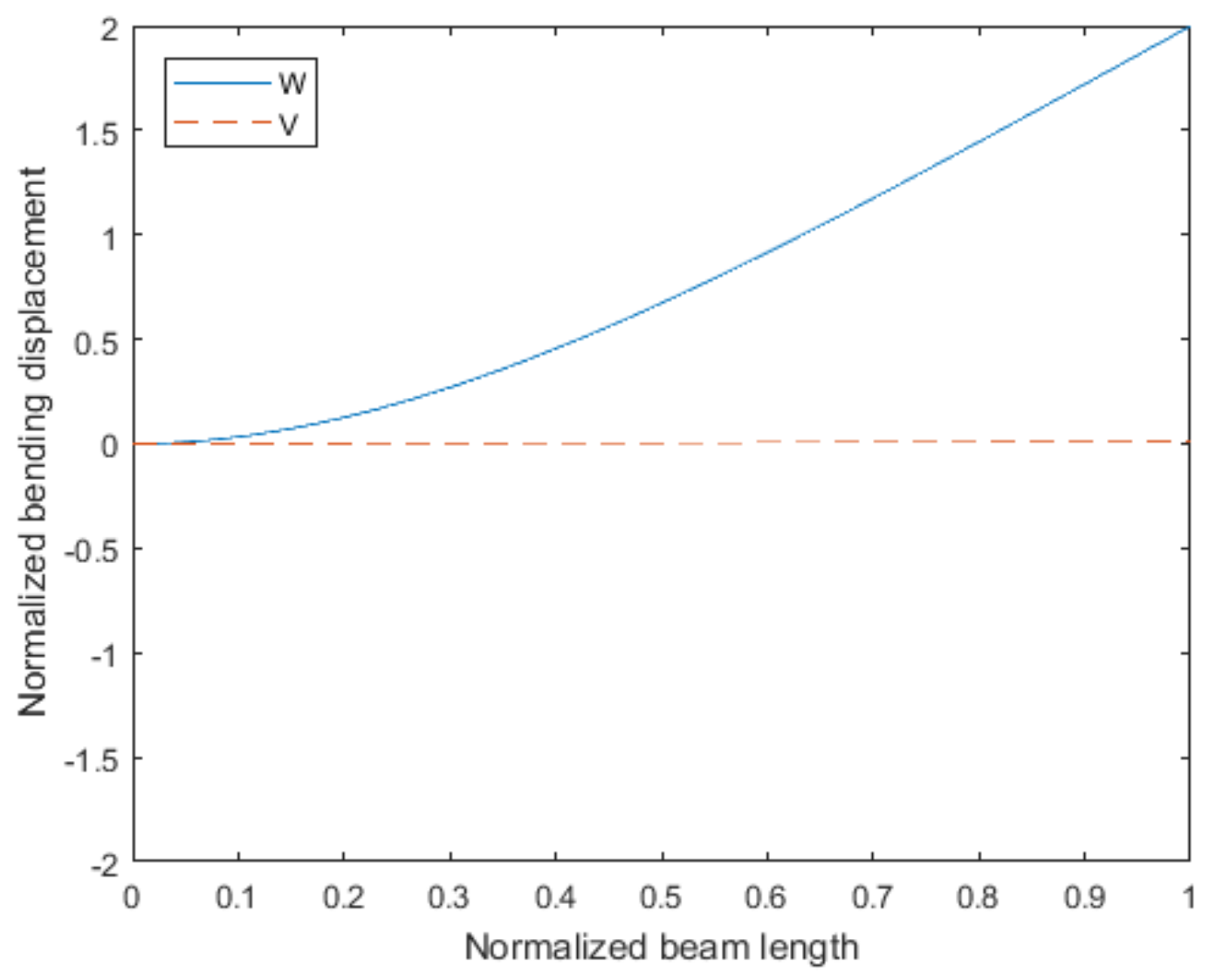

Figure 2.5: First mode shapes for a C-F FGM beam $(k=1)$. 


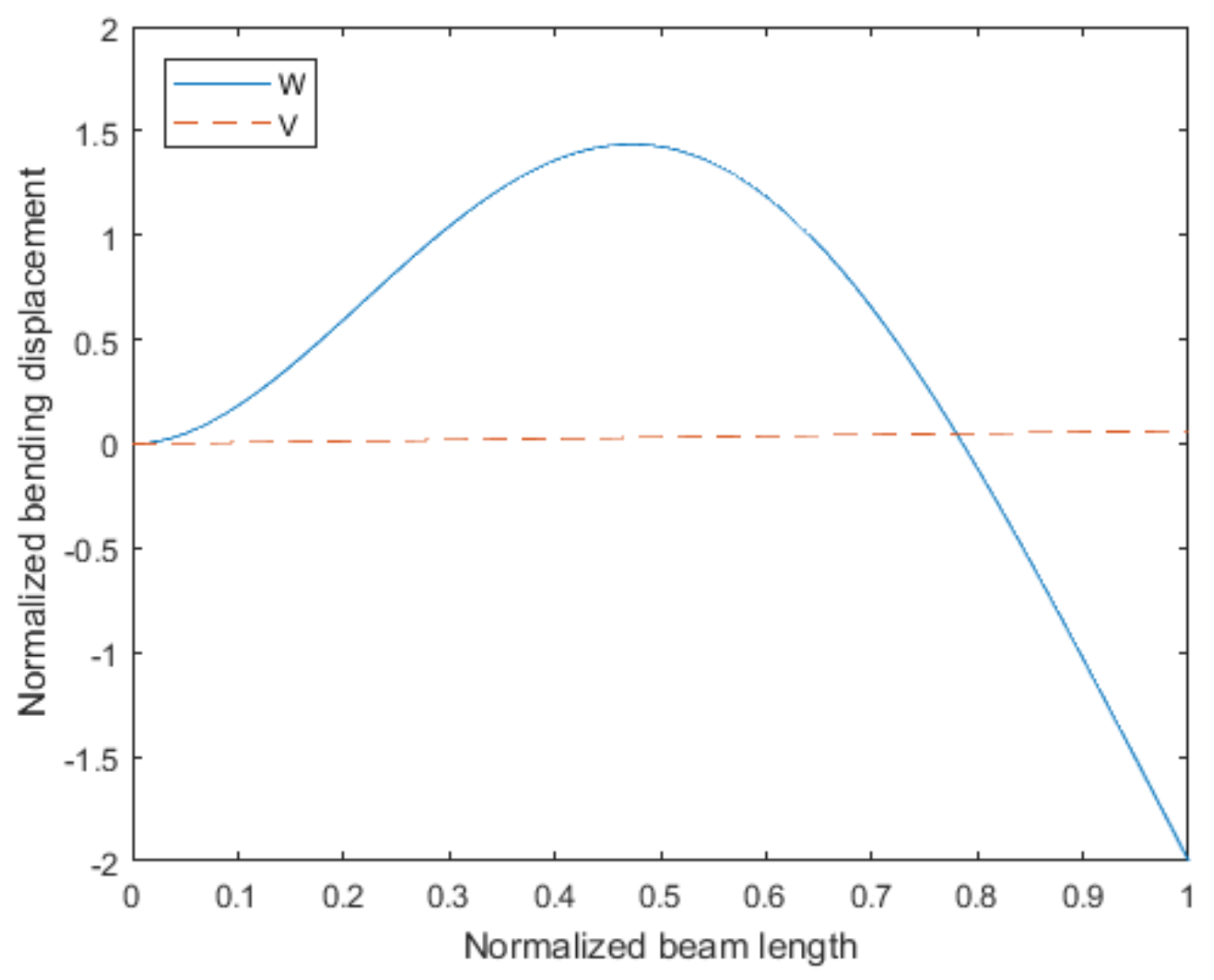

Figure 2.6: Second mode shapes for a C-F FGM beam $(k=1)$. 


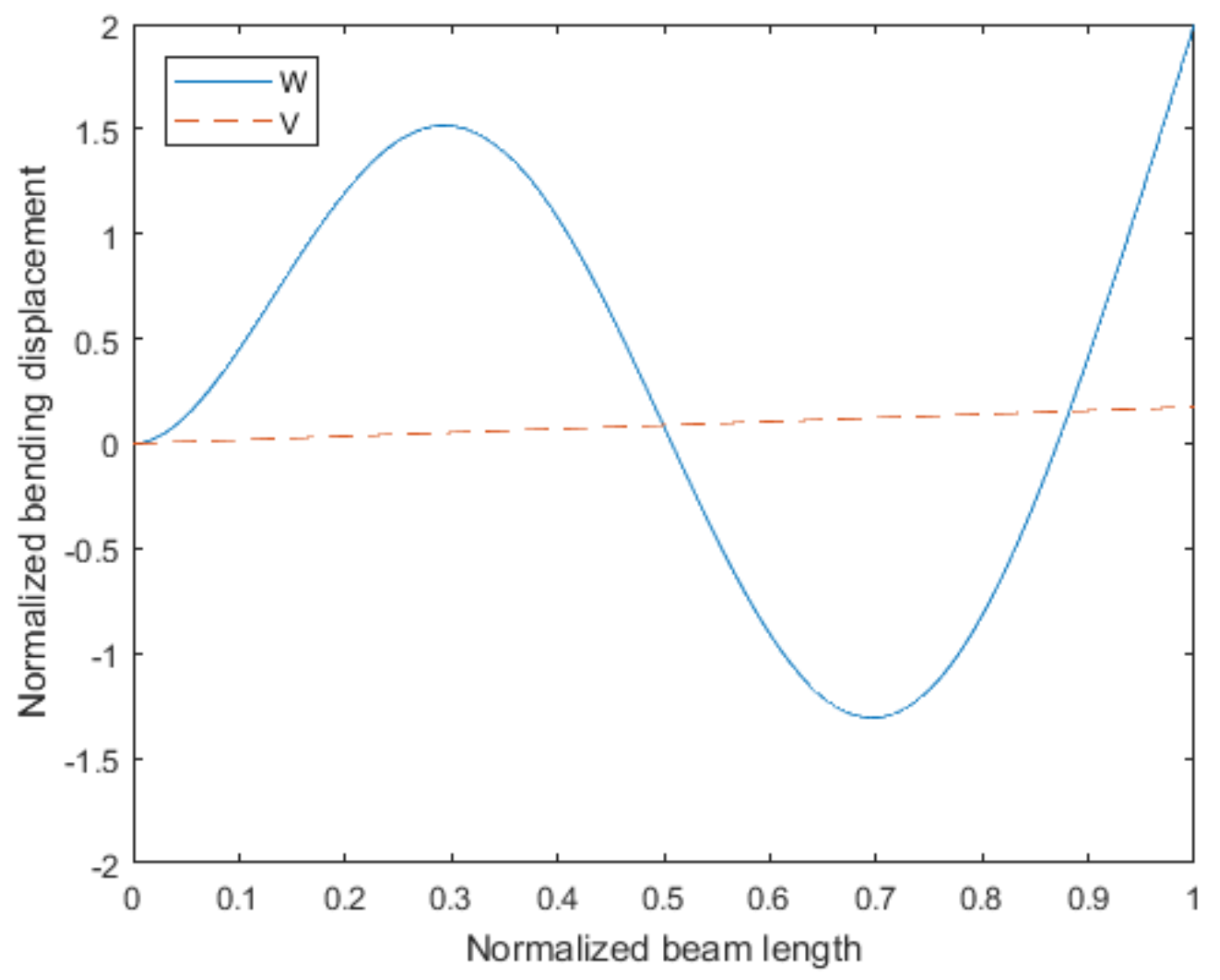

Figure 2.7: Third mode shapes for a C-F FGM beam $(k=1)$. 


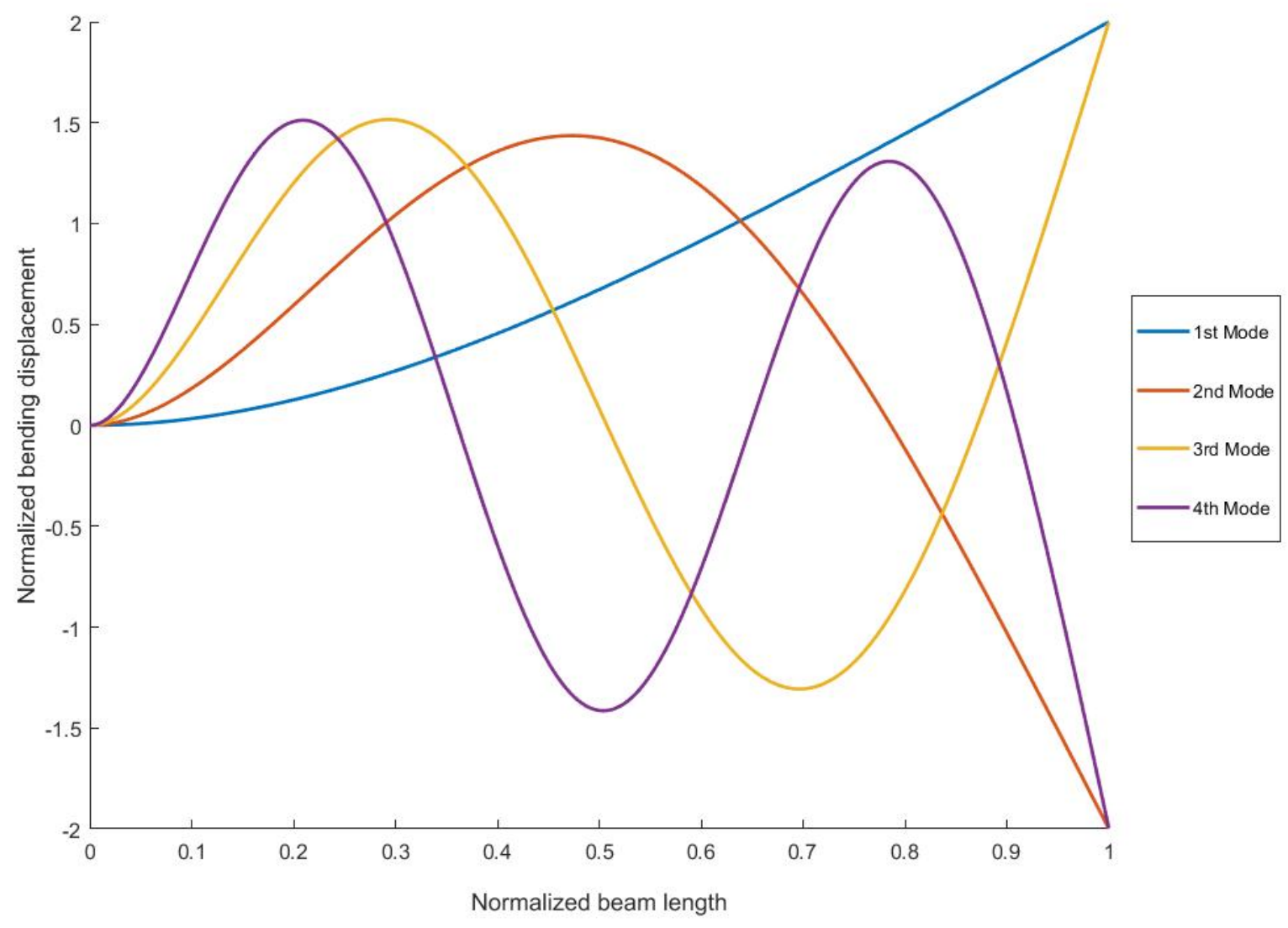

Figure 2.8: First 4 mode shapes for a FGM beam $(k=1)$ with C-F boundary conditions. 


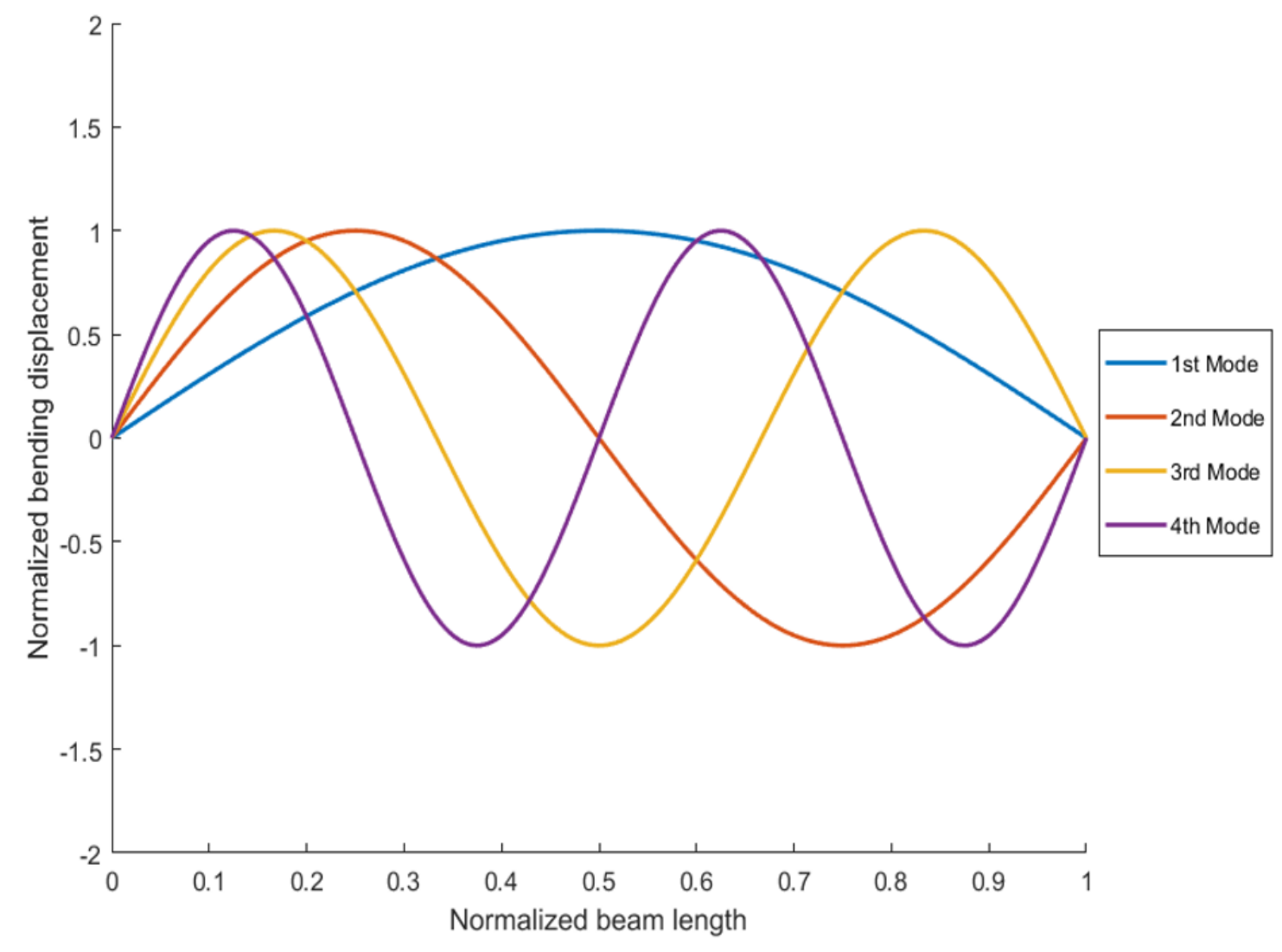

Figure 2.9: First 4 mode shapes for a FGM beam $(k=1)$ with S-S boundary conditions. 


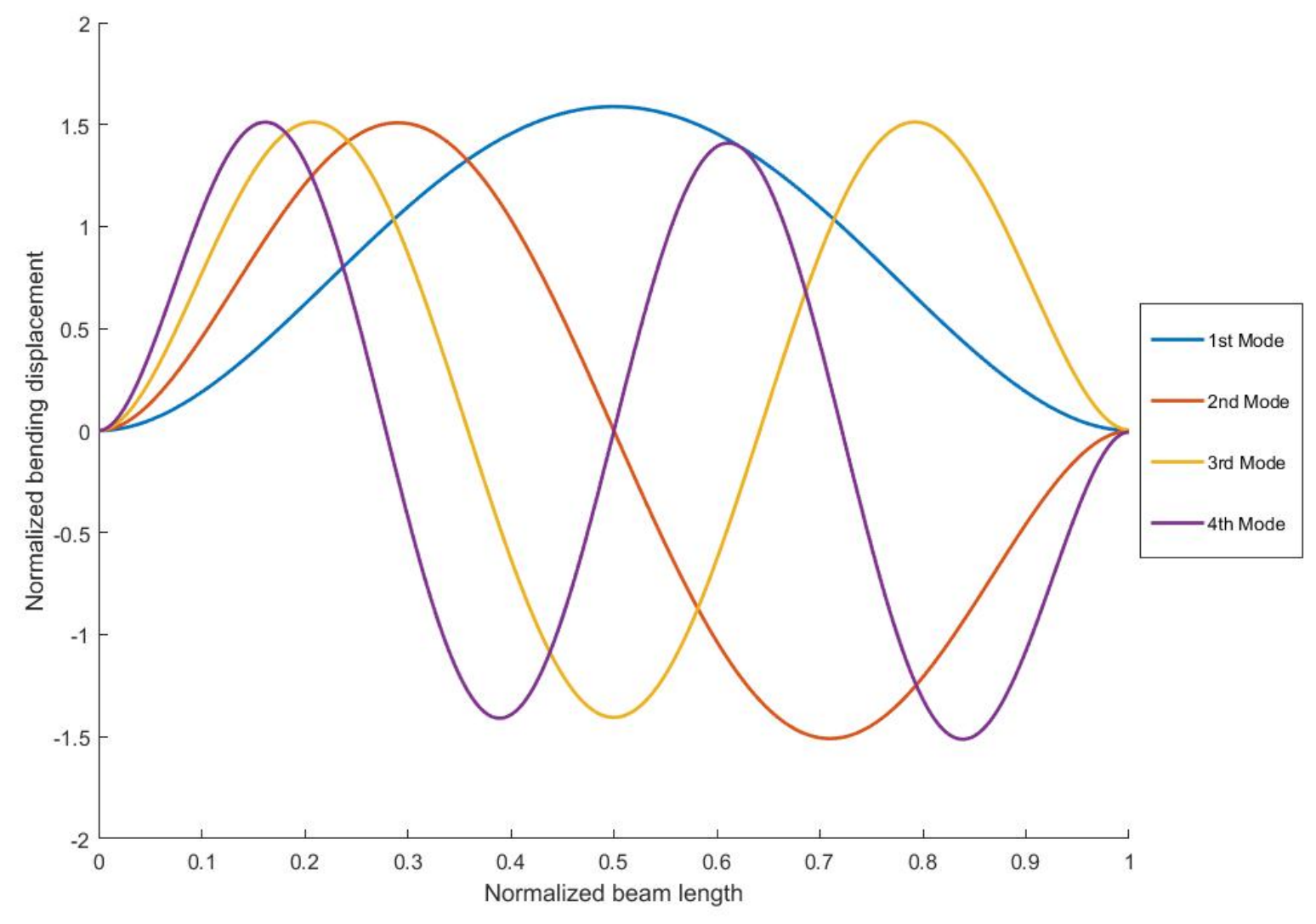

Figure 2.10: First 4 mode shapes for a FGM beam $(k=1)$ with C-C boundary conditions. 


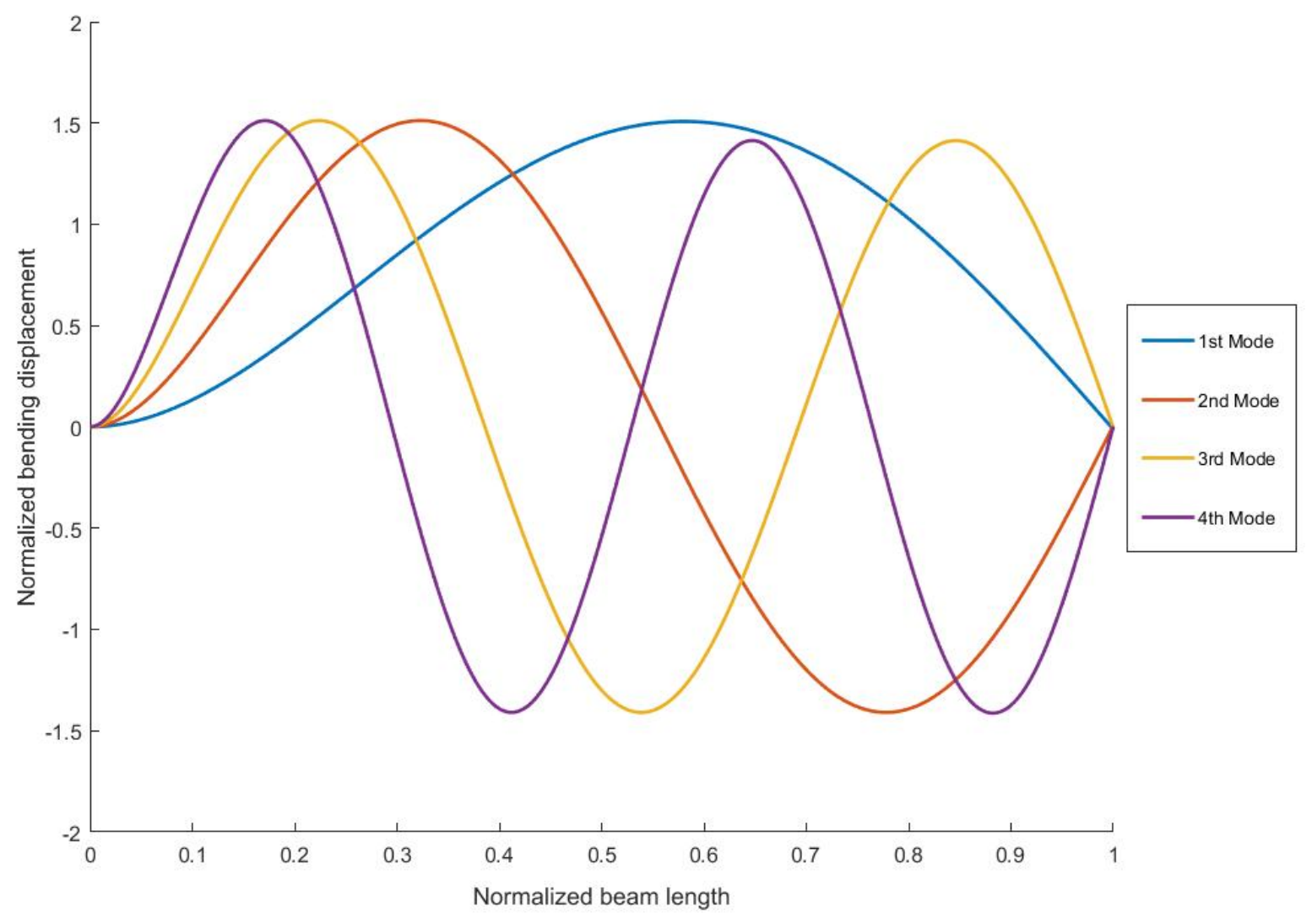

Figure 2.11: First 4 mode shapes for a FGM beam $(k=1)$ with C-P boundary conditions. 


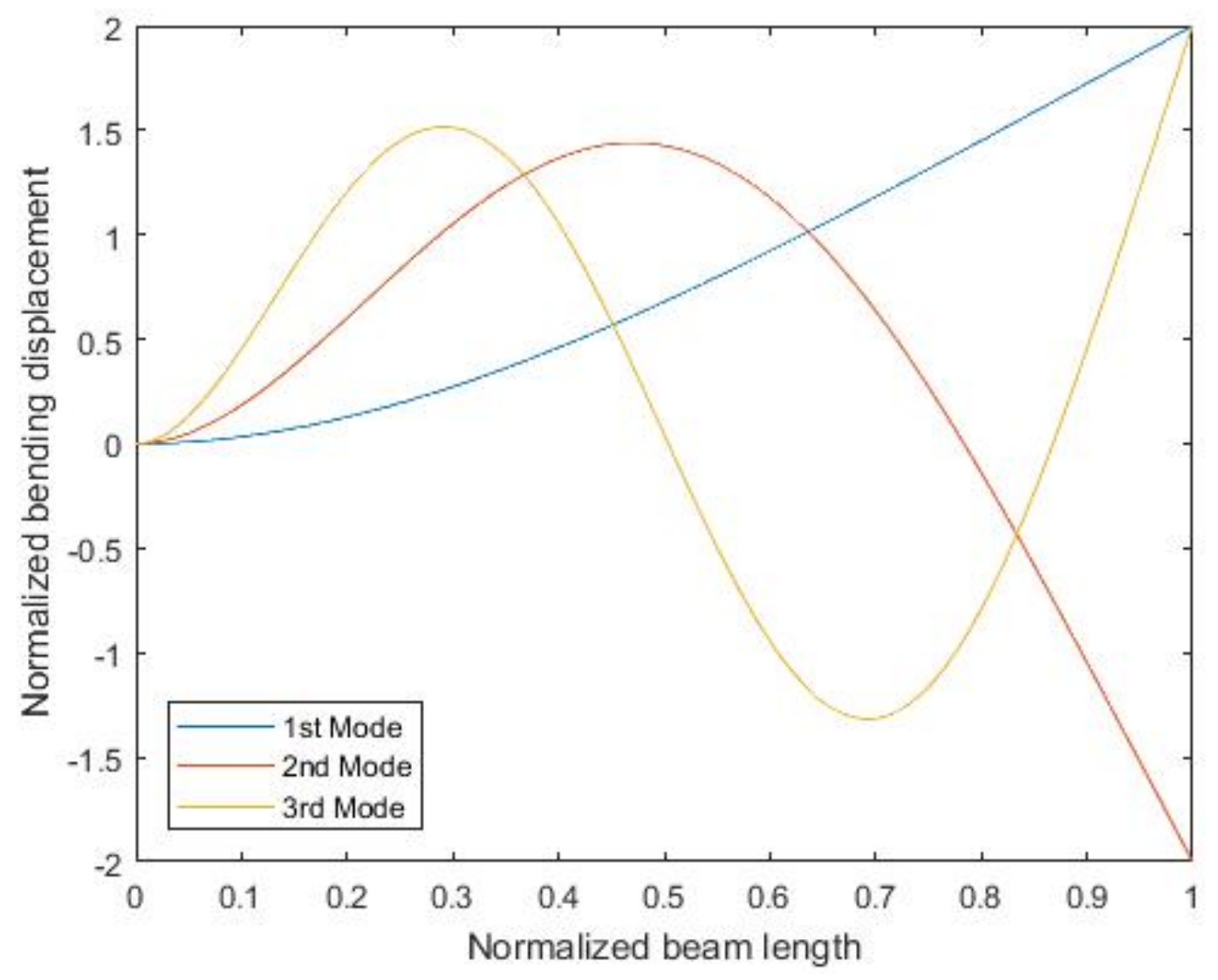

Figure 2.12: First 3 mode shapes for a FGM C-F beam $(k=0.1)$. 


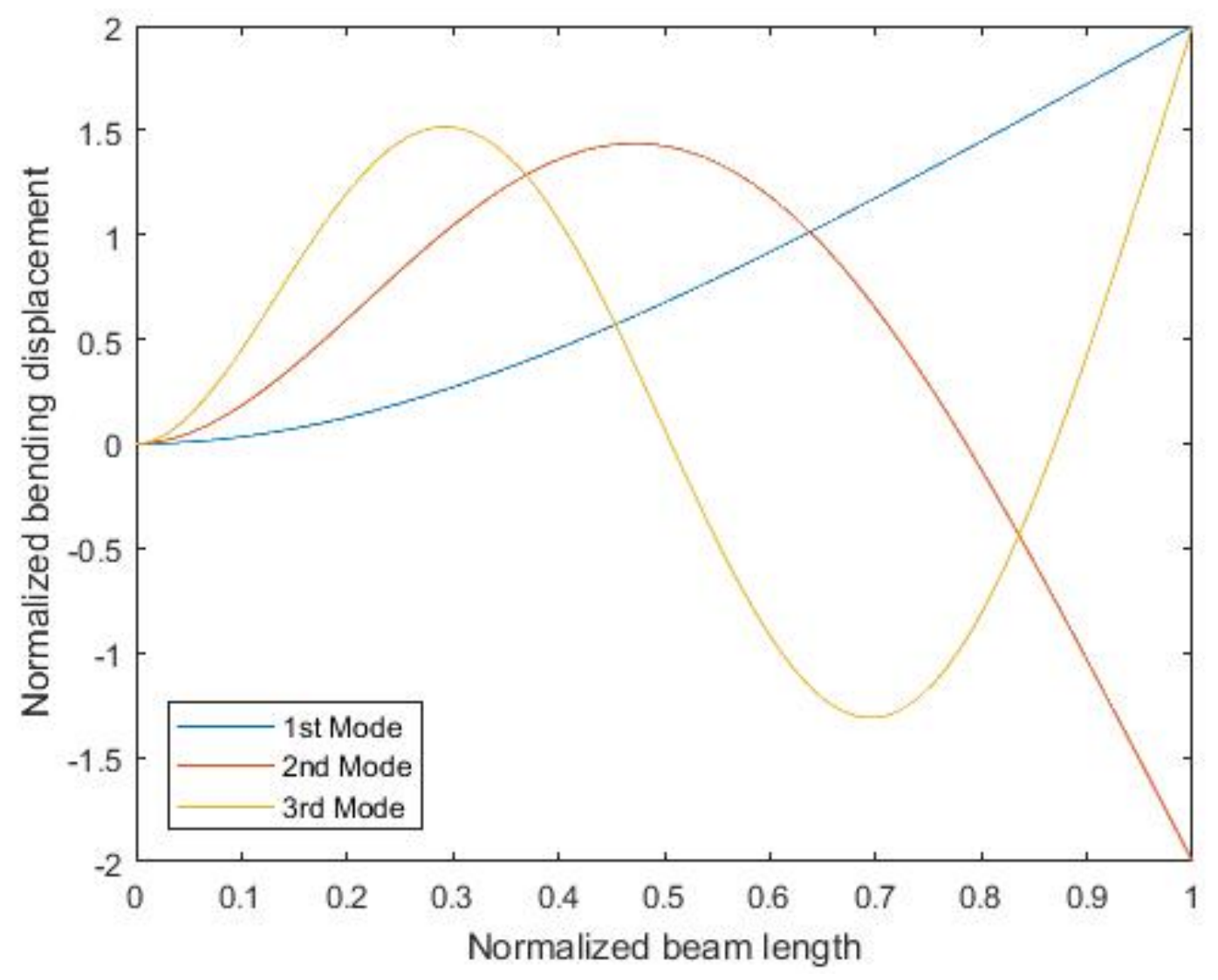

Figure 2.13: First 3 mode shapes for a FGM C-F beam $(k=5)$. 


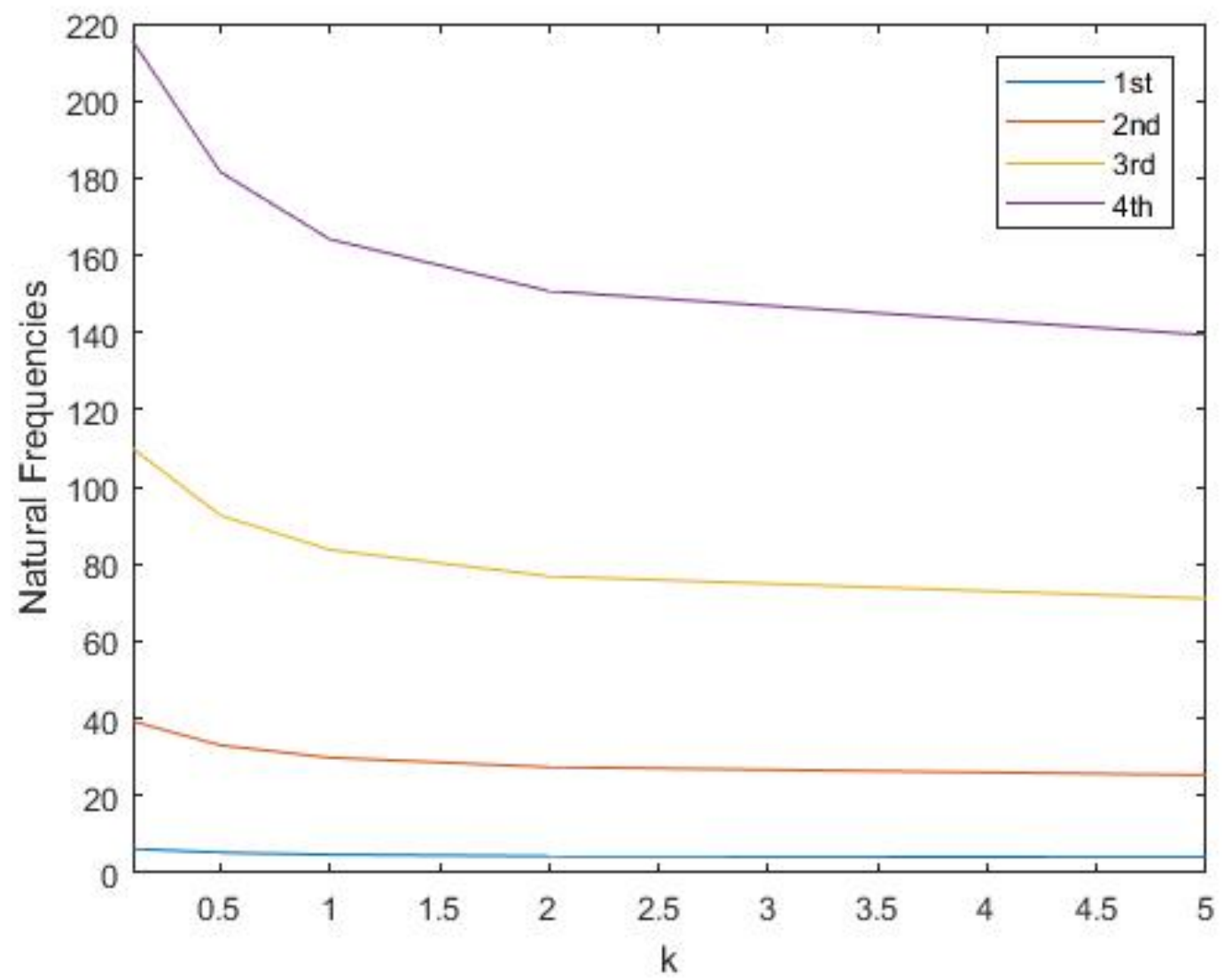

Figure 2.14: The effect of $k$ on the first four natural frequencies for C-F boundary condition. 


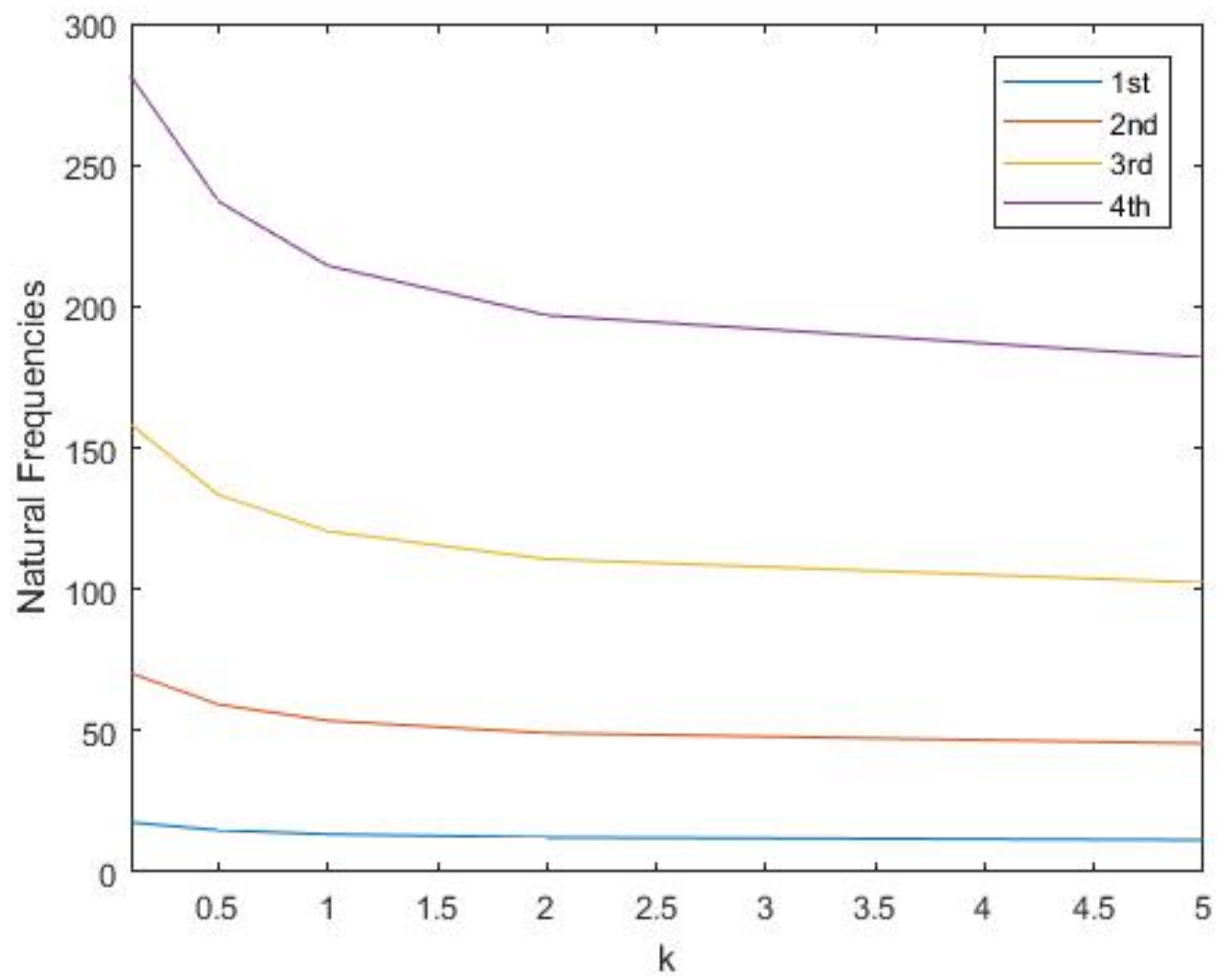

Figure 2.15: The effect of $k$ on the first four natural frequencies for S-S boundary condition. 


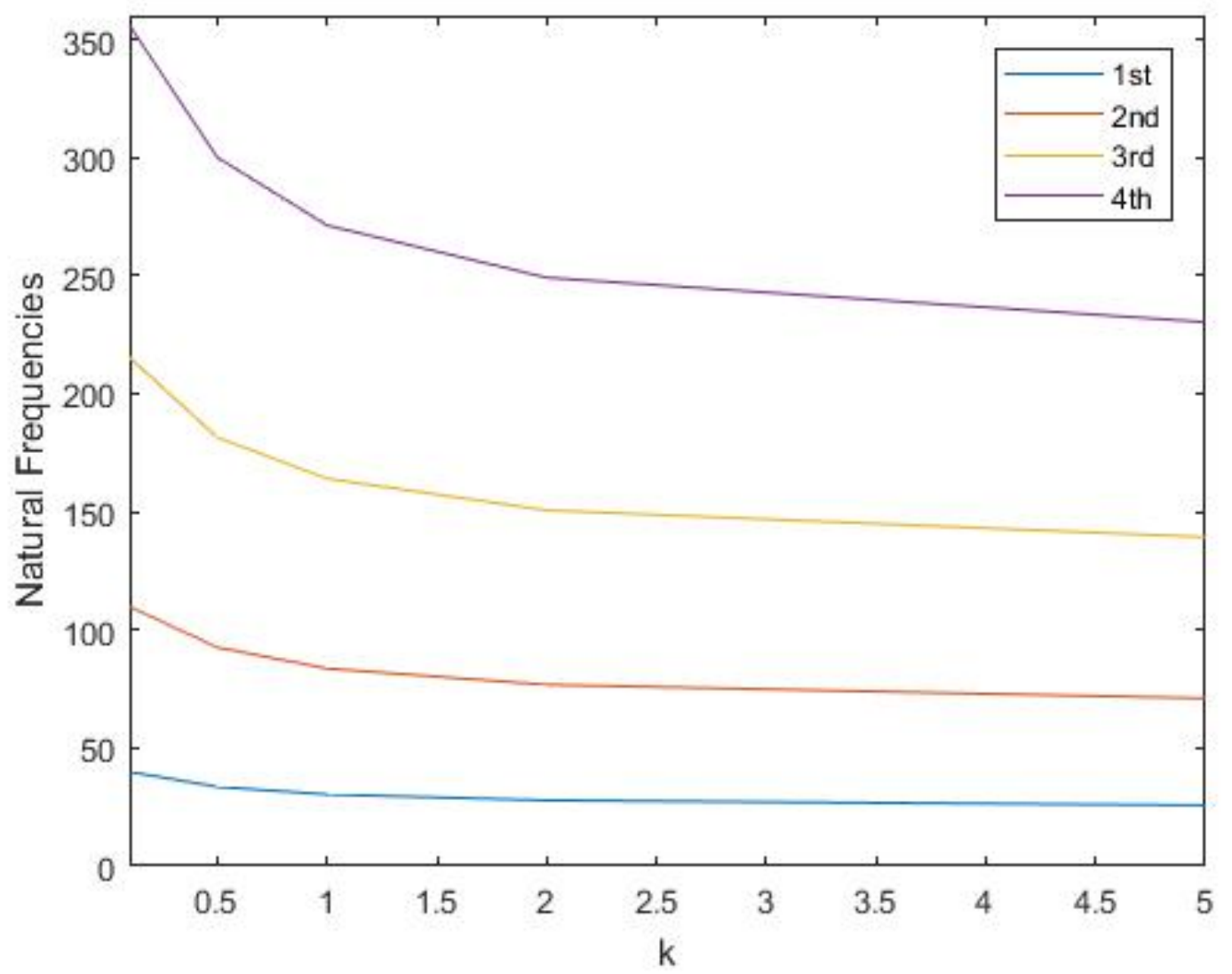

Figure 2.16: The effect of $k$ on the first four natural frequencies for $\mathrm{C}-\mathrm{C}$ boundary condition. 


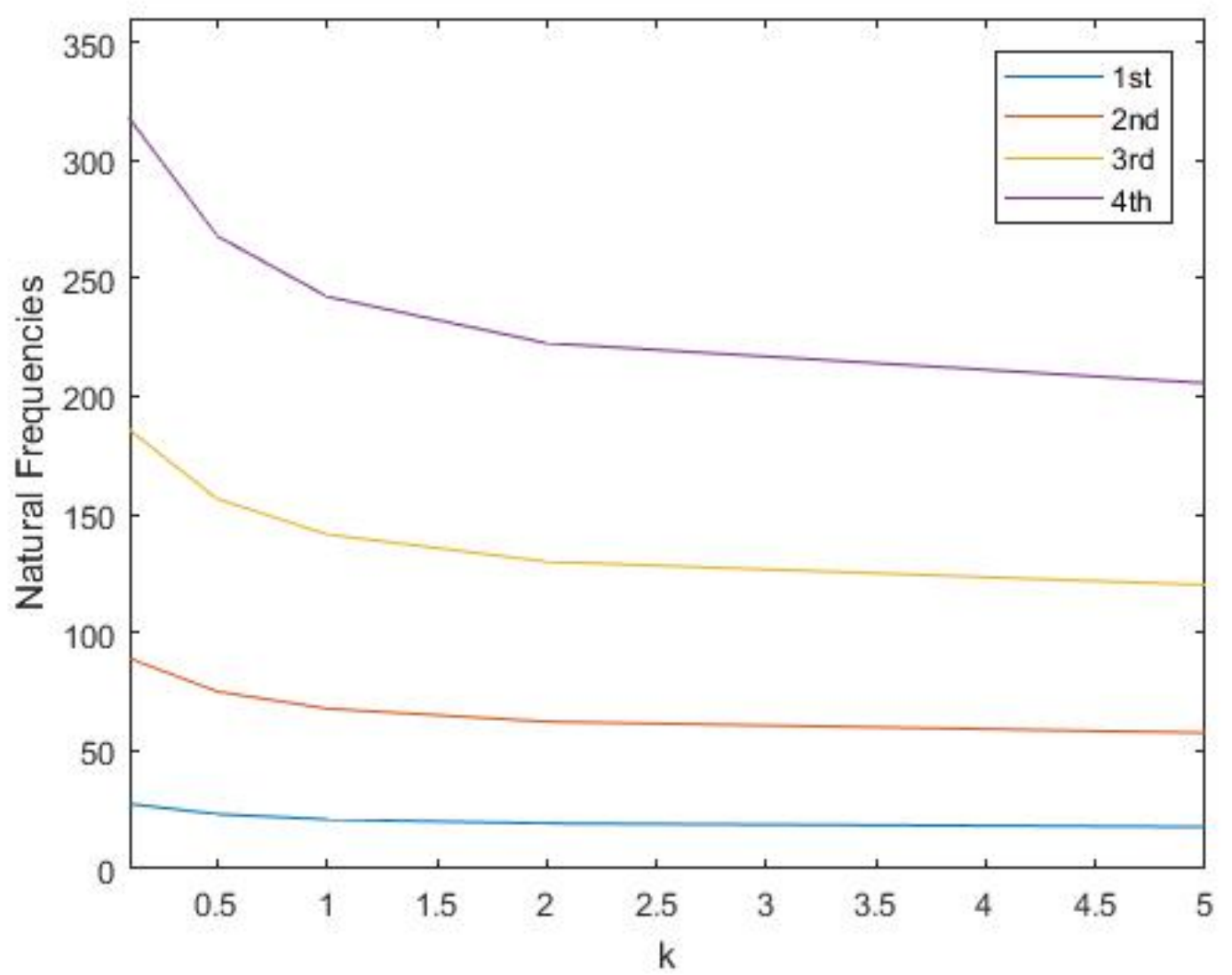

Figure 2.17: The effect of $k$ on the first four natural frequencies for C-P boundary condition. 


\section{Chapter 3}

\section{Verification Using Commercial FEM Software}

\subsection{Introduction}

In the previous chapter the DFE formulation for FGM beams was presented and the vibration characteristics were investigated under various conditions. Results from the DFE were numerically validated against DSM, FEM and other data available in the open literature. However, there was some deviation between DSM results reported in the relevant literature and the results generated using an in-house DSM code. In this chapter, to further validate and build confidence in the results presented, a FGM beam model will be analyzed using the commercial FEM software package, ANSYS ${ }^{\circledR}$.

\subsection{ANSYS ${ }^{\circledR}$ Model}

A 3D model of a FGM beam was created in ANSYS ${ }^{\circledR}$. ANSYS ${ }^{\circledR}$ workbench's 3D modeling tools provide a relatively simple way of introducing a material gradient effect into the model. By creating layers similar to a layered sandwich beam and constraining each layer a simple FGM model can be created. A visual representation of the cross section is shown on the left in Figure 3.1. Material properties are calculated for each element based on its location on the cross section using expressions (1) and (2). Each element 
is homogenous with material properties calculated at the centre point. An adequate number of elements in the cross section is important to capture the material grading effect.

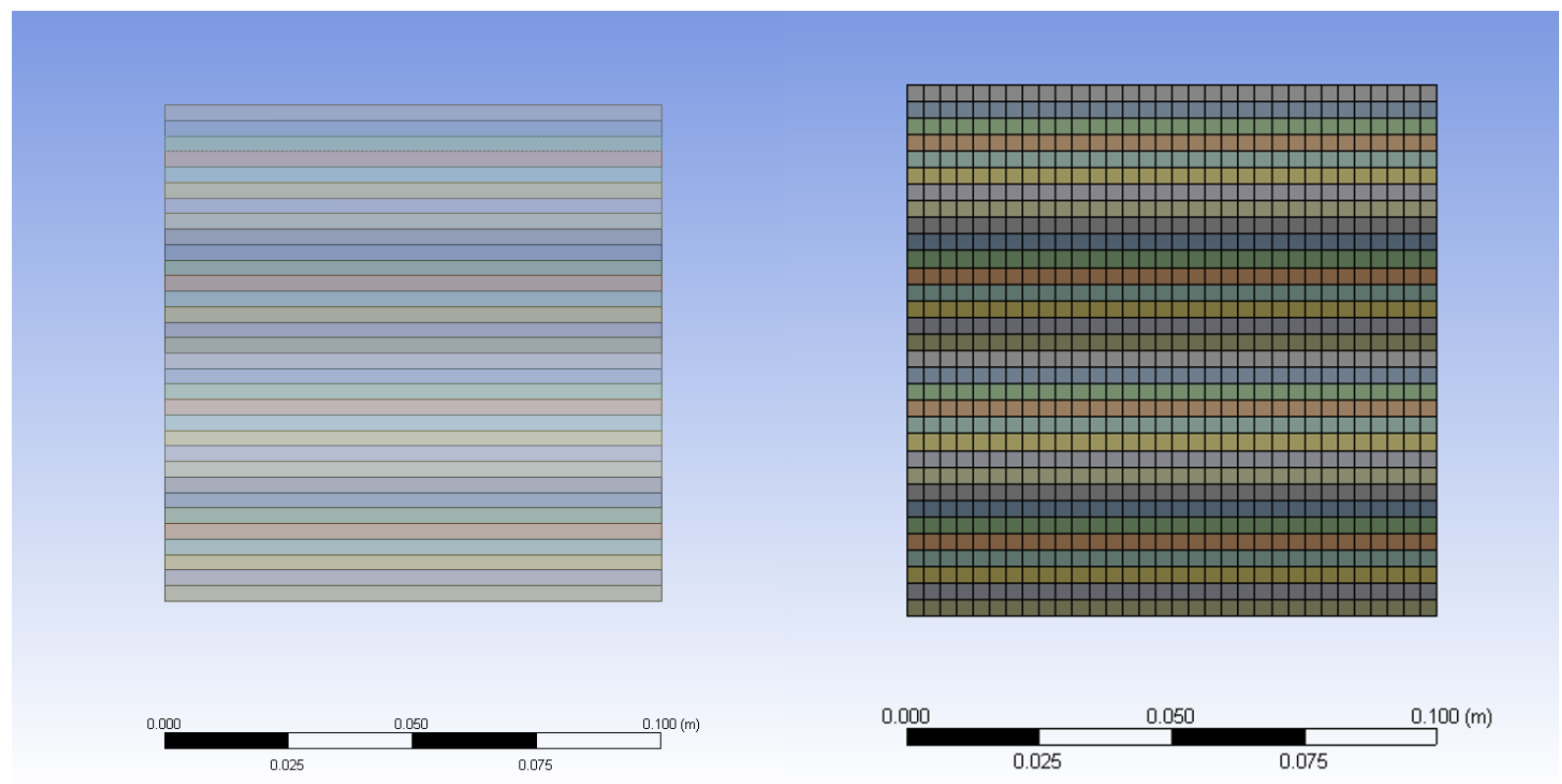

Figure 3.1: Cross section and mesh of ANSYS ${ }^{\circledR}$ FGM model.

Material properties and geometry are the same as the values used for the third verification and parametric study reported earlier in this thesis (see Chapter 2 section 6). Material properties are $E_{b}=210 \mathrm{GPa}, \rho_{b}=7800 \mathrm{~kg} / \mathrm{m}^{3}, E_{t}=390 \mathrm{GPa}, \rho_{t}=3960 \mathrm{~kg} / \mathrm{m}^{3}, \mathrm{k}=1$ and the FGM beam crosssectional geometry is $b=0.1, h=0.1$, and $L / h=100$ [35]. 30 layers were found to be adequate to model material grading and converge to the solution. An additional 2 elements were added to simplify model creation so that each layer thickness could be divided evenly. A visual representation of the cross section mesh is shown on the right in Figure 3.1. Note, that when using too many layers, for example 64, each layer's thickness becomes very small and the model may become unstable. The instability is due to how the elements are constrained, the contact constraint forces two nodes to be coincident. However the element sides can penetrate leading to large errors. This is easily noticed when analyzing the mode shapes with increased scaled deformation.

The length of the elements along the $y$ axis is varied to change the number of elements in the model. Two different size meshes were created, a coarse mesh of 10240 elements (32 x 32 x 10) and a fine mesh of 40960 elements $(32 \times 32 \times 40)$. The three dimensional quadratic SOLID186 element from the ANSYS ${ }^{\circledR}$ 
element library was used to mesh the body. It is a 20 node homogenous element having three degrees of freedom per node (translation in $x, y$, and $z$ ). The standard Block Lanczos solver was used to solve for the natural frequencies and mode shapes.

\subsection{ANSYS ${ }^{\circledR}$ Results}

The first four natural frequencies for C-F, S-S, C-C, and C-P boundary conditions were found using the model generated in ANSYS ${ }^{\circledR}$. For each frequency, the equation (71) is used to calculate the normalized frequency $\lambda$.

Table 3.1: Course and fine mesh ANSYS ${ }^{\circledR}$ results for various boundary conditions.

\begin{tabular}{|c|c|c|c|c|c|c|}
\hline \multicolumn{7}{|c|}{ Non-dimensional fundamental natural frequency $\left(\lambda_{i}\right)$} \\
\hline Boundary Condition & $\begin{array}{c}\text { Frequency } \\
\text { No. } \\
\text { i }\end{array}$ & $\begin{array}{c}\text { ANSYS } \\
32 \times 32 \times 10\end{array}$ & $\begin{array}{c}\text { ANSYS } \\
32 \times 32 \times 40\end{array}$ & $\begin{array}{c}\text { DSM } \\
(1 \mathrm{ELE})^{a}\end{array}$ & $\begin{array}{c}\mathrm{DFE} \\
(10 \mathrm{ELE})^{a}\end{array}$ & $\begin{array}{c}\text { FEM } \\
(10 \mathrm{ELE})^{a}\end{array}$ \\
\hline \multirow{4}{*}{$\mathrm{C}-\mathrm{F}$} & 1 & 4.7682 & 4.7699 & 4.7669 & 4.7672 & 4.7672 \\
\hline & 2 & 29.853 & 29.863 & 29.870 & 29.883 & 29.883 \\
\hline & 3 & 83.522 & 83.522 & 83.599 & 83.703 & 83.722 \\
\hline & 4 & 163.65 & 163.40 & 163.81 & 164.11 & 164.26 \\
\hline \multirow{4}{*}{$\mathrm{S}-\mathrm{S}$} & 1 & 13.327 & 13.376 & 13.381 & 13.382 & 13.382 \\
\hline & 2 & 53.429 & 53.429 & 53.515 & 53.542 & 53.547 \\
\hline & 3 & 115.91 & 119.93 & 120.38 & 120.51 & 120.58 \\
\hline & 4 & 213.21 & 212.48 & 213.94 & 214.36 & 214.69 \\
\hline \multirow{4}{*}{$\mathrm{C}-\mathrm{C}$} & 1 & 30.311 & 30.397 & 30.326 & 30.333 & 30.352 \\
\hline & 2 & 83.539 & 83.677 & 83.576 & 83.627 & 83.734 \\
\hline & 3 & 163.55 & 163.76 & 163.79 & 164.00 & 164.38 \\
\hline & 4 & 271.07 & 270.15 & 270.63 & 271.21 & 272.40 \\
\hline \multirow{4}{*}{$\mathrm{C}-\mathrm{P}$} & 1 & 20.893 & 20.900 & 20.947 & 20.954 & 20.955 \\
\hline & 2 & 67.645 & 67.657 & 67.770 & 67.832 & 67.842 \\
\hline & 3 & 141.06 & 140.94 & 141.32 & 141.56 & 141.66 \\
\hline & 4 & 241.55 & 240.52 & 241.55 & 242.21 & 242.70 \\
\hline
\end{tabular}

${ }^{a}$ Results from in-house MATLAB code

The coarse ANSYS ${ }^{\circledR}$ model results, shown in Table 3.1, show very good agreement with those obtained from the DFE, DSM and FEM formulations derived in this research. The element formulations in Chapter 2 also used 10 axial elements, but a single element was used for the cross-section in contrast to the 32 x 32 layers used in the ANSYS ${ }^{\circledR}$ model. Using a FGM element eases the modeling, as the material 
variation is built into the formulation. Slight deviations can be seen, which can be most likely attributed to the differences between the ANSYS ${ }^{\circledR}$ elements and the derived formulations. The SOLID186 element is derived using higher-order equations and includes 3D effects. Nonetheless the deviations are very small $(<0.4 \%)$ for most frequencies. An anomaly in the results was found for the third frequency for the simply supported boundary condition. However, by adding more axial elements the issue is resolved, as seen in the fine mesh model. The fine mesh model generally showed less deviation in higher mode results. Again, some deviation can be found. As mentioned earlier this was attributed to the difference in the elements' formulation. 


\section{Chapter 4}

\section{Conclusion}

\subsection{Concluding Remarks}

Based on the Dynamic Finite Element (DFE) formulation, a new element was developed to conduct vibrational analysis of Euler-Bernoulli functionally graded beams. The DFE results were compared with 'exact' results from DSM and those obtained from FEM and sources from literature. Comparisons were made between DFE, FEM, and DSM results for various $L / h$ ratios, $k$ values and material properties. The results were further validated using the commercial FEM software package ANSYS ${ }^{\circledR}$. DFE exhibited higher convergence rates compared to FEM, particularly at higher frequencies. In the absence of material grading, the results obtained from a one-element DFE model are 'exact' within the limits of the theory.

\subsection{Future Work}

From the successful implementation of DFE for Euler-Bernoulli FGM beam, the next step would be to extend the element formulation to more complex FGM beam theories. The first-order shear deformation theory, or the Timoshenko beam theory, would be the next logical beam theory to apply the DFE formulation. By using the Timoshenko theory, shear deformation and rotary inertia effects would be accounted for. Su and Banerjee [75] have successfully extended the DSM method to FGM Timoshenko beams and could be used as a reference for comparison and validation purposes.

The majority of research on FGM has dealt with the through thickness grading of material prop- 
erties. To enable more design choices axial grading can be considered as well. Therefore, analytical and numerical methods for axial graded beams are required. Elishakoff et al. [21-23] have developed analytical and numerical solutions to axial graded beams. The method used to solve for the axial graded beams seemed to only satisfy the simply supported boundary conditions. Further investigation would be required to understand if the DFE method would be able to model axially graded beams with various boundary conditions. 


\section{Appendix 1}

\section{Hermite based Shape Functions}

The following shape functions approximate the axial displacement along the domain:

$$
\begin{gathered}
N_{v 1}=1-\frac{y}{L} \\
N_{v 2}=\frac{y}{L}
\end{gathered}
$$

The following shape functions approximate the bending displacement along the domain:

$$
\begin{gathered}
N_{w 1}=\frac{1}{L^{3}}\left(2 y^{3}-3 y^{2} L+L^{3}\right) \\
N_{w 2}=\frac{1}{L^{3}}\left(y^{3} L-2 y^{2} L^{2}+y L^{3}\right) \\
N_{w 3}=\frac{1}{L^{3}}\left(-2 y^{3}+3 y^{2} L\right) \\
N_{w 4} \frac{1}{L^{3}}\left(y^{3} L-y^{2} L^{2}\right)
\end{gathered}
$$




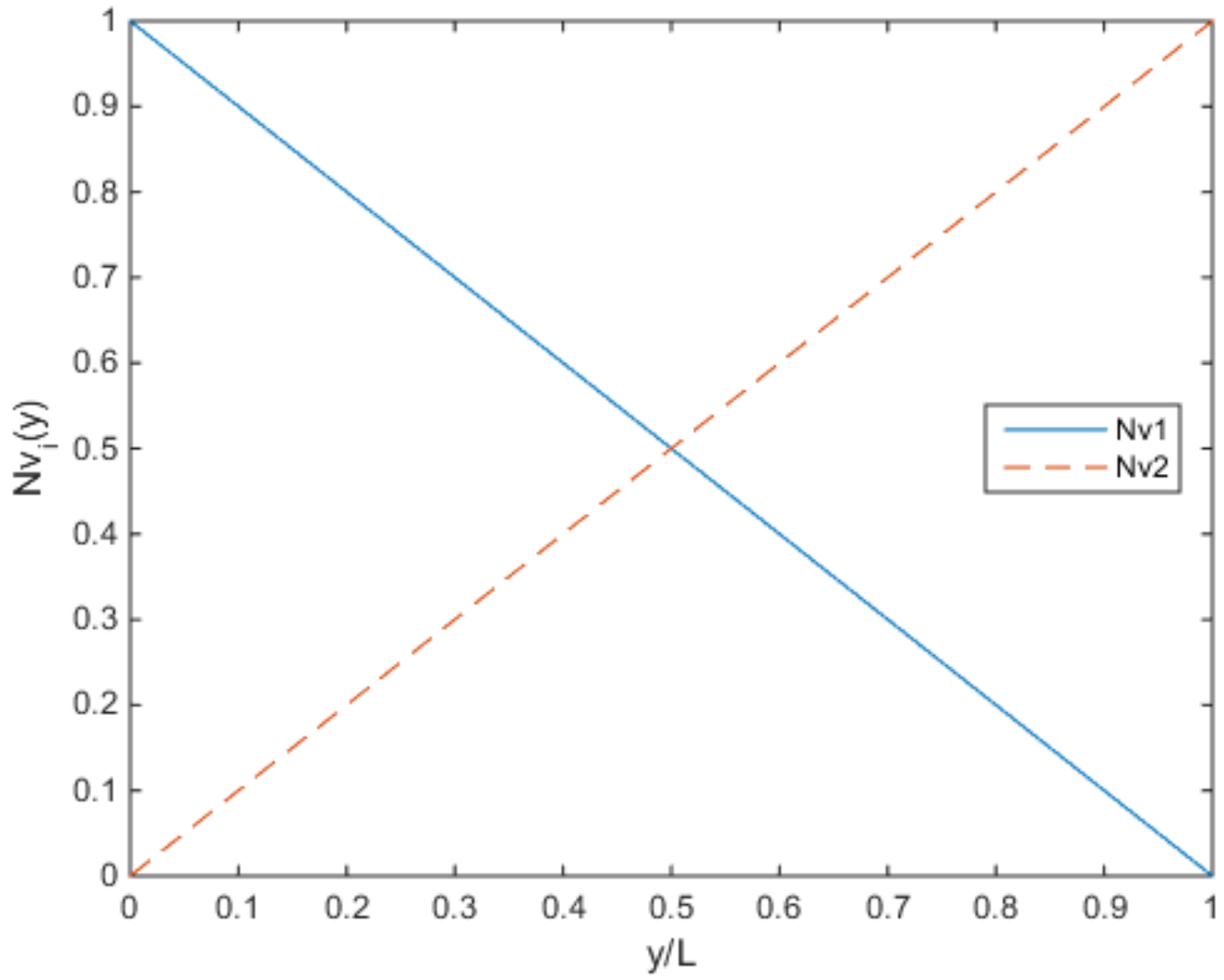

Figure 1.1: Hermite shape function for axial displacement. 


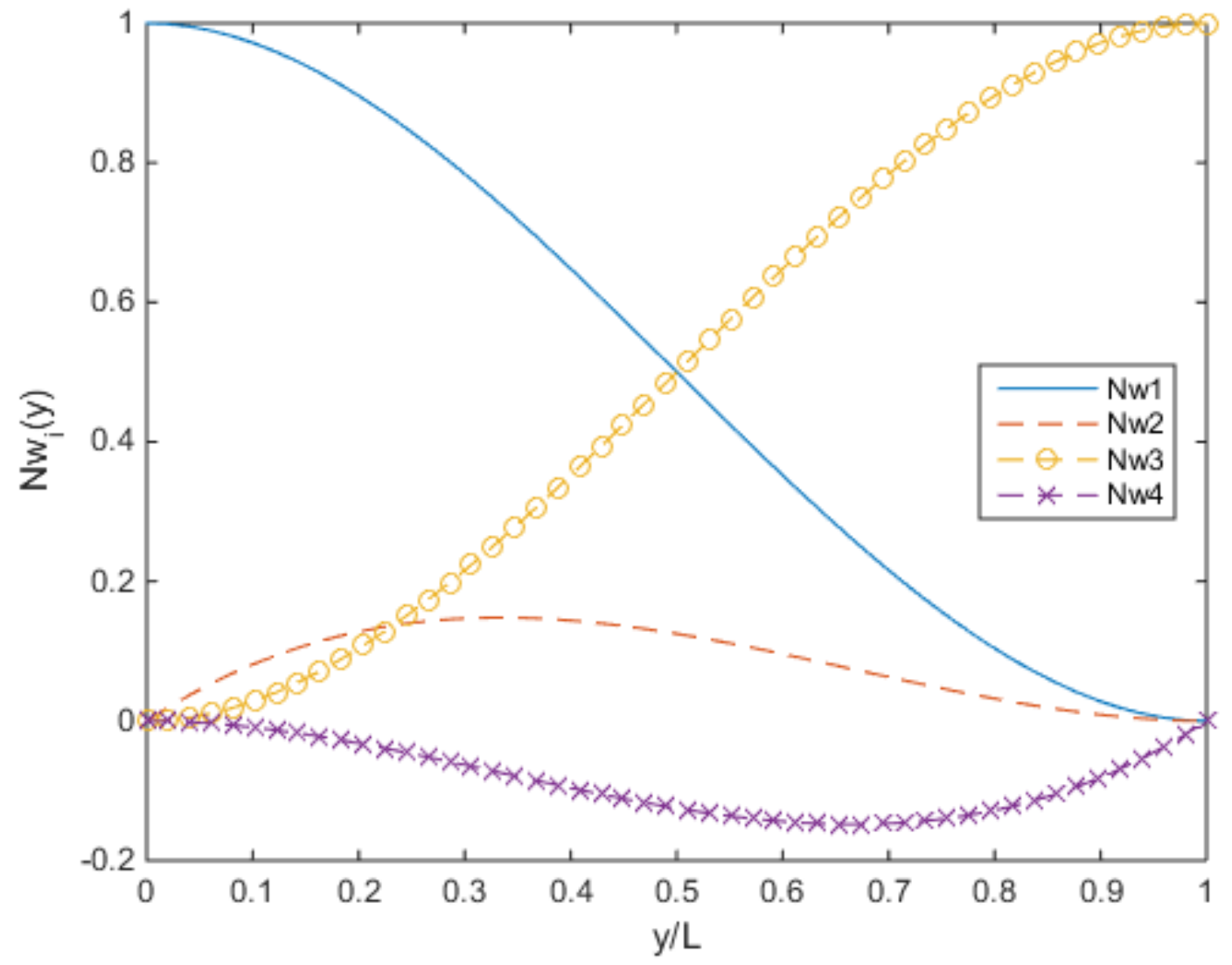

Figure 1.2: Hermite shape function for bending displacement. 


\section{Appendix 2}

\section{Dynamic Trigonometric Shape}

\section{Functions}

The following shape functions, also presented in an earlier work by author [81], approximate the axial displacement along the domain $[10,80]$ :

$$
\begin{gathered}
N_{v 1}=\cos (\gamma \xi)-\frac{\cos (\gamma) \sin (\gamma \xi)}{D_{t}} \\
N_{v 2}=\frac{\sin (\gamma \xi)}{D_{t}}
\end{gathered}
$$

where,

$$
D_{t}=\sin (\gamma)
$$

The following shape functions approximate the bending displacement along the domain $[10,80]$ :

$$
\begin{gathered}
N_{w 1}=\frac{\alpha \beta}{D_{f}}\{-\cos (\alpha \xi)+\cos (\alpha(1-\xi)) \cosh (\beta)+\cos (\alpha) \cosh (\beta(1-\xi)) \\
\left.-\cosh (\beta \xi)-\frac{\beta}{\alpha} \sin (\alpha(1-\xi)) \sinh (\beta)+\frac{\alpha}{\beta} \sin (\alpha) \sinh (\beta(1-\xi))\right\}
\end{gathered}
$$




$$
\begin{gathered}
N_{w 2}=\frac{1}{D_{f}}\{\beta[\cosh (\beta(1-\xi) \sin (\alpha))-\cosh (\beta) \sin (\alpha(1-\xi))-\sin (\alpha \xi)] \\
+\alpha[\cos (\alpha(1-\xi)) \sinh (\beta)-\cos (\alpha) \sinh (\beta(1-\xi))-\sinh (\beta \xi)]\} \\
N_{w 3}=\frac{\alpha \beta}{D_{f}}\{-\cos (\alpha(\xi-l))+\cos (\alpha \xi) \cosh (\beta)-\cosh (\beta(1-\xi)) \\
\left.+\cos (\alpha) \cosh (\beta \xi)-\frac{\beta}{\alpha} \sin (\alpha \xi) \sinh (\beta)+\frac{\alpha}{\beta} \sin (\alpha) \sinh (\beta \xi)\right\} \\
N_{w 4}=\frac{1}{D_{f}}\{\beta[-\cosh (\beta \xi) \sin (\alpha)+\sin (\alpha(1-\xi))+\cosh (\beta) \sin (\alpha \xi)] \\
+\alpha[-\cos (\alpha \xi) \sinh (\beta)+\sinh (\beta(1-\xi))+\cos (\alpha) \sinh (\beta \xi)]\}
\end{gathered}
$$

where,

$$
D_{f}=\alpha \beta\left\{-2(1-\cos (\alpha) \cosh (\beta))+\left(\frac{\alpha^{2}-\beta^{2}}{\alpha \beta}\right) \sin (\alpha) \sinh (\beta)\right\}
$$




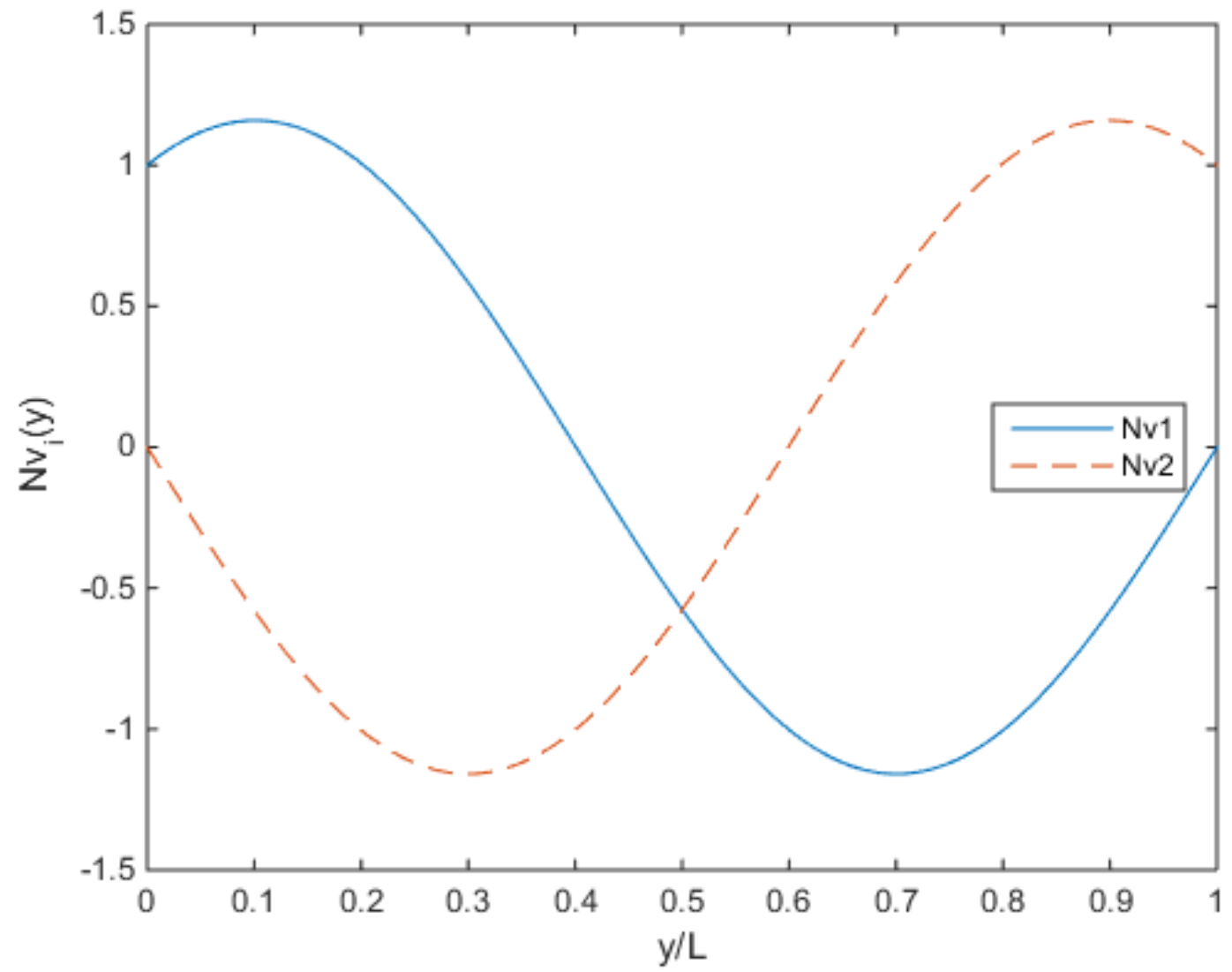

Figure 2.1: Axial dynamic trigonometric shape function $\lambda=2500$. 


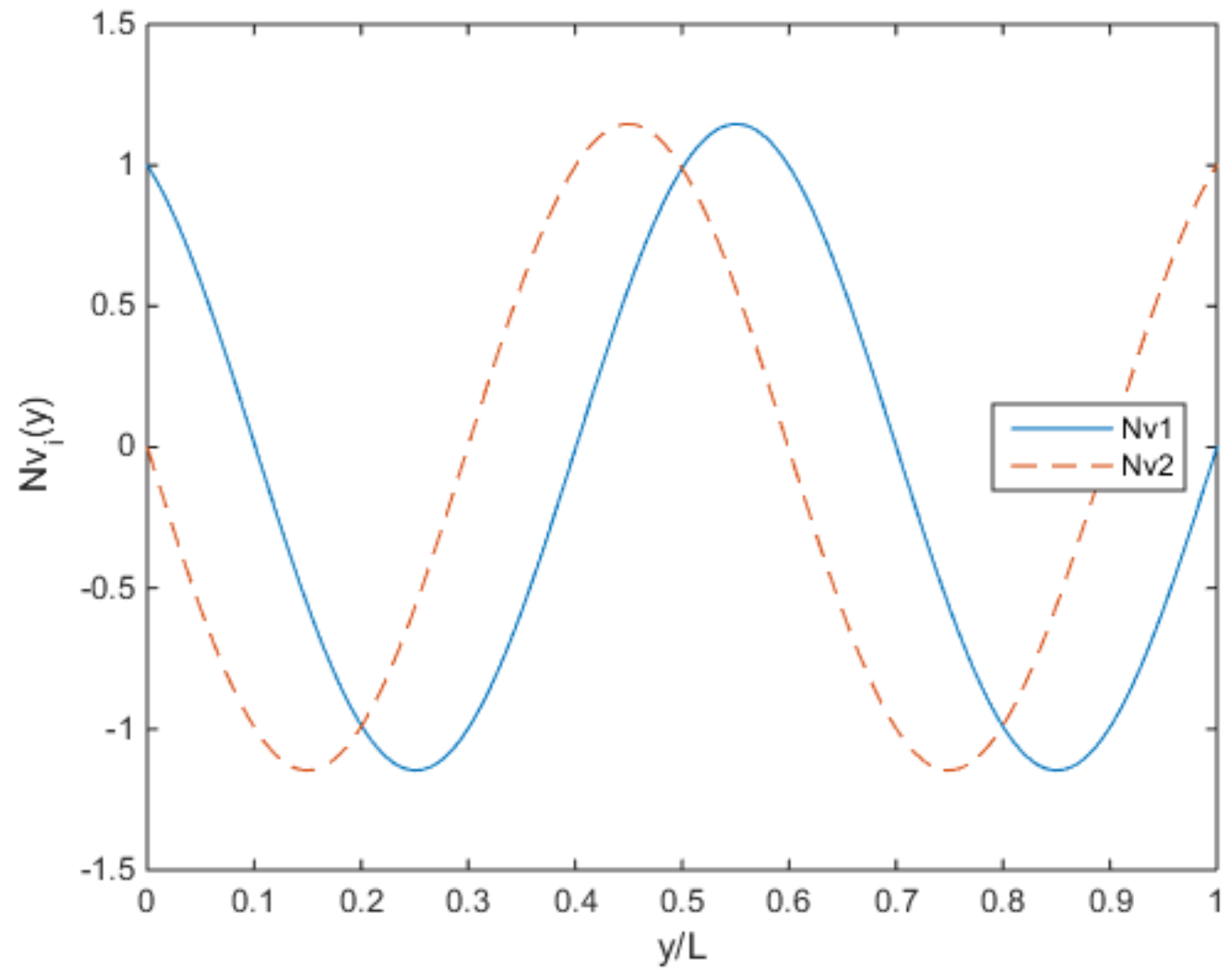

Figure 2.2: Axial dynamic trigonometric shape function $\lambda=5000$. 


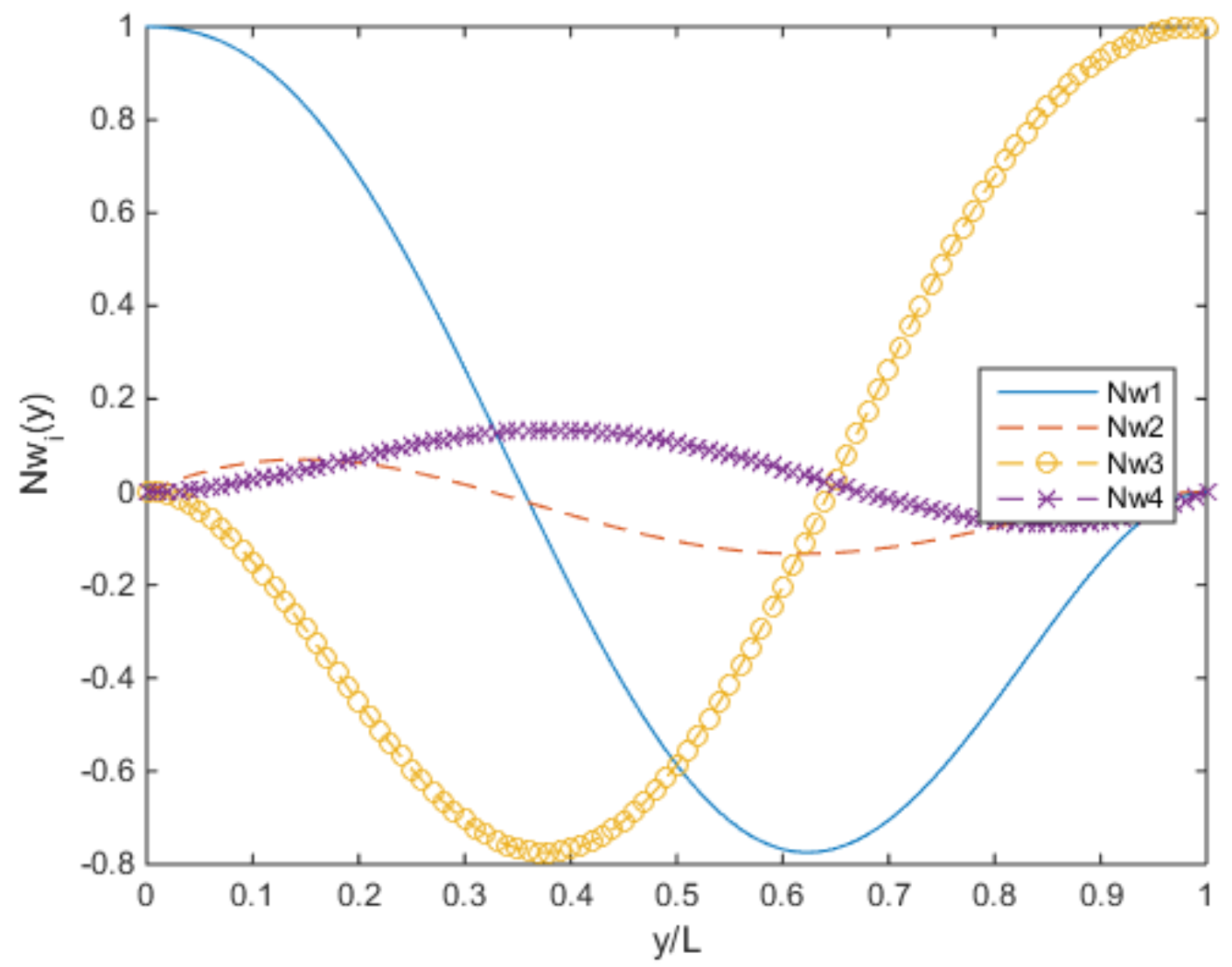

Figure 2.3: Bending dynamic trigonometric shape function $\lambda=50$. 


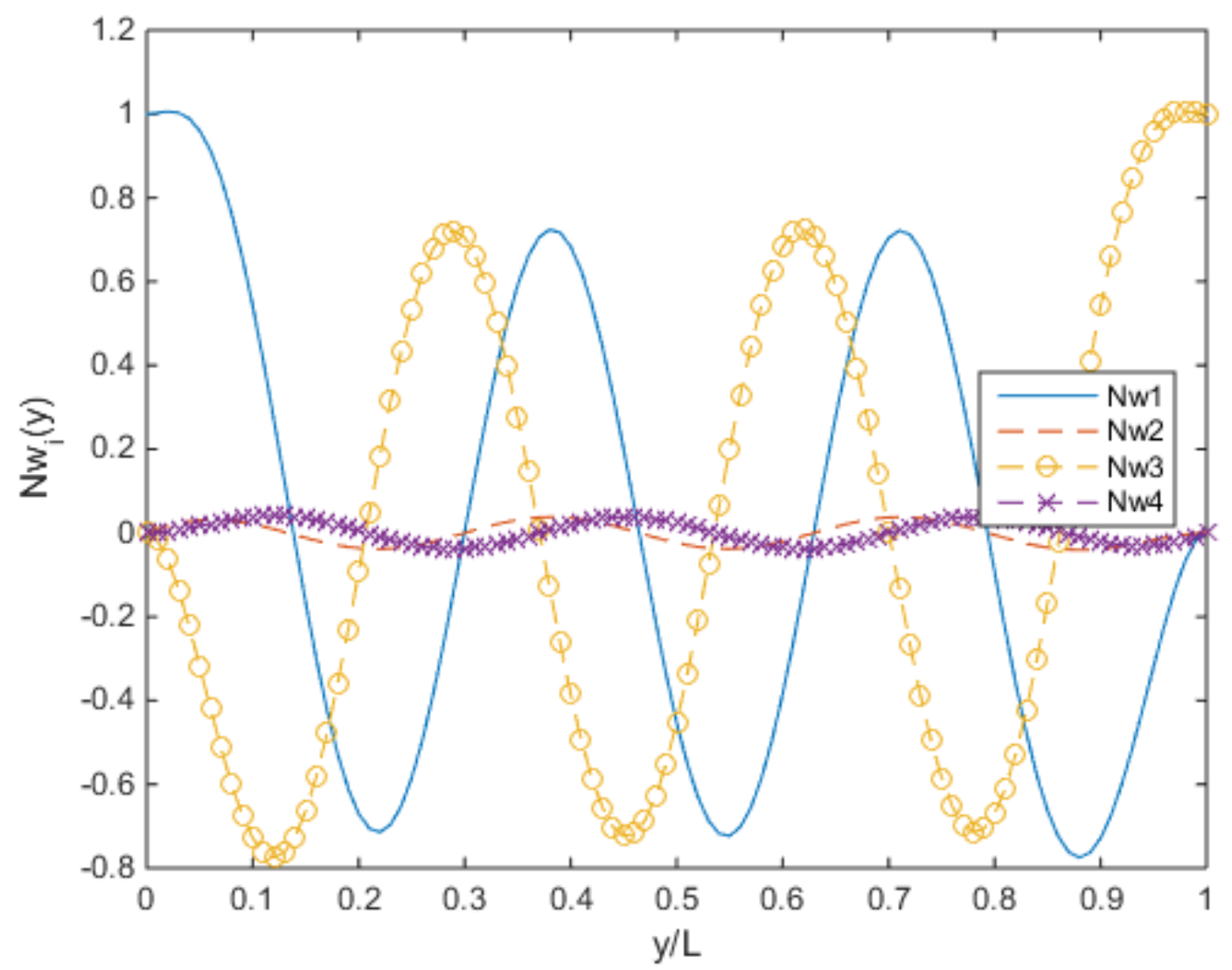

Figure 2.4: Bending dynamic trigonometric shape function $\lambda=500$. 


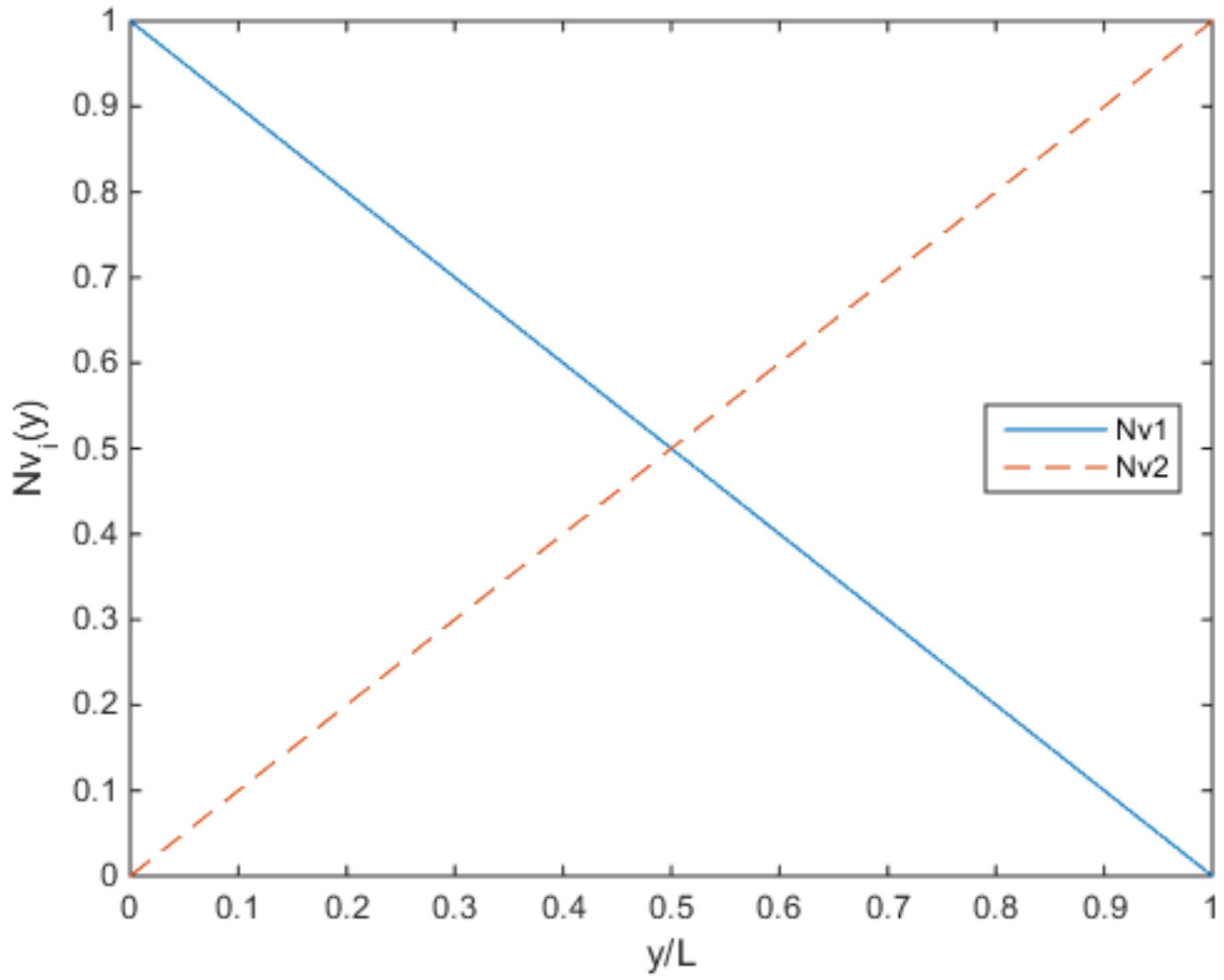

Figure 2.5: Axial dynamic trigonometric shape function $\lambda=0$. 


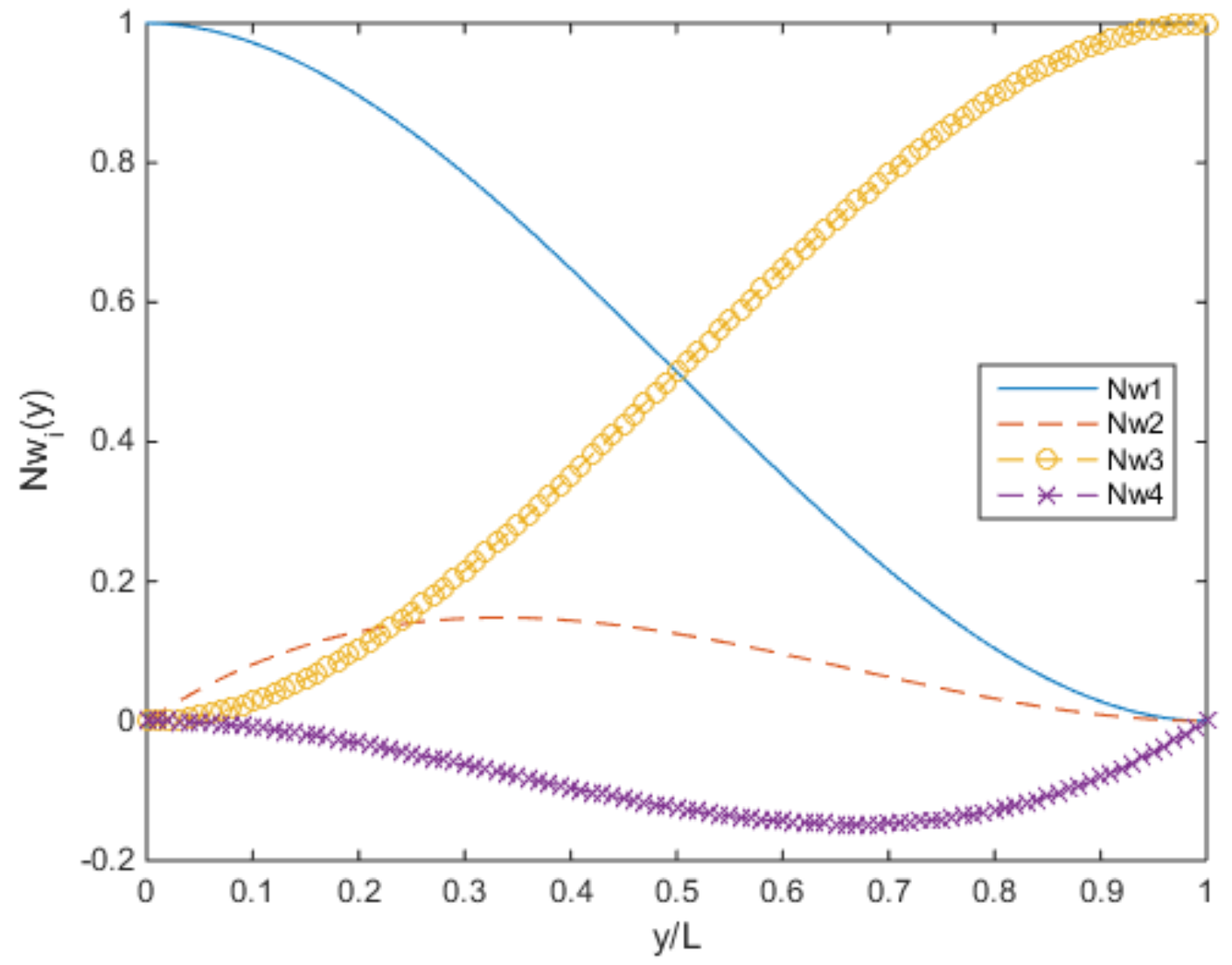

Figure 2.6: Bending dynamic trigonometric shape function $\lambda=0$. 


\section{Appendix 3}

\section{Coupled and Uncoupled Submatrices}

There are four coupled and four uncoupled matrix components. The four uncoupled element stiffness matrices are:

$$
\begin{gathered}
{[K(\omega)]_{u 1}^{n}=\left.\frac{A_{0}}{l}\left[\begin{array}{ll}
N_{1 v}^{\prime} N_{1 v} & N_{1 v}^{\prime} N_{2 v} \\
N_{2 v}^{\prime} N_{1 v} & N_{2 v}^{\prime} N_{2 v}
\end{array}\right]\right|_{0} ^{1}} \\
{[K(\omega)]_{u 2}^{n}=\left.\frac{\omega^{2} I_{2}}{l}\left[\begin{array}{llll}
N_{1 w}^{\prime} N_{1 w} & N_{1 w}^{\prime} N_{2 w} & N_{1 w}^{\prime} N_{3 w} & N_{1 w}^{\prime} N_{4 w} \\
N_{2 w}^{\prime} N_{1 w} & N_{2 w}^{\prime} N_{2 w} & N_{2 w}^{\prime} N_{3 w} & N_{2 w}^{\prime} N_{4 w} \\
N_{3 w}^{\prime} N_{1 w} & N_{3 w}^{\prime} N_{2 w} & N_{3 w}^{\prime} N_{3 w} & N_{3 w}^{\prime} N_{4 w} \\
N_{4 w}^{\prime} N_{1 w} & N_{4 w}^{\prime} N_{2 w} & N_{4 w}^{\prime} N_{3 w} & N_{4 w}^{\prime} N_{4 w}
\end{array}\right]\right|_{0} ^{1}} \\
{[K(\omega)]_{u 3}^{n}=\left.\frac{A_{2}}{l^{3}}\left[\begin{array}{llll}
N_{1 w}^{\prime \prime} N_{1 w}^{\prime} & N_{1 w}^{\prime \prime} N_{2 w}^{\prime} & N_{1 w}^{\prime \prime} N_{3 w}^{\prime} & N_{1 w}^{\prime \prime} N_{4 w}^{\prime} \\
N_{1 w}^{\prime \prime} N_{1 w}^{\prime} & N_{2 w}^{\prime \prime} N_{2 w}^{\prime} & N_{2 w}^{\prime \prime} N_{3 w}^{\prime} & N_{2 w}^{\prime \prime} N_{4 w}^{\prime} \\
N_{1 w}^{\prime \prime} N_{1 w}^{\prime} & N_{3 w}^{\prime \prime} N_{2 w}^{\prime} & N_{3 w}^{\prime \prime} N_{3 w}^{\prime} & N_{3 w}^{\prime \prime} N_{4 w}^{\prime} \\
N_{1 w}^{\prime \prime} N_{1 w}^{\prime} & N_{4 w}^{\prime \prime} N_{2 w}^{\prime} & N_{4 w}^{\prime \prime} N_{3 w}^{\prime} & N_{4 w}^{\prime \prime} N_{4 w}^{\prime}
\end{array}\right]\right|_{0} ^{1}} \\
{[K(\omega)]_{u 4}^{n}=\left.\frac{A_{2}}{l^{3}}\left[\begin{array}{llll}
N_{1 w}^{\prime \prime \prime} N_{1 w} & N_{1 w}^{\prime \prime \prime} N_{2 w} & N_{1 w}^{\prime \prime \prime} N_{3 w} & N_{1 w}^{\prime \prime \prime} N_{4 w} \\
N_{2 w}^{\prime \prime \prime} N_{1 w} & N_{2 w}^{\prime \prime \prime} N_{2 w} & N_{2 w}^{\prime \prime \prime} N_{3 w} & N_{2 w}^{\prime \prime \prime} N_{4 w} \\
N_{3 w}^{\prime \prime \prime} N_{1 w} & N_{3 w}^{\prime \prime \prime} N_{2 w} & N_{3 w}^{\prime \prime \prime} N_{3 w} & N_{3 w}^{\prime \prime \prime} N_{4 w} \\
N_{4 w}^{\prime \prime \prime} N_{1 w} & N_{4 w}^{\prime \prime \prime} N_{2 w} & N_{4 w}^{\prime \prime \prime} N_{3 w} & N_{4 w}^{\prime \prime \prime} N_{4 w}
\end{array}\right]\right|_{0} ^{1}}
\end{gathered}
$$


and the four coupled element matrices are written as:

$$
\begin{gathered}
{[K(\omega)]_{c 1}^{n}=\omega^{2} \int_{0}^{1} I_{1}\left[\begin{array}{cccc}
N_{1 v} N_{1 w}^{\prime} & N_{1 v} N_{2 w}^{\prime} & N_{1 v} N_{3 w}^{\prime} & N_{1 v} N_{4 w}^{\prime} \\
N_{2 v} N_{1 w}^{\prime} & N_{2 v} N_{2 w}^{\prime} & N_{2 v} N_{3 w}^{\prime} & N_{2 v} N_{4 w}^{\prime}
\end{array}\right] \delta \xi} \\
{[K(\omega)]_{c 2}^{n}=\int_{0}^{1} \frac{A_{1}}{l^{2}}\left[\begin{array}{llll}
N_{1 v}^{\prime} N_{1 w}^{\prime \prime} & N_{1 v}^{\prime} N_{2 w}^{\prime \prime} & N_{1 v}^{\prime} N_{3 w}^{\prime \prime} & N_{1 v}^{\prime} N_{4 w}^{\prime \prime} \\
N_{2 v}^{\prime} N_{1 w}^{\prime \prime} & N_{2 v}^{\prime} N_{2 w}^{\prime \prime} & N_{2 v}^{\prime} N_{3 w}^{\prime \prime} & N_{2 v}^{\prime} N_{4 w}^{\prime \prime}
\end{array}\right] \delta \xi} \\
{[K(\omega)]_{c 3}^{n}=\omega^{2} \int_{0}^{1}\left[\begin{array}{lll}
N_{1 w}^{\prime} N_{1 v} & N_{1 w}^{\prime} N_{2 v} \\
N_{2 w}^{\prime} N_{1 v} & N_{2 w}^{\prime} N_{2 v} \\
N_{3 w}^{\prime} N_{1 v} & N_{3 w}^{\prime} N_{2 v} \\
N_{4 w}^{\prime} N_{1 v} & N_{4 w}^{\prime} N_{2 v}
\end{array}\right] \delta \xi} \\
{[K(\omega)]_{c 3}^{n}=\int_{0}^{1} \frac{A_{1}}{l^{2}}\left[\begin{array}{ll}
N_{1 w}^{\prime \prime} N_{1 v}^{\prime} & N_{1 w}^{\prime \prime} N_{2 v}^{\prime} \\
N_{2 w}^{\prime \prime} N_{1 v}^{\prime} & N_{2 w}^{\prime \prime} N_{2 v}^{\prime} \\
N_{3 w}^{\prime \prime} N_{1 v}^{\prime} & N_{3 w}^{\prime \prime} N_{2 v}^{\prime} \\
N_{4 w}^{\prime \prime} N_{1 v}^{\prime} & N_{4 w}^{\prime \prime} N_{2 v}^{\prime}
\end{array}\right] \delta \xi}
\end{gathered}
$$




\section{Appendix 4}

\section{Classical Solution}

The classical solution for a single material Euler-Bernoulli beam under C-F, S-S, C-C, and C-P boundary condition is presented using a conventional method found in standard textbooks [84]. Using the standard Euler-Bernoulli governing equation:

$$
E I \frac{\delta^{4} W}{\delta x^{4}}-\rho A \omega^{2} W=0
$$

where $W$ is the lateral displacement, $E$ is the elastic modulus, $I$ is the mass moment of inertia, $\rho$ is density, $A$ is area, and $\omega$ is the frequency.

The general closed-form solution to the standard Euler-Bernoulli equation is as follows:

$$
W(x)=C_{1} \sin (\beta x)+C_{2} \cos (\beta x)+C_{3} \sinh (\beta x)+C_{4} \cosh (\beta x)
$$

where $C_{1234}$ is a constant and $\beta$ is based on the characteristic equation of (1):

$$
\beta^{4}=\frac{\omega^{2} \rho A}{E I}
$$

For a C-F beam the boundary conditions for the fixed end of the beam are:

$$
W(0)=0
$$




$$
\frac{\delta W}{\delta x}(0)=0
$$

The boundary conditions for the free end of a C-F beam are:

$$
\begin{gathered}
\frac{\delta W^{2}}{\delta x^{2}}(l)=0 \\
\frac{\delta W^{3}}{\delta x^{3}}(l)=0
\end{gathered}
$$

Applying the fixed end boundary conditions, (4) and (5), to the general closed-form solution (2) yields the following constant coefficient relationship:

$$
\begin{gathered}
W(0)=\left(C_{2}+C_{4}\right)=0 \\
C_{2}=-C_{4} \\
\frac{\delta W}{\delta x}(0)=\left(\beta C_{1}+\beta C_{3}\right)=0 \\
C_{1}=-C_{3}
\end{gathered}
$$

Applying the free end boundary conditions, (6) and (7), to the general closed-form solution (2) yields the following expression:

$$
\begin{gathered}
\frac{\delta W^{2}}{\delta x^{2}}(l)=-\left(C_{1} \sin (\beta l)+C_{2} \cos (\beta l)+C_{1} \sinh (\beta l)+C_{2} \cosh (\beta l)\right)=0 \\
(\sin (\beta l)+\sinh (\beta l)) C_{1}+(\cos (\beta l)+\cosh (\beta l)) C_{2}=0 \\
\frac{\delta W^{3}}{\delta x^{3}}(l)=\left(-C_{1} \cos (\beta l)+C_{2} \sin (\beta l)-C_{1} \cosh (\beta l)-C_{2} \sinh (\beta l)\right)=0 \\
(-\cosh (\beta l)-\cos (\beta l)) C_{1}+(\sin (\beta l)-\sinh (\beta l)) C_{2}=0
\end{gathered}
$$

To find the non-trivial solution for $C_{1}$, and $C_{2}$, the determinant of their coefficients must be zero.

$$
\left|\begin{array}{cc}
\sin (\beta l)+\sinh (\beta l) & \cos (\beta l)+\cosh (\beta l) \\
-\cosh (\beta l)-\cos (\beta) & \sin (\beta l)-\sinh (\beta l)
\end{array}\right|=0
$$


Expanding the determinant yields the frequency equation:

$$
\cos (\beta l) \cosh (\beta l)=-1
$$

The first three values of $\beta l$ to satisfy the above equation is listed:

$$
\begin{aligned}
& \beta_{1} l=1.875104 \\
& \beta_{2} l=4.694091 \\
& \beta_{3} l=7.854757
\end{aligned}
$$

By manipulating equation (3), the natural frequency can be found:

$$
\begin{gathered}
\beta^{4} L^{4}=\frac{m \omega^{2} L^{4}}{E I} \\
\omega^{2}=\frac{\beta^{4} L^{4} E I}{m L^{4}} \\
\omega=(\beta L)^{2} \sqrt{\frac{E I}{\rho A L^{4}}}
\end{gathered}
$$

Examples of three frequencies found are:

$$
\begin{aligned}
& \omega_{1}=516.81 \\
& \omega_{2}=3238.8 \\
& \omega_{3}=9068.6
\end{aligned}
$$

Applying the normalized frequency equation results in:

$$
\begin{aligned}
& \lambda_{1}=3.5160 \\
& \lambda_{2}=22.035 \\
& \lambda_{3}=61.697
\end{aligned}
$$


For a S-S beam the boundary conditions for the simply supported ends are:

$$
\begin{gathered}
W(0)=0 \\
\frac{\delta W^{2}}{\delta x^{2}}(0)=0 \\
W(l)=0 \\
\frac{\delta W^{2}}{\delta x^{2}}(l)=0
\end{gathered}
$$

Applying the simply supported boundary conditions, (18) and (19), to the general closed-form solution (2) yields the following constant coefficient relationship:

$$
\begin{gathered}
W(0)=\left(C_{2}+C_{4}\right)=0 \\
\frac{\delta W^{2}}{\delta x^{2}}(0)=\left(\beta C_{4}-\beta C_{2}\right)=0
\end{gathered}
$$

Equation (22) and (23) give:

$$
C_{2}=C_{4}=0
$$

Applying the second simply supported end boundary condition, (20) and (21), to the general closedform solution (2) yields the following expression:

$$
\begin{gathered}
W(l)=\left(C_{1} \sin (\beta l)+C_{3} \sinh (\beta l)\right)=0 \\
\frac{\delta W^{2}}{\delta x^{2}}(l)=\left(-C_{1} \sin (\beta l)+C_{3} \sinh (\beta l)\right)=0
\end{gathered}
$$


To find the non-trivial solution for $C_{1}$, and $C_{3}$, the determinant of their coefficients must be zero.

$$
\left|\begin{array}{cc}
\sin (\beta l) & \sinh (\beta l) \\
-\sin (\beta l) & \sinh (\beta l)
\end{array}\right|=0
$$

Expanding the determinant yields the frequency equation:

$$
2 \sin (\beta l) \sinh (\beta l)=0
$$

The first three non-trivial solution to (28) are $\beta l$ values of:

$$
\begin{aligned}
& \beta_{1} l=\pi \\
& \beta_{2} l=2 \pi \\
& \beta_{3} l=3 \pi
\end{aligned}
$$

Using equation (15) examples of three frequencies found are:

$$
\begin{aligned}
& \omega_{1}=1450.695 \\
& \omega_{2}=5802.782 \\
& \omega_{3}=13056.26
\end{aligned}
$$

Applying the normalized frequency equation results in:

$$
\begin{aligned}
& \lambda_{1}=9.8696 \\
& \lambda_{2}=39.478 \\
& \lambda_{3}=88.826
\end{aligned}
$$


For a C-C beam the boundary conditions for the fixed ends are:

$$
\begin{gathered}
W(0)=0 \\
\frac{\delta W}{\delta x}(0)=0 \\
W(l)=0 \\
\frac{\delta W}{\delta x}(l)=0
\end{gathered}
$$

Applying the fixed end boundary conditions, (32) and (33), to the general closed-form solution (2) yields the following constant coefficient relationship:

$$
\begin{gathered}
W(0)=\left(C_{2}+C_{4}\right)=0 \\
C_{2}=-C_{4} \\
\frac{\delta W}{\delta x}(0)=\left(\beta C_{1}+\beta C_{3}\right)=0 \\
C_{1}=-C_{3}
\end{gathered}
$$

Applying the second fixed end boundary condition, (34) and (35), to the general closed-form solution (2) yields the following expression:

$$
\begin{gathered}
W(l)=\left(C_{1} \sin (\beta l)+C_{2} \cos (\beta l)-C_{1} \sinh (\beta l)-C_{2} \cosh (\beta l)\right)=0 \\
(\sin (\beta l)-\sinh (\beta l)) C_{1}+(\cos (\beta l)-\cosh (\beta l)) C_{2}=0 \\
\frac{\delta W}{\delta x}(l)=\left(C_{1} \cos (\beta l)-C_{2} \sin (\beta l)-C_{1} \cosh (\beta l)-C_{2} \sinh (\beta l)\right)=0 \\
(\cos (\beta l)-\cosh (\beta l)) C_{1}+(-\sin (\beta l)-\sinh (\beta l)) C_{2}=0
\end{gathered}
$$


To find the non-trivial solution for $C_{1}$, and $C_{2}$, the determinant of their coefficients must be zero.

$$
\left|\begin{array}{cc}
\sin (\beta l)-\sinh (\beta l) & \cos (\beta l)-\cosh (\beta l) \\
\cos (\beta l)-\cosh (\beta l) & -\sin (\beta l)-\sinh (\beta l)
\end{array}\right|=0
$$

Expanding the determinant yields the frequency equation:

$$
\cos (\beta l) \cosh (\beta l)=1
$$

The first three values of $\beta l$ to satisfy the above equation is listed:

$$
\begin{aligned}
& \beta_{1} l=4.730041 \\
& \beta_{2} l=7.853205 \\
& \beta_{3} l=10.99561
\end{aligned}
$$

Using equation (15) examples of three frequencies found are:

$$
\begin{aligned}
& \omega_{1}=3288.564 \\
& \omega_{2}=9065.054 \\
& \omega_{3}=17771.13
\end{aligned}
$$

Applying the normalized frequency equation results in:

$$
\begin{aligned}
& \lambda_{1}=22.373 \\
& \lambda_{2}=61.673 \\
& \lambda_{3}=120.90
\end{aligned}
$$


For a C-P beam the boundary conditions for the fixed ends are:

$$
\begin{gathered}
W(0)=0 \\
\frac{\delta W}{\delta x}(0)=0
\end{gathered}
$$

For the pinned end the boundary conditions are:

$$
\begin{gathered}
W(l)=0 \\
\frac{\delta W^{2}}{\delta x^{2}}(l)=0
\end{gathered}
$$

Applying the fixed end boundary conditions, (45) and (46), to the general closed-form solution (2) yields the following constant coefficient relationship:

$$
\begin{gathered}
W(0)=\left(C_{2}+C_{4}\right)=0 \\
C_{2}=-C_{4} \\
\frac{\delta W}{\delta x}(0)=\left(\beta C_{1}+\beta C_{3}\right)=0 \\
C_{1}=-C_{3}
\end{gathered}
$$

Applying the pinned end boundary condition, (47) and (48), to the general closed-form solution (2) yields the following expression:

$$
\begin{gathered}
W(l)=\left(C_{1} \sin (\beta l)+C_{2} \cos (\beta l)-C_{1} \sinh (\beta l)-C_{2} \cosh (\beta l)\right)=0 \\
(\sin (\beta l)-\sinh (\beta l)) C_{1}+(\cos (\beta l)-\cosh (\beta l)) C_{2}=0 \\
\frac{\delta W^{2}}{\delta x^{2}}(l)=\left(-C_{1} \sin (\beta l)-C_{2} \cos (\beta l)-C_{2} \cosh (\beta l)-C_{1} \sinh (\beta l)\right)=0 \\
(-\sin (\beta l)-\sinh (\beta l)) C_{1}+(-\cos (\beta l)-\cosh (\beta l)) C_{2}=0
\end{gathered}
$$


To find the non-trivial solution for $C_{1}$, and $C_{2}$, the determinant of their coefficients must be zero.

$$
\left|\begin{array}{cc}
\sin (\beta l)-\sinh (\beta l) & \cos (\beta l)-\cosh (\beta l) \\
-\sin (\beta l)-\sinh (\beta l) & -\cos (\beta l)-\cosh (\beta l)
\end{array}\right|=0
$$

Expanding the determinant yields the frequency equation:

$$
\tan (\beta l)=\tanh (\beta l)
$$

The first three values of $\beta l$ to satisfy the above equation is listed:

$$
\begin{aligned}
& \beta_{1} l=3.926602 \\
& \beta_{2} l=7.068583 \\
& \beta_{3} l=10.21018
\end{aligned}
$$

Using equation (15) examples of three frequencies found are:

$$
\begin{aligned}
& \omega_{1}=2266.263 \\
& \omega_{2}=7344.145 \\
& \omega_{3}=15322.98
\end{aligned}
$$

Applying the normalized frequency equation results in:

$$
\begin{aligned}
& \lambda_{1}=15.418 \\
& \lambda_{2}=49.965 \\
& \lambda_{3}=104.25
\end{aligned}
$$




\section{Appendix 5}

\section{Original Data Tables for Validation}

\section{Study}

Table 5.1: Reference values for $k=0.3$ in the original non-dimensional form.

\begin{tabular}{|c|c|c|c|c|c|c|}
\hline \multirow{3}{*}{$L / h$} & \multicolumn{4}{|c|}{ Non-dimensional fundamental natural frequency $\left(\lambda_{i}\right)$} \\
\cline { 2 - 6 } & \multicolumn{3}{|c|}{ Ref. [67] } & \multicolumn{2}{|c|}{ DSM Ref [74]. } \\
\cline { 2 - 5 } & Pure Al & \multicolumn{2}{|c|}{$k=0.3$} & \multirow{2}{*}{ Pure Al } & $k=0.3$ \\
\cline { 2 - 6 } & EB & TB & EB & TB & & \\
\hline 10 & 2.837 & 2.804 & 2.731 & 2.701 & 2.837 & 2.776 \\
\hline 30 & 2.847 & 2.843 & 2.741 & 2.738 & 2.847 & 2.786 \\
\hline 100 & 2.848 & 2.848 & 2.743 & 2.742 & 2.848 & 2.787 \\
\hline
\end{tabular}

Table 5.2: Reference values for $k=1$ in the original non-dimensional form.

\begin{tabular}{|c|c|c|c|}
\hline \multirow{2}{*}{$L / h$} & \multicolumn{3}{|c|}{ Non-dimensional fundamental natural frequency $\left(\lambda_{i}\right)$} \\
\cline { 2 - 3 } & \multicolumn{2}{|c|}{ Ref. [35] } & DSM \\
& EB & TB & $74]$. \\
\hline 5 & 15.179 & 14.633 & 15.436 \\
\hline 10 & 3.8455 & 3.8076 & 3.9059 \\
\hline 100 & 0.038626 & 0.038622 & 0.039218 \\
\hline
\end{tabular}




\section{List of Contributions}

1. Aaron Gee and Seyed M. Hashemi. A Dynamic Finite Element for Free Vibration of Functionally Graded Beams. Shock and Vibration. Submitted: July, 2017. (Under review, Ref.\#5395103). 


\section{References}

[1] Won-Jong Ji and Young-Hoon Moon. Fabrication of functionally graded properties by direct laser melting of compositionally selective metallic powder. In 15th International Conference on Control, Automation and Systems, 2015.

[2] Fumio Watari, Atsuro Yokoyama, Mamoru Omori, Toshio Hirai, Hideomi Kondo, Motohiro Uo, and Takao Kawasaki. Biocompatibility of materials and development to functionally graded implant for bio-medical application. Composites Science and Technology, 64(6):893-908, 2004.

[3] Karen Taminger and Robert Hafley. Electron beam freeform fabrication: A rapid metal deposition process. In 3rd Annual Automotive Composites Conference, 2003.

[4] Lin Li, W.U.H. Syed, and A.J. Pinkerton. Rapid additive manufacturing of functionallly graded structures using simultaneous wire and powder laser deposition. Virtual and Physical Prototyping, 1(4):217-225, 2006.

[5] R.M. Mahamood and E.T. Akinlabi. Laser metal deposition of functionally graded ti6al4v/tic. Materials \&3 Design, 84:402-410, 2015.

[6] Rasheedat Mahamood and Esther Akinlabi. Functionally Graded Materials. Springer International Publishing, 2017.

[7] Daryl Logan. A first course in the finite element method. Thomson, 2006.

[8] J.R. Banerjee. Dynamic stiffness formulation for structural elements: a general approach. Computeres $\&$ Structures, 63(1):101-103, 1997. 
[9] J.R. Banerjee, A.J. Sobey, H. Su, and J.P. Fitch. Use of computer algebra in hamiltonian calculations. Advances in Engineering Software, 39(6):521-525, 2008.

[10] Seyed Mohammad Hashemi. Free Vibrational Analysis of Rotating Beam-Like Structures: A Dynamic Finite Element Approach. PhD thesis, Universite Laval, 1998.

[11] Joseph Zuiker and George Dvorak. The effective properties of functionally graded composites -1. extension of the mori-tanaka method to linerarly varying fields. Composites Engineering, 4(1):19-35, 1994.

[12] A.J. Markworth, K.S. Ramesh, and W.P. Parks. Modelling studies applied to functionally graded materials. Journal of Materials Science, 30:2183-2193, 1995.

[13] Michael M. Gasik. Micromechanical modelling of functionally graded materials. Computational Materals Science, 13:42-55, 1998.

[14] M. Grujicic and Y. Zhang. Determination of effective elastic properties of functionally graded materials using voronoi cell finite element method. Materials Science \& Engineering, A251:64-76, 1998.

[15] J. Aboudi, M.-J. Pindera, and S.M. Arnold. Higher-order theory for functionally graded materials. Composites Part B: Engineering, 30:777-832, 1999.

[16] John J. Lannutti. Functionally graded materials: properties, potential and design guidelines. Composites Engineering, 4(1):81-94, 1994.

[17] F. Erdogan. Fracture mechanics of functionally graded materials. Composites Engineering, 5(7):753$770,1995$.

[18] A.E. Giannakopoulos, S. Suresh, M. Finot, and M. Olsson. Elastoplastic analysis of thermal cycling: layered materials with compositional gradients. Acta Metallurgica Et Materialia, 43(4):1335-1354, 1995.

[19] A. Chakraborty, S. Gopalakrishnan, and J.N. Reddy. A new beam finite element for the analysis of functionally graded materials. Mechanical Sciences, 45:519-539, 2003. 
[20] C.T. Loy, K.Y. Lam, and J.N. Reddy. Vibration of functionally graded cylindrical shells. International Journal of Mechanical Sciences, 41:309-324, 1999.

[21] I. Elishakoff and S. Candan. Apparently first closed-form solution for vibration: inhomogeneous beams. International Journal of Solids and Structures, 38:3411-3441, 2001.

[22] I. Elishakoff and Z. Guede. Analytical polynomial solutions for vibrating axially graded beams. Mechanics of Advanced Materials and Structures, 11:517-533, 2004.

[23] Ivo Calio and Issac Elishakoff. Can a trigonometric function serve both as the vibrtion and the buckling mode of an axially graded structure? Mechanics Based Design of Structures and Machines, $32(4): 401-421,2004$.

[24] Lei Wu, Qi shen Wang, and Issac Elishakoff. Semi-inverse method for axially functionally graded beams with an anti-symmetric vibration mode. Journal of Sound and Vibration, 284:1190-1202, 2005.

[25] X.-F. Li. A unified approach for analyzing static and dynamic behaviors of functionally graded timoshenko and euler-bernoulli beams. Journal of Sound and Vibrations, 318:1210-1229, 2008.

[26] S. Kapuria, M. Bhattacharyya, and A.N. Kumar. Bending and free vibration response of layered functionally graded beams: A theoretical model and its experimental validation. Composite Structures, 82:390-402, 2008.

[27] Xian-Fang Li, Bao-Lin Wang, and Jie-Cai Han. A higher-order theory for static and dynamic analyses of functionally graded beams. Archive of Applied Mechanics, 80(10):1197-1212, 2010.

[28] Huu-Tai Thai and Thuc P. Vo. Bending and free vibration of functionally graded beams using various higher-order shear deformatioin beam theories. International Journal of Mechanical Sciences, 62:57$66,2012$.

[29] Latifa Ould Larbi, Abdelhakim Kaci, Mohammed Sid Ahmed Houari, and Abdelouahed Tounsi. An efficient shear deformation beam theory based on neutral surface position for bending and free vibration of functionally graded beams. Mechancs Based Design of Structures and Machines, 41:421-433, 2013. 
[30] Trung-Kien Nguyen, Thuc P. Vo, and Huu-Tai Thai. Static and free vibration of axially loaded functionally graded beams based on the first-order shear deformation theory. Composites: Part B, 55:147-157, 2013.

[31] K.K. Pradhan and S. Chakraverty. Effects of different shear deformation theories on free vibration of functionally graded beams. International Journal of Mechanical Sciences, 82:149-160, 2014.

[32] Shi rong Li, Ze qing Wan, and Jing hua Zhang. Free vibration of functionally graded beams based on both classical and first-order shear deformation beam theories. Applied Mathematics and Mechanics, 35(5):591-606, 2014.

[33] Thuc P. Vo, Huu-Tai Thai, Trung-Kien Nguyen, and Fawad Inam. Static and vibration analysis of functionally graded beams using refined shear deformation theory. Meccanica, 49:155-168, 2014.

[34] Karan K. Pradhan and S. Chakraverty. Generalized power-law exponent based shear deformation theory for free vibration of functionally graded beams. Applied Mathematics and Computation, $268: 1240-1258,2015$.

[35] G. Giunta, D. Crisafulli, S. Belouettar, and E. Carrera. Hierarchical theories for the free vibration analysis of functionally graded beams. Composite Structures, 94:68-74, 2011.

[36] Khelifa Zoubida, Tahar Hassaine Daouadji, Lazreg Hadji, Abdelouahed Tounsi, and Adda Bedia El Abbes. A new higher order shear deformation model of functionally graded beams based on neutral surface position. Transactions of the Indian Institute of Metals, 69(3):683-691, 2016.

[37] Lazreg Hadji, Zoubida Khelifa, and Adda Bedia El Abbes. A new higher order shear deformation model for functionally graded beams. KSCE Journal of Civil Engineering, 20(5):1835-1841, 2016.

[38] Xuan Wang and Shirong Li. Free vibrational analysis of functionally graded material beams based on levinson beam theory. Applied Mathematics and Mechanics, 37(7):861-878, 2016.

[39] Young Huang and Xian-Fang Li. A new approach for free vibration of axially functionally graded beams with non-uniform cross-section. Journal of Sound and Vibration, 329:2291-2303, 2010.

[40] A. Shahba, R. Attarnejad, M. Tavanaie Marvi, and S. Hajilar. Free vibration and stability analysis of axially functionally graded tapered timoshenko beams with classical and non-classical boundary conditions. Composites: Part B, 42:801-808, 2011. 
[41] H. Hein and L. Feklistova. Free vibrations of non-uniform and axially functionally graded beams using haar wavelets. Engineering Structures, 33:3696-3701, 2011.

[42] Yong Huang, Ling-E Yang, and Qi-Zhi Luo. Free vibration of axially functionally graded timoshenko beams with non-uniform cross-section. Composites: Part B, 45:1493-1498, 2013.

[43] A.-Y. Tang, J.-X. Wu, X.-F. Li, and K.Y. Lee. Exact frequency equations of free vibration of exponentially non-uniform functionally graded timoshenko beams. International Journal of Mechanical Sciences, 89:1-11, 2014.

[44] Korak Sarkar and Ranjan Ganguli. Closed-form solutions for axially functionally graded timoshenko beams having uniform cross-section and fixed-fixed boundary condition. Composites: Part $B, 58: 361-370,2014$.

[45] Sundaramoorthy Rajasekaran and Emad Norouzzadeh Tochaei. Free vibration analysis of axially functionally graded tapered timoshenko beams using differential transformation element method and differential quadrature element method of lowest-order. Meccanica, 49(4):995-1009, 2014.

[46] D.V. Bambill, C.A. Rossit, and D.H. Felix. Free vibrations of stepped axially functionally graded timoshenko beams. Meccanica, 50(4):1073-1087, 2015.

[47] X.-F. Li, Y.-A. Kang, and J.-X. Wu. Exact frequency equations of free vibration of exponentially functionally graded beams. Applied Acoustics, 74(3):413-420, 2013.

[48] Mohammad Rezaiee-Pajand and Seyed Mojtaba Hozhabrossadati. Analytical and numerical method for free vibration of double-axially functionally graded beams. Composite Structures, 152:488-498, 2016.

[49] Xiaobai Li, Li Li, Yujin Hu, Zhe Ding, and Weiming Deng. Bending, buckling and vibration of axially functionally graded beams based on nonlocal strain gradient theory. Composite Structures, 165:250-265, 2017.

[50] Zhi hai Wang, Xiao hong Wang, Guo dong Xu, Su Cheng, and Tao Zeng. Free vibration of twodirectional functionally graded beams. Composite Structures, 135:191-198, 2016. 
[51] Thao An Huynh, Xuan Qui Lieu, and Jaehong Lee. Nurbs-based modeling of bidirectioinal functionally graded timoshenko beams for free vibration problem. Composite Structures, 160:1178-1190, 2017.

[52] Nuttawit Wattanasakulpong and Jarruwat Charoensuk. Vibration characteristics of stepped beams made of fgm using differential transformation method. Meccanica, 50(4):1089-1101, 2015.

[53] Ahmad Shahba, Reza Attarnejad, and Hossein Zarrinzadeh. Free vibration analysis of centrifugally stiffened tapered functionally graded beams. Mechanics of Advanced Materials and Structures, 20(5):331-338, 2013.

[54] Liviu Librescu, Sang-Yong Oh, and Ohseop Song. Thin-walled beams made of functionally graded materials and operating in a high temperature environment: Vibration and stability. Journal of Thermal Stresses, 28:331-338, 2005.

[55] Sang-Yong Oh, Liviu Librescu, and Ohseop Song. Vibration and instability of functionally graded circular cylindrical spinning thin-walled beams. Journal of Sound and Vibration, 285:1071-1091, 2005.

[56] Liviu Librescu, Sang-Yong Oh, Ohseop Song, and Ho-Sik Kang. Dynamics of advanced rotating blades made of functionally graded materials and operating in a high-temperature field. Journal of Engineering Mathematics, 61(1):1-16, 2008.

[57] M.T. Piovan and R. Sampaio. Vibrations of axially moving flexible beams made of functionally graded materials. Thin-Walled Structures, 46(2):112-121, 2008.

[58] M.T. Piovan and R. Sampaio. A study on the dynamics of rotating beams with functionally graded properties. Journal of Sound and Vibration, 327:134-143, 2009.

[59] Farzad Ebrahimi and Mohadese Mokhtari. Free vibration analysis of a rotating mori-tanaka-based functionally graded beam via differential transformation method. Arabian Journal for Science and Engineering, 41(2):577-590, 2016.

[60] Yutaek Oh and Hong Hee Yoo. Vibration analysis of rotating pretwisted tapered blades made of functionally graded materials. International Journal of Mechanical Sciences, 119:68-79, 2016. 
[61] Kemal Mazanoglu and Serkan Guler. Flap-wise and chord-wise vibrations of axially functionally graded tapered beams rotating around a hub. Mechanical Systems and Signal Processing, 89:97-107, 2017.

[62] S.A. Fazelzadeh, P. Malekzadeh, P. Zahedinejad, and M. Hosseini. Vibration analysis of functionally graded thin-walled rotating blades under high temperature supersonic flow using the differential quadrature method. Journal of Sound and Vibration, 306:333-348, 2007.

[63] H.J. Xiang and J. Yang. Free and forced vibration of a laminated fgm timoshenko beam of variable thickness under heat conduction. Composites: Part B, 39(2):292-303, 2008.

[64] Chunhua Jin and Xinwei Wang. Accurate free vibration analysis of euler functionally graded beams by the weak form quadrature element method. Composite Structures, 125:41-50, 2015.

[65] M. Shakeri, M. Akhlaghi, and S.M. Hoseini. Vibration and radial wave propagation velocity in functionally graded thick hollow cylinder. Composite Structures, 76:174-181, 2006.

[66] Mesut Simsek. Bi-directional functionally graded materials (bdfgms) for free and forced vibration of timoshenko beams with various boundary conditions. Composite Structures, 133:968-978, 2015.

[67] Mesut Simsek. Vibration analysis of a functionally graded beam under a moving mass by using different beam theories. Composite Structures, 92(4):904-917, 2010.

[68] H. Ashrafi, K. Asemi, M. Shariyat, and M. Salehi. Two-dimensional modeling of heterogeneous structures using graded finite element and boundary element methods. Meccanica, 48(3):663-680, 2013.

[69] K.K. Pradhan and S. Chakraverty. Free vibration of euler and timoshenko functionally graded beams by rayleigh-ritz method. Composites: Part B, 51:175-184, 2013.

[70] Nuttawit Wattanasakulpong and Qibo Mao. Dynamic response of timoshenko functionally graded beams with classical and non-classical boundary conditions using chebyshev collocation method. Composite Structures, 119:346-354, 2015.

[71] Nuttawit Wattanasakulpong and Arisara Chaikittiratana. Flexural vibration of imperfect functionally graded beams based on timoshenko beam theory: Chebyshev collocation method. Meccanica, 50(5):1331-1342, 2015. 
[72] Volkan Kahya and Muhittin Turan. Finite element model for vibration and buckling of functionally graded beams based on the first-order shear deformation theory. Composites: Part B, 109:108-115, 2017.

[73] Yang Zhao, Yixin Huang, and Mingquan Guo. A novel approach for free vibration of axially functionally graded beams with non-uniform cross-section based on chebyshev polynomials theory. Composite Structures, 168:277-284, 2017.

[74] H. Su, J.R. Banerjee, and C.W. Cheung. Dynamic stiffness formulation and free vibration analysis of functionally graded beams. Composite Structures, 106:854-862, 2013.

[75] H. Su and J.R. Banerjee. Development of dynamic stiffness method for free vibration of functionally graded timoshenko beams. Computers and Structures, 147:107-116, 2015.

[76] S. Rajasekaran. Buckling and vibration of axially functionally graded nonuniform beams using differential transformation based dynamic stiffness approach. Meccanica, 48(5):1053-1070, 2013.

[77] Jung Woo Lee and Jung Youn Lee. Free vibration analysis of functionally graded bernoulli-euler beams using an exact transfer matrix expression. International Journal of Mechanical Sciences, $122: 1-17,2017$.

[78] Deng Hao and Cheng Wei. Dynamic characteristics analysis of bi-directional functionally graded timoshenko beams. Composite Structures, 141:253-263, 2016.

[79] S. Mohammad Hashemi and Marc J. Richard. A dynamic finite element (dfe) method for free vibrations of bending-torsion coupled beams. Aerospace Science and Technology, 4(1):41-55, 2000.

[80] Mir Tahmaseb Kashani, Supun Jayasinghe, and Seyed M. Hashemi. Dynamic finite element analysis of bending-torsion coupled beams subjected to combined axial load and end moment. Shock and Vibration, 2015:12, 2015.

[81] Seyed M. Hashemi and Ernest J. Adique. A quasi-exact dynamic finite element for free vibration analysis of sandwich beams. Applied Composite Materials, 17(2):259-269, 2010.

[82] Nicholas H. Erdelyi and Seyed M. Hashemi. A dynamic stiffness element for free vibration analysis of delaminated layered beams. Modelling and Simulation in Engineering, 2012:8, 2012. 
[83] R. Hibbeler. Mechanics of Materials. Prentice Hall, 2010.

[84] Francis S. Tse, Ivan E. Morse, and Rolland T. Hinkle. Mechanical vibrations: theory and applications. Allyn and Bacon, 1978. 